\title{
The Effects of Feeding Growing Female Rats Different Sources of Omega-3 Polyunsaturated Fatty Acids on Lipogenic Gene Expression and Lipid Metabolism in Liver and Adipose Tissues
}

\author{
Kaitlin Mock \\ West Virginia University
}

Follow this and additional works at: https://researchrepository.wvu.edu/etd

\footnotetext{
Recommended Citation

Mock, Kaitlin, "The Effects of Feeding Growing Female Rats Different Sources of Omega-3

Polyunsaturated Fatty Acids on Lipogenic Gene Expression and Lipid Metabolism in Liver and Adipose Tissues" (2013). Graduate Theses, Dissertations, and Problem Reports. 369.

https://researchrepository.wvu.edu/etd/369

This Thesis is protected by copyright and/or related rights. It has been brought to you by the The Research Repository @ WVU with permission from the rights-holder(s). You are free to use this Thesis in any way that is permitted by the copyright and related rights legislation that applies to your use. For other uses you must obtain permission from the rights-holder(s) directly, unless additional rights are indicated by a Creative Commons license in the record and/ or on the work itself. This Thesis has been accepted for inclusion in WVU Graduate Theses, Dissertations, and Problem Reports collection by an authorized administrator of The Research Repository @ WVU. For more information, please contact researchrepository@mail.wvu.edu.
} 
The Effects of Feeding Growing Female Rats Different Sources of Omega-3

Polyunsaturated Fatty Acids on Lipogenic Gene Expression and Lipid Metabolism in Liver and Adipose Tissues

\author{
Kaitlin Mock
}

Thesis submitted to the

Davis College of Agriculture, Natural Resources and Design

at West Virginia University

in partial fulfillment of the requirements

for the degree of

Master of Science in Nutritional and Food Sciences

\title{
Committee Members:
}

Janet Tou, Ph.D., Chair

Vagner Benedito, Ph.D.

Jianbo Yao, Ph.D.

Division of Animal and Nutritional Sciences

Morgantown, West Virginia

2013

Keywords: Omega-3 Fatty Acid; Omega-6 Fatty Acid; ALA; EPA; DHA; Fish Oil; Krill Oil;

Salmon Oil; Tuna Oil; Menhaden Oil; Flaxseed Oil; Lipogenesis; Lipolysis

Copyright 2013 Kaitlin L. Mock 


\begin{abstract}
The Effects of Feeding Growing Female Rats Different Sources of Omega-3 Polyunsaturated Fatty Acids on Lipogenic Gene Expression and Lipid Metabolism in Liver and Adipose Tissues
\end{abstract}

\author{
Kaitlin Mock
}

\begin{abstract}
Omega-3 polyunsaturated fatty acid (n-3 PUFA) consumption has increased through diet and supplementation due to reports of health benefits. The objective of this study was to determine whether different n-3 PUFA sources play a role in lipid metabolism by altering lipogenic gene expression, serum lipids and lipoproteins, and inflammation. Young (aged 28 days) female Sprague-Dawley rats were assigned to one of six diets: corn oil (CO, control), flaxseed oil (FO), krill oil (KO), menhaden oil (MO), salmon oil (SO), or tuna oil (TO). qPCR was used to analyze relative gene expression. Only MO-fed rats had down-regulated gene expression of the lipogenic transcription factor sterol regulatory element binding protein $1 \mathrm{c}$ (SREBP-1c) $(\mathrm{P}=0.007)$, and downstream enzymes, fatty acid synthase (FAS) $(\mathrm{P}=0.001)$ and stearoyl coenzyme A desaturase 1(SCD-1) $(\mathrm{P}=0.008)$. MO-fed rats had lower $(\mathrm{P}<0.001)$ hepatic arachidonic acid (ARA) content compared to rats fed SO, TO, and CO. Rats fed all n-3 PUFA sources had down-regulated FAS gene expression, except KO. There were no significant changes in expression of lipogenic genes in the hepatic tissue of rats fed KO. Only TO, with the lowest eicosapentaenoic acid:docosahexaenoic acid (EPA:DHA) ratio in hepatic tissue, downregulated SCD-1 gene expression. In the gonadal adipose tissue, FO was the only oil source to alter lipolytic gene expression. PPAR $\gamma$ was up-regulated in $\mathrm{FO}(\mathrm{P}=0.04)$ compared to $\mathrm{CO}$-fed rats. FO had the highest $(\mathrm{P}<0.05)$ EPA:DHA ratio in gonadal adipose tissue. All n-3 PUFA sources decreased lipogenesis, evidenced by decreased $(\mathrm{P}<0.05)$ serum high density lipoprotein (HDL-C), and marine sources of n-3 PUFAs decreased $(\mathrm{P}<0.05)$ serum total cholesterol (CHL). Higher dietary 18:1 may be transported to extrahepatic tissues as indicated by the absence of decreased $(\mathrm{P}>0.05)$ serum total CHL in FO. All n-3 LC-PUFA sources altered inflammation related hepatic Inhibitor of Kappa B alpha (IKB $\alpha$ ) gene expression, except the MO group which was the only n-3 PUFA that down-regulated lipogenic transcription factor SREBP-1c. Based on the study results, the MO diet caused a low hepatic ARA content and subsequently affected lipogenic gene expression the most; high EPA and DHA content in the SO and TO diets caused the most decrease in circulating lipids; and all n-3 PUFAs affected gene expression related to inflammation, except for the MO diet group which altered the transcription factor SREBP-1c. Therefore, different sources of n-3 PUFAs had different effects on lipogenesis and lipolysis gene expression which affects lipid metabolism indicated by reduced circulating lipids and lipoproteins, and inflammation which may play a role in cardiovascular disease (CVD) risk.
\end{abstract}




\section{Acknowledgements}

Thank you Dr. Tou for inviting me into your lab for the opportunity to pursue this research project in completion of a Master's degree. I truly appreciate all the time you spent helping and guiding me through this endeavor.

Thank you Dr. Benedito for being a part of my committee, and also for all the time you spent teaching me lab techniques. I appreciate all the help you have provided.

Thank you Dr. Yao for being a part of my committee, and also for the Animal Biotechnology course you taught. I learned a great deal in that course that helped me progress in my research project.

I would like to thank the Davis College for this opportunity.

Thank you to all my family and friends for supporting me. 


\section{Table of Contents}

\subsection{Introduction}

Page 1

2.0 Study Objectives Page 4

2.1 Hypothesis

2.2 Study Objectives

3.0 Literature Review

Page 5

3.1 Omega 3 and Omega 6 Polyunsaturated Fatty Acids

3.2 Omega 3 Polyunsaturated Fatty Acids and Lipogenesis

3.3 Omega 3 Polyunsaturated Fatty Acids and Lipolysis

3.4 Omega 3 Polyunsaturated Fatty Acids and Serum Lipids and Lipoproteins

3.5 Omega 3 Polyunsaturated Fatty Acids and Eicosanoid Synthesis

3.6 Omega 3 Polyunsaturated Fatty Acids and Inflammation

3.7 Summary

4.0 Materials and Methods Page 21

4.1 Diets

4.2 Animal Feeding Study

4.3 Determination of Gene Expression

4.4 Determination of Fatty Acid Composition

4.5 Liver Triglyceride Content

4.6 Serum Lipid and Lipoprotein Analysis

4.7 Determination of 2-Series Eicosanoids

4.8 Statistical Analysis

\subsection{Results}

Page 28

5.1 Dietary Fatty Acid Content

5.2 Body and Organ Weights

5.3 Liver and Gonadal Adipose Tissue Polyunsaturated Fatty Acids

5.4 Liver and Gonadal Adipose Tissue Lipogenic Gene Expression 
5.5 Liver and Gonadal Adipose Tissue Saturated and Monounsaturated Fatty Acids 5.6 Liver and Gonadal Adipose Tissue Lipolytic Gene Expression

5.7 Liver Total Triglyceride Content

5.8 Serum Lipids and Lipoproteins

5.9 Liver and Gonadal Adipose Tissue Inflammation

5.10 Eicosanoids

6.0 Discussion

Page 33

7.0 Conclusion Page 39

8.0 Future Research

Page 40

9.0 References

Page 73 


\section{List of Tables}

Table 1. Diet Characteristics

Page 42

Table 2. Genes Analyzed

Page 43

Table 3. Dietary Fatty Acids and Lipids Classes

Page 44

Table 4. Serum Lipids

Page 63

Appendix 1. Whole Diet Composition

Page 69

Appendix 2. Food Intake, Body Weight, and Organ Weights

Page 70

Appendix 3. Liver Fatty Acid Profile

Page 71

Appendix 4. Gonadal Adipose Tissue Fatty Acid Profile

Page 72 


\section{List of Figures}

Figure 1. n-3 and n-6 PUFA Synthesis

Page 6

Figure 2. Lipogenesis Pathway

Page 9

Figure 3. Eicosanoid Synthesis Pathway

Page 18

Figure 4. Lipogenic Gene Expression in Liver Tissue

Figure 4a. Hepatic SREBP-1c Expression

Page 45

Figure 4b. Hepatic FAS Expression

Page 46

Figure 4c. Hepatic SCD-1 Expression

Page 47

Figure 5. Lipogenic Gene Expression in Gonadal Adipose Tissue

Figure 5a. Gonadal Adipose SREBP-1c Expression

Page 48

Figure 5b. Gonadal Adipose FAS Expression

Page 49

Figure 5c. Gonadal Adipose SCD-1 Expression

Page 50

Figure 6. Saturated and Monounsaturated Fatty Acid Content in Liver Tissue

Figure 6a. Hepatic Palmitic Acid

Page 51

Figure 6b. Hepatic Stearic Acid

Page 52

Figure 6c. Hepatic Palmitoleic Acid

Page 53

Figure 6d. Hepatic Oleic Acid

Page 54 
Figure 7. Saturated Fatty Acid Content in Gonadal Adipose Tissue

Figure 7a. Gonadal Adipose Palmitic Acid

Page 55

Figure 7b. Gonadal Adipose Stearic Acid

Page 56

Figure 7c. Gonadal Adipose Palmitoleic Acid

Page 57

Figure 7d. Gonadal Adipose Oleic Acid

Page 58

Figure 8. Lipolytic Transcription Factor PPAR $\alpha$ Gene Expression in Liver

Page 59

Figure 9. Lipolytic Gene Expression in Gonadal Adipose Tissue

Figure 9a. Gonadal Adipose PPAR $ү$ Expression

Page 60

Figure 9b. Gonadal Adipose HSL Expression

Page 61

Figure 10. Total Liver Triglyceride Content

Page 62

Figure 11. Eicosanoid Enzyme COX 2 Gene Expression in Liver Tissue Page 64

Figure 12. Inflammation Marker IKB $\alpha$ Gene Expression in Liver Tissue Page 65

Figure 13. Inflammation Marker IKB $\alpha$ Gene Expression in Gonadal Adipose Page 66

Figure 14. Eicosanoid Metabolites

Figure 14a. Urinary $\mathrm{PGE}_{2}$ Page 67

Figure $14 \mathrm{~b}$. Urinary $\mathrm{TXB}_{2}$ Page 68 


\section{List of Abbreviations}

ALA

ARA

CHL

$\mathrm{CO}$

$\operatorname{COX} 2$

CVD

DHA

EPA

FA

FAS

FO

GAPDH

HDL-C

HSL

$\mathrm{IKB} \alpha$

$\mathrm{KO}$
Alpha-Linolenic Acid

Arachidonic Acid

Cholesterol

Corn Oil

Cyclooxygenase 2

Cardiovascular Disease

Docosahexaenoic Acid

Eicosapentaenoic Acid

Fatty Acid

Fatty Acid Synthase

Flaxseed Oil

Glyceraldehyde 3-Phosphate Dehydrogenase

High Density Lipoprotein

Hormone Sensitive Lipase

Inhibitor of Kappa B Alpha

Krill Oil 


\begin{tabular}{|c|c|}
\hline LA & Linoleic Acid \\
\hline LC-PUFA & Long Chain Polyunsaturated Fatty Acid \\
\hline LDL-C & Low Density Lipoprotein \\
\hline LPS & Lipopolysaccharide \\
\hline MO & Menhaden Oil \\
\hline MUFA & Monounsaturated Fatty Acid \\
\hline$n-3$ & Omega-3 \\
\hline $\mathrm{n}-6$ & Omega-6 \\
\hline $\mathrm{PGE}_{2}$ & Prostaglandin $\mathrm{E}_{2}$ \\
\hline PL & Phospholipid \\
\hline PPAR $\alpha$ & Peroxisome Proliferator-Activated Receptor Alpha \\
\hline PPAR $\gamma$ & Peroxisome Proliferator-Activated Receptor Gamma \\
\hline PUFA & Polyunsaturated Fatty Acid \\
\hline SCD-1 & Stearoyl Coenzyme A Desaturase 1 \\
\hline SFA & Saturated Fatty Acid \\
\hline SO & Salmon Oil \\
\hline SREBP-1c & Sterol Regulatory Element Binding Protein 1c \\
\hline
\end{tabular}


TG

TO

$\mathrm{TXB}_{2}$

VLDL
Triglyceride

Tuna Oil

Thromboxane $\mathrm{B}_{2}$

Very Low Density Lipoprotein 


\subsection{Introduction}

Omega-3 polyunsaturated fatty acid (n-3 PUFA) consumption has been reported to provide many health benefits, particularly the potential to decrease cardiovascular disease (CVD)-related events. In a human study, Skulas-Ray et al. (1) found that subjects provided eicosapentaenoic acid (EPA, 20:5n-3) and docosahexaenoic acid (DHA, 22:6n-3) (3.4 g per day), for 8 weeks significantly decreased serum triglyceride (TG) levels compared to subjects provided corn oil (CO). However, the effects of n-3 PUFA supplementation on serum lipids and lipoproteins have been inconsistent (2). Therefore, the health benefits of n-3 PUFAs may involve other mechanisms.

The n-3 long-chain polyunsaturated fatty acid (LC-PUFA), EPA is the substrate for 3series eicosanoids, which plays a role in vasodilation, with less platelet aggregation, and less inflammation than 2-series eicosanoids, which may lower the risk of CVD (3) (4). On the other hand, the omega-6 long chain polyunsaturated fatty acid (n-6 LC-PUFA), arachidonic acid (ARA, 20:5n-6), is the substrate for pro-thrombotic and inflammatory 2-series eicosanoids. Proinflammation and increased thrombosis increases the risk of CVD. EPA and ARA compete for the cyclooxygenase 2 (COX 2) enzyme to form their respective eicosanoids (4). This has important implications because decreased ARA reduces synthesis of pro-thrombotic and inflammatory 2-series eicosanoids by COX 2. Male Long Evans rats which received total parenteral nutrition fortified with fish oil (40\% of total calories), rich in n-3 LC-PUFAs, had decreased 2-series platelet aggregating, thromboxane $\mathrm{B}_{2}\left(\mathrm{TXB}_{2}\right)$ and pro-inflammatory, prostaglandin F1 $\alpha$ (5). Most rodent feeding studies of n-3 PUFAs have used male rats (2) (6-12). Yet, gender differences in the metabolism of n-3 PUFAs has been reported (13). Therefore, our study used female rats to further our understanding of n-3 PUFA metabolism. 
Dietary fatty acids also play a role in lipogenesis and lipolysis. Studies have shown that n-3 PUFAs decreased lipogenesis and increased lipolysis $(2,6,8,9,14-18)$. Enhancing lipogenesis promotes adiposity and in turn, obesity, which is a risk factor for CVD. Additionally, lipogenesis can affect circulating serum lipids and lipoproteins, which are also risk factors for CVD. The sterol regulatory element binding protein -1c (SREBP-1c) is a transcriptional regulator of various lipogenic genes including fatty acid synthase (FAS) and stearoyl CoenzymeA desaturase 1(SCD-1). The multi-enzyme complex, FAS, adds two carbons to malonyl-CoA through a series of reactions that result in the synthesis of the main lipogenesis product, palmitic acid (16:0). Further down the lipogenesis pathway, the rate limiting enzyme SCD-1 regulates the synthesis of saturated fatty acids (SFA) into monounsaturated fatty acids (MUFAs) (19). In turn, MUFAs regulate synthesis of TGs and cholesterol (CHL) (20). In a study by Flachs et al. (15), mice fed a diet high in EPA and DHA showed down-regulated gene expression of SCD-1 in epididymal and subcutaneous fat; however, the study did not measure serum TG and CHL.

Increased n-3 PUFA consumption is recommended due to reports of decreased CVD risk and various other health benefits. This has led to the availability of numerous n-3 PUFA sources. The n-3 PUFAs include alpha-linolenic acid (ALA), EPA, and DHA. ALA is an essential fatty acid in mammals and must be obtained through the diet. One of the richest sources of ALA is flaxseed oil (FO) (21). ALA can be converted into n-3 LC-PUFAs, EPA and DHA. However, conversion to these n-3 LC-PUFAs is inefficient. Approximately 5\% of ALA is converted to EPA and $<0.5 \%$ is converted to DHA (22). Due to low conversion rate of ALA to EPA and DHA, intake of pre-formed n-3 LC-PUFAs in the diet is recommended. Many marine sources are rich in n-3 LC-PUFAs. Menhaden oil (MO) is high in total n-3 PUFAs. Salmon oil (SO) is a rich source of EPA, and tuna oil (TO) is a rich source of DHA (23). Fatty 
acids in fish oils such as SO, TO, and MO are in TG form; whereas, krill oil (KO) is in the TG and phospholipid (PL) form (24). This difference has been suggested to affect bioavailability (25). Increased EPA and DHA in plasma lipids depend on the bioavailability of pre-formed LCPUFAs from fish oil or concentrates (26). Our laboratory previously showed that feeding different sources of n-3 fatty acids affected n-3 LC-PUFAs and n-6 LC-PUFAs composition in liver and gonadal adipose tissues (23). Therefore, this thesis investigated the effect of feeding growing female rats different n-3 PUFA sources on the regulation of lipogenic and lipolytic gene expression and lipid metabolism in liver and adipose tissues. 


\subsection{Study Objectives}

2.1 Hypothesis: Consumption of different sources of n-3 PUFAs exert health benefits by

decreasing lipogenic gene expression and increasing lipolytic gene expression. In turn, n3 PUFAs decrease serum lipids and lipoproteins. Additionally, increased tissue n-3 PUFA content reduces inflammation by decreasing 2-series eicosanoid synthesis.

\subsection{Study Objectives}

Objective 1: To determine the effect of feeding growing female rats different sources of n-3 PUFAs on expression of genes regulating lipogenesis and lipolysis.

Objective 2: To determine the effect of feeding growing female rats different sources of n-3 PUFAs on serum lipids and lipoproteins.

Objective 3: To determine the effect of feeding growing female rats different sources of n-3 PUFAs on inflammation. 


\subsection{Literature Review}

\subsection{Omega-3 and Omega-6 Polyunsaturated Fatty Acids}

Mammals lack the delta-12 and delta-15 desaturase enzymes, subsequently two fatty acids, the omega- 6 polyunsaturated fatty acid, LA (18:2n-6) and the omega-3 polyunsaturated fatty acid, ALA (18:3n-3) are essential fatty acids and therefore, must be obtained through the diet (4). The n-6 PUFAs are the main fatty acids found in vegetable oils. The fatty acid composition of corn oil (CO) is comprised of $61.1 \%$ LA (12). Flaxseed oil is richer in ALA than other commonly consumed n-3 PUFA sources, such as walnuts and soybean oils (27). After consumption, LA can be synthesized into the n-6 LC-PUFA, ARA (20:4n-6) and ALA can be synthesized into the n-3 LC-PUFAs, EPA (20:5n-3) and DHA (22:6n-3) (4). The synthesis of ARA from LA utilizes the same enzymes as the synthesis of EPA and DHA from ALA. Therefore, LA and ALA compete for the same enzymes.

As shown in Figure 1, the initial and rate limiting enzyme in the pathway is delta-6 desaturase. ALA has greater affinity for the delta-6 desaturase enzyme compared to LA (4). Consumed in equal amounts, this favors synthesis of n-3 PUFAs over n-6 PUFAs. Therefore, consuming ALA increases tissue EPA and DHA. However, conversion of ALA to EPA and DHA is low due to oxidation rather than tissue storage of ALA (26). Females have been suggested to have lower oxidation rates of ALA (13) and therefore, more efficient conversion of ALA to n-3 LC-PUFAs. 
Figure 1: Synthesis of n-3 and n-6 PUFAs

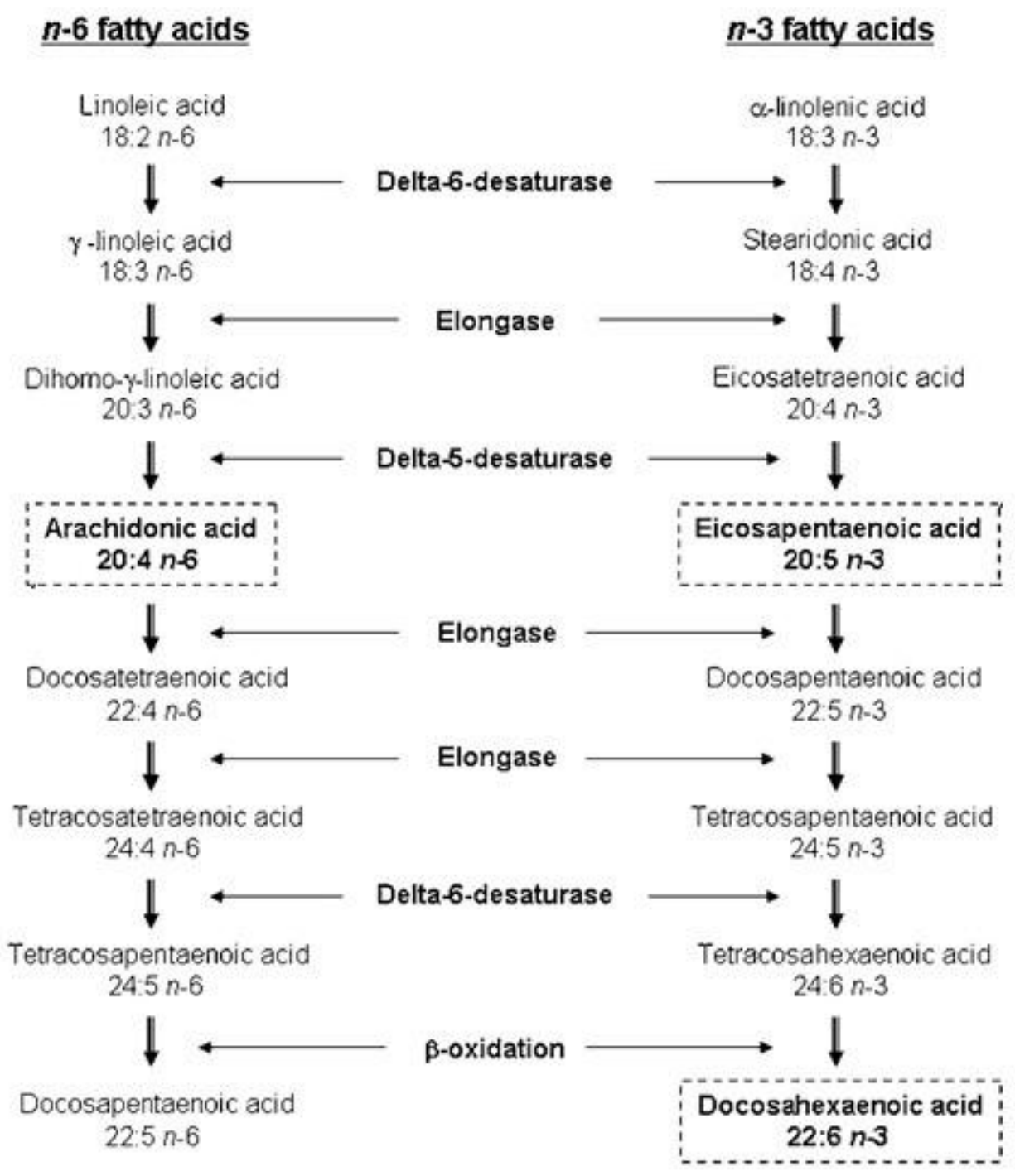

Adapted from Nutrition Reviews, May 2010, Vol. 68 Issue 5

The conversion rate of ALA to EPA and DHA is about $5 \%$ and $<0.5 \%$, respectively (22).

This has led to suggestions to consume foods rich in pre-formed EPA and DHA, such as fish oil.

In a rodent study, male spontaneously hypertensive rats provided a combination of EPA and

DHA in fish oil showed reduced plasma TGs and total CHL, which are CVD risk factors, 
compared to CO-fed rats (12). However, studies have reported inconsistent results regarding n-3 PUFAs' effects on serum lipids and lipoproteins. Intake of ALA $(1,356 \mathrm{mg} / 100 \mathrm{~g}$ diet) in male Wistar rats did not significantly decrease serum TG and CHL levels, suggesting ALA may be diverted to other metabolic pathways (28). Therefore, other mechanisms such as lipogenesis and lipolysis may be involved.

\subsection{Omega-3 Polyunsaturated Fatty Acids and Lipogenesis}

As reviewed by Lodhi et al.(29), de novo synthesis of lipids mainly occurs in the liver and adipose tissues. As shown in Figure 2, lipogenesis begins with the synthesis of citrate from acetyl CoA and oxaloacetate. In the cytosol, citrate lyase, converts citrate to acetyl CoA. The committed step of fatty acid synthesis is the synthesis of malonyl CoA from acetyl CoA which is regulated by acetyl CoA carboxylase (ACC). The multi-enzyme complex, FAS adds two carbons to malonyl-CoA through a series of reactions that result in the synthesis of the 16 carbon fatty acid, palmitic acid. Male Wistar rats (age 6 weeks old) fed a high (62\% energy) fat "cafeteria" diet ad libitum for 5 weeks showed up-regulated $(\mathrm{P}<0.001)$ FAS gene expression in the liver (9). However, supplementation of EPA ethyl ester ( $1 \mathrm{~g} / \mathrm{kg}$ body weight) attenuated $(\mathrm{P}<0.05)$ increased FAS gene expression in hepatic tissue (9). Male Sprague-Dawley rats fed a high (58\%) glucose diet containing 10\% menhaden oil rich in EPA and DHA, for 5 days resulted in a 97\% decrease in hepatic mRNA expression of FAS as measured by dot analysis, compared to rats fed the high glucose diet containing $10 \%$ triolein, a TG containing monounsaturated fatty acids (MUFAs), oleic acid (18:1n-9) (6). Raclot et al. (8) fed male Wistar rats (age 50 days old) diets with fat sources consisting of MUFAs, EPA ethyl ester, DHA ethyl ester, both EPA and DHA ethyl esters, or fish oil. FAS gene expression normalized to the fish oil group was 
decreased $(\mathrm{P}<0.05)$ in rats fed DHA ethyl ester and DHA and EPA ethyl esters groups compared to the MUFA group. 
Figure 2: Lipogenesis Pathway

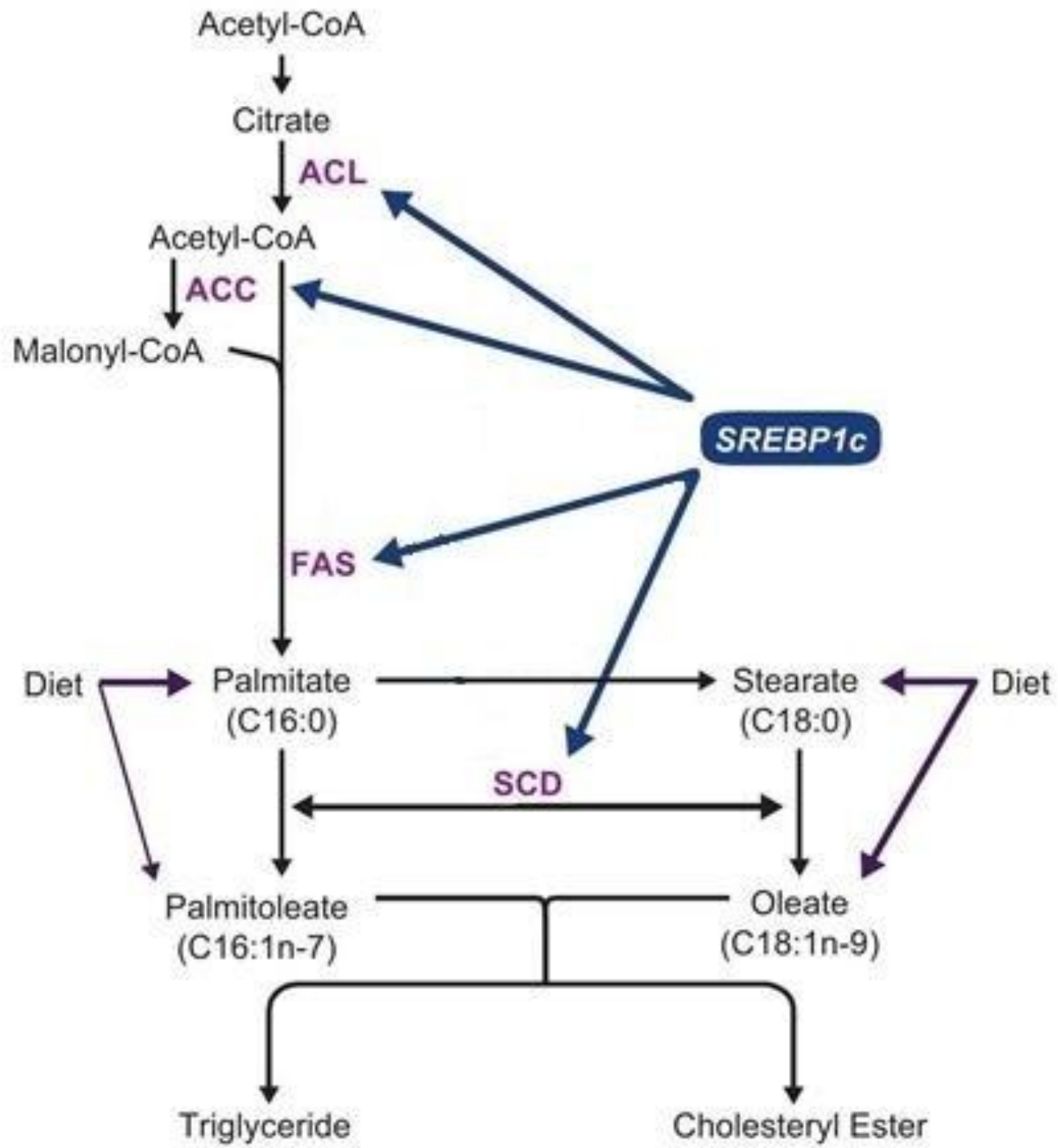

Adapted from Critical Reviews in Biochemistry \& Molecular Biology, Jun2010, Vol. 45 Issue 3 
Male Sprague-Dawley rats fed a high fat diet (35\% kcal lard) supplemented with $2.5 \%$ krill oil, which contains n-3 PUFAs in phospholipid form, resulted in a 60\% inhibition of FAS activity in the liver cytosol compared to rats fed a high $(35 \% \mathrm{kcal})$ fat diet without krill oil supplementation and rats fed a low $(6 \% \mathrm{kcal})$ fat diet (14).

The end product of FAS is palmitic acid (16:0). Longer-chain fatty acids can be synthesized by addition of 2 carbons by elongase enzymes. Unsaturated fatty acids can be synthesized by desaturase enzymes which add double bonds. The desaturase enzyme, SCD-1 synthesizes the MUFAs, palmitoleic acid (16:1n-7) and oleic acid (18:1n-9). SREBP-1c is a transcriptional regulator of various lipogenic genes including SCD-1(Figure 2). Lu et al. (2) found that obese male rats (age 8 weeks old) fed a hypercholesterolemic diet supplemented with fish oil derived DHA/EPA decreased SREBP-1c mRNA expression in hepatic tissue $(\mathrm{P}<0.01)$ and adipose tissue $(\mathrm{P}<0.05)$ compared to rats fed a hypercholesterolemic diet without DHA/EPA supplementation. Since the transcriptional factor SREBP-1c regulates SCD-1, which synthesizes palmitoleic and oleic acid which are precursors of TG and CHL (Figure 2), down-regulation of genes regulating lipogenesis may reduce risk of CVD and fatty liver.

Muhlhausler et al. (18) examined multiple genes related to lipid metabolism in the adipose tissue. Growing (age 6 weeks) female Dark Agouti rats were fed 100\% macadamia oil diet (containing $0.016 \%$ ALA and $0.27 \%$ LA) for 3 weeks to ensure comparable baseline fatty acid. After 3 weeks, the growing rats were fed the experimental diets consisting of a basal diet with $5 \%(\mathrm{v} / \mathrm{v})$ fat with varying amounts of ALA $(0.095 \%, 0.19 \%, 0.38 \%, 0.76 \%, 1.00 \%, 2.05 \%$, $4.1 \%$, and $6.3 \%$ total energy) ad libitum for 3 weeks. In omental adipose tissue, mRNA expression of the transcription factor SREBP-1c and the enzymes, SCD-1 and FAS resulted in a dose-dependent increase until a maximal dose of $0.38 \%$ ALA. In retroperitoneal adipose tissue, 
dietary ALA showed a dose-dependent decrease $(\mathrm{P}<0.05)$ in SREBP-1c expression. FAS expression was lowest $(\mathrm{P}<0.001)$ when ALA in the diet was $\geq 4.1 \%$ total energy (18). Male C57BL/6J mice fed a semi-synthetic high fat (20\% total energy) diet consisting of $56 \%$ total lipid as flaxseed oil rich in ALA and 44\% total lipid as EPA/DHA supplementation (EPAX 1050TG) significantly reduced SCD-1 gene expression in epididymal adipose tissue compared to the mice fed semi-synthetic high fat diet with 100\% total lipid as flaxseed oil (15). Male C57BL/6J mice fed a high fat (35.2\% total energy) diet with $81 \%$ rapeseed oil rich in ALA, $4 \%$ sunflower oil, and 15\% EPA/DHA (EPAX 1050TG) resulted in decreased SCD-1 expression in the epididymal fat adipocytes compared to mice fed a high fat diet with 95\% rapeseed oil and 5\% sunflower oil (15). The studies indicated that n-3 PUFAs decrease lipogenic gene expression, with the n-3 LC-PUFAs, EPA and DHA, showing greater effectiveness. In contrast, weaned male Hooded-Wistar rats were fed diets with equal amounts of LA, but different amounts of ALA $(0.2 \%, 0.5 \%, 1 \%, 1.9 \%$, and $2.9 \%)$ for 3 weeks showed no significant differences in hepatic SREBP-1c expression (30). Additionally, SREBP-1c did not significantly differ when fed a high (6.6\% weight) PUFA diet consisting of $5 \%$ by weight of the total diet as soybean oil, a rich source of ALA and LA, compared to a low (0.4\%) PUFA consisting of 5\% macadamia oil, rich in palmitoleic acid (30). Tu et al. (30) reported that n-3 PUFAs did not alter lipogenic gene expression in hepatic tissue. However, other studies reported that n-3 PUFAs altered lipogenic gene expression in adipose tissue $(15,18)$. Therefore, our study examined lipogenic gene expression in both the liver and adipose tissue. Since the body regulates lipid stores through a balance of lipogenesis and lipolysis, the next section discusses n-3 PUFAs' effects on lipolysis. 


\subsection{Omega-3 Polyunsaturated Fatty Acids and Lipolysis}

As reviewed in Kraemer et al. (31), hormones such as glucagon, catecholamines, and corticotropin stimulate the enzyme, hormone sensitive lipase (HSL) (11). In turn, HSL releases fatty acids stored in the adipose tissue. Male Wistar rats (age 6 weeks old) fed a high fat diet (62\% total energy) decreased $(\mathrm{P}<0.001)$ HSL mRNA levels in retroperitoneal adipose tissue compared to rats fed a standard pelleted diet (6\% lipid as total energy). Rats fed a high fat diet supplemented with EPA ethyl ester $(1 \mathrm{~g} / \mathrm{kg})$ for 35 days attenuated the decreased HSL mRNA levels observed in rats fed a high fat diet (16). Male Wistar rats (age 50 days old) fed high-fat (200g/kg diet) diets supplemented with DHA ethyl esters or a mixture of EPA and DHA ethyl esters for 4 weeks decreased $(\mathrm{P}<0.05)$ HSL mRNA levels, when normalized to rats fed a high-fat diet with fish oil, in retroperitoneal adipose tissue compared to rats fed high-fat diets supplemented with EPA ethyl esters or a mixture of lard and olive oil containing no n-3 PUFAs (8). The results indicated that lipolysis was down-regulated. In a human double-blind crossover study, men with type 2 diabetes were provided either a fish oil or sunflower oil supplement for 2 months. Participants had higher HSL mRNA levels after being provided the fish oil supplement compared to when provided sunflower oil supplementation (17). The higher HSL mRNA levels in type 2 diabetic men with fish oil supplementation coincided with significantly lower circulating TG levels (17), suggesting lower risk of CVD.

HSL is regulated by the transcription factors PPAR $\alpha$ (32) and PPAR $\gamma(33)$. PPAR $\gamma$ is a transcription factor that regulates genes involved in the release and uptake of fatty acids from the adipose tissue. Muhlhausler et al. (18) found that feeding female Dark Agouti rats varying amounts of ALA $(0.095 \%, 0.19 \%, 0.38 \%, 0.76 \%, 1.00 \%, 2.05 \%, 4.1 \%$, and $6.3 \%$ total energy) had no significant effect on PPAR $\gamma$ gene expression in omental adipose tissue. 
The transcription factor, PPAR $\alpha$, regulates the expression of genes involved in hepatic mitochondrial and peroxisome fatty acid oxidation. Tu et al. (30) fed weaned male HoodedWistar rats different doses (0.2 to 2.9\%) of ALA in the diet for 3 weeks and reported no significant differences in hepatic PPAR $\alpha$ gene expression. Similarly, in a feeding study of a high (6.6\%) PUFA diet with 5\% by weight of total diet as soybean oil or a low (0.4\%) PUFA diet with $5 \%$ by weight of total diet as macadamia oil, showed no significant differences in PPAR $\alpha$ expression (30). The results indicated that the amount of PUFAs did not affect gene expression of the lipolytic transcription factor, PPAR $\alpha$. On the other hand, the type of fatty acid affected HSL and PPAR $\alpha$ expression. PUFAs, but not SFAs, bind directly to PPAR $\alpha$, which can induce $\beta$-oxidation (34). Perez-Echarri et al. (9) fed male rats a standard rat pellet diet or a high (62\% energy) fat "cafeteria" diet supplemented with EPA ethyl ester ( $1 \mathrm{~g} / \mathrm{kg}$ body weight) found EPA ethyl ester supplementation decreased $(\mathrm{P}<0.01)$ PPAR $\alpha$ mRNA expression in hepatic tissue.

EPA and DHA can be in TG and PL forms. To our knowledge, no studies have been conducted to compare the effects of n-3 PUFAs in different lipid forms on HSL, PPAR $\alpha$, or PPAR $\gamma$ gene expression. Therefore, our study examined the effects of feeding n-3 PUFA sources with different types and structural forms of n-3 LC-PUFAs. Since altering lipogenesis and lipolysis balance can affect circulating lipids, the next section reviews the effects of dietary lipids on serum lipids and lipoproteins.

\subsection{Omega-3 Polyunsaturated Fatty Acids and Serum Lipids and Lipoproteins}

As reviewed by Magkos (35), the liver packages de novo synthesized TGs into very low density lipoproteins (VLDL). VLDLs are hydrolyzed by lipoprotein lipase (LPL), which releases TG to form VLDL remnants and intermediate-density lipoproteins (IDL), which in turn are taken up by the liver to be converted into low density lipoproteins (LDL-C) that transport 
CHL to the tissues. High density lipoproteins (HDL-C) transport excess cholesterol from the tissues back to the liver (36).

Zhu et al. (37) fed adult male rats a high $(0.5 \mathrm{ml} / 100 \mathrm{~g}$ body weight) fat diet $(78.8 \%$ feed, $1 \%$ cholesterol, $10 \%$ yolk powder, $10 \%$ lard, and $0.2 \%$ cholate) supplemented with various doses of krill oil $(16.65,33.3,99.9,199.8 \mathrm{~g} / \mathrm{L})$ for 4 weeks. All doses of krill oil decreased $(\mathrm{P}<0.05)$ total serum cholesterol, triglycerides, and LDL-C compared to baseline levels (37). High fat diets supplemented with krill oil doses of $16.65 \mathrm{~g} / \mathrm{L}$ and $33.3 \mathrm{~g} / \mathrm{L}$ dosage decreased $(\mathrm{P}<0.05)$ serum TGs compared to the high fat diet (37). High fat diets supplemented with all doses of krill oil decreased $(\mathrm{P}<0.05)$ total cholesterol and LDL-C levels (37). High $(99.9 \mathrm{~g} / \mathrm{L}$ and $199.8 \mathrm{~g} / \mathrm{L})$ doses of krill oil also significantly $(\mathrm{P}<0.05)$ increased HDL-C levels $(37)$. Our study compared the effects of various marine sources of n-3 LC-PUFAs, including krill oil, on serum lipids and lipoproteins.

Morgado et al. (11) compared the effects of fish oil rich in n-3 PUFAs, sunflower oil rich in n-6 PUFAs, olive oil rich in omega-9 (n-9) PUFAs, and coconut oil rich in saturated fatty acids (SFAs) on serum lipid profiles in growing (age 8-10 weeks old) male Wistar rats. The diets were isocaloric with $15 \%$ of the total kcal as lipids consisting of $5 \%$ from sunflower oil to provide essential fatty acids and $10 \%$ from the experimental oil source. Diets were fed $a d$ libitum. Plasma total CHL and TG concentrations were significantly decreased in rats fed fish oil compared to sunflower oil, olive oil, and coconut oil. In addition, VLDL and HDL-C levels were significantly decreased in rats fed fish oil compared to the sunflower oil, olive oil, and coconut oil groups. Decreased HDL-C coincides with decreased total CHL because rodents mainly transport cholesterol in the HDL-C fraction (36). However, it was not specified whether the serum lipids were fasting values and duration of the feeding study was not provided. 
Another study used obese male rats fed either hypercholesterolemic diet or hypercholesterolemic diet supplemented with $5 \%$ of total fat (15\% w/w) as EPA/DHA derived from fish oil for 16 weeks(2). Fasting serum CHL and TG were decreased $(\mathrm{P}<0.05)$ in rats fed the EPA/DHA supplemented diet. However, there were no significant effects on HDL-C and LDL-C fractions. Based on the study results, supplementation with n-3 LC-PUFAs decreased serum lipids, but not serum lipoproteins (11) (2). Therefore, n-3 PUFAs may reduce CVD risk through other mechanisms such as: platelet aggregation, vasoconstriction, and inflammation.

\subsection{Omega-3 Polyunsaturated Fatty Acids and Eicosanoid Synthesis}

The n-6 PUFA, ARA, is the substrate for 2-series eicosanoids. The eicosanoids consist of prostaglandins and thromboxanes (38). Prostaglandins regulate inflammation. Thromboxanes regulate platelet aggregation and contraction of vascular smooth muscle (39). EPA competes with ARA for the eicosanoid synthesizing enzyme, cyclooxygenase 2 (COX 2) (Figure 3). EPA is the substrate for 3 -series eicosanoids. The 3 -series eicosanoids have less potent inflammation, and platelet aggregation and vasoconstriction compared to the 2-series eicosanoids (Figure 3). Therefore, increased n-3 LC-PUFAs can reduce CVD risk by altering eicosanoids.

Yeh et al. (5) utilized total parenteral nutrition (TPN) to analyze the short-term effect of n-3 PUFA intake on prostaglandin synthesis. Male Long Evans rats were fed standard rat chow, or isonitrogenous TPN containing either safflower oil rich in LA or fish oil rich in EPA, as a fat emulsion for 7 days. The fish oil TPN group had the lowest $(\mathrm{P}<0.05)$ plasma thromboxane $\mathrm{B}_{2}$ $\left(\mathrm{TXB}_{2}\right)$ concentrations among the groups (5). However, the type of fish oil utilized in this study was not specifically stated and DHA was not measured (5). Another study examined safflower oil, fish oil, and ALA provided as a TG mixture of 97\% ALA (40). Weanling male Sprague- 
Dawley rats were fed isocaloric basal diets containing (10\% by weight) fat as ALA, refined menhaden oil, or safflower oil for 12 weeks. Incubation of lung homogenates of rats fed ALA and menhaden oil decreased $(\mathrm{P}<0.05) \mathrm{TXB}_{2}$ concentrations compared to rats fed safflower oil rich in LA (40). The results indicated that supplementation of n-3 PUFAs decreased 2-series eicosanoids.

Sohal et al. (41) studied the effects of n-3 PUFAs on $\mathrm{PGE}_{2}$. Male Sprague-Dawley rats were fed a diet high in n-3 PUFAs (19\% total fat) or a diet low in n-3 PUFAs (1.4\% total fat) from fish oil. At week 3, diabetes was induced in half of the rats by a single tail-vein injection of streptozotocin (50 mg/kg body wt) in acetate buffer. The high n-3 PUFA diet decreased $(\mathrm{P}<0.0001)$ synthesis of $\mathrm{PGE}_{2}$ by approximately $75 \%$. The results indicated that high (19\% total fat) amounts of n-3 PUFAs competitively inhibited synthesis of 2-series prostaglandins.

Male Fischer rats provided azoxymethane injections to initiate colon cancer were fed a purified diet with either $15 \%$ flaxseed meal rich in ALA or $15 \%$ corn meal rich in LA ad libitum (42). The rats fed corn meal had higher $(\mathrm{P}<0.05)$ COX 2 levels in colon microsomes (42). Rats with chronic renal failure, providing 7:1 EPA:DHA supplementation attenuated the up-regulated COX 2 protein abundance in renal tissue associated with surgically induced chronic renal failure (43). Sankaran et al. (44) fed weanling Han:SPRD-cy rats, a genetic model of polycystic kidney disease, a high fat $(20 \mathrm{~g} / 100 \mathrm{~g}$ diet $)$ or low fat $(5 \mathrm{~g} / 100 \mathrm{~g}$ diet $)$ diet containing cottonseed oil rich in LA, menhaden oil rich in EPA and DHA, or soybean oil (4:1g/g) rich in ALA and LA for 6 weeks. Han:SPRD-cy rats fed the high menhaden oil diets had approximately five times more COX 2 protein levels and low menhaden oil diets had 1.2 times more COX 2 protein levels in the kidneys compared to rats fed the high or low fat cottonseed diets (44). On the other hand, weanling male Han:SPRD-cy rats provided 7\% corn oil rich in LA or 7\% flaxseed/corn oil 
containing flaxseed/corn oil $(4: 1, \mathrm{~g} / \mathrm{g})$ rich in ALA diets for 12 weeks showed no significant differences in renal COX 2 protein or gene expression (44). 
Figure 3: Eicosanoid Synthesis Pathway
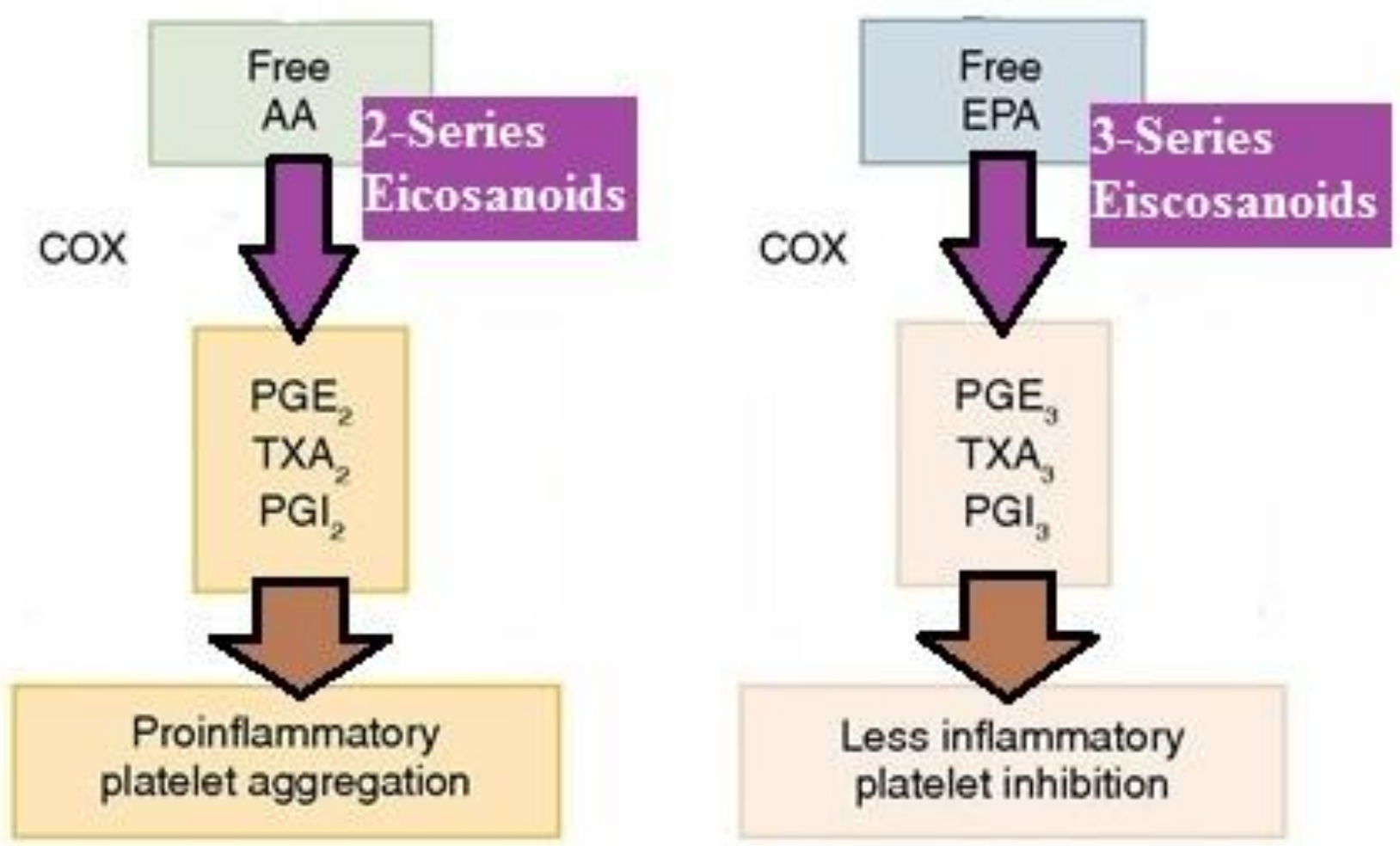

Adapted from the American Joumal of Health-System Pharmacy, 7/1/2009, Vol.66 Issue 13

The study results indicated that n-3 LC-PUFAs, EPA and DHA, but not ALA decreased COX 2.

COX 2 protein and gene expression altered inflammation which plays a role in disease

progression. The literature showed beneficial effects of n-3 PUFA supplementation in disease

states. However, the general public is currently being advised to consume n-3 PUFAs as a

preventative measure against disease risk. Therefore, our study analyzed the effects of n-3

PUFA supplementation using non-diseased animals. 


\subsection{Omega-3 Polyunsaturated Fatty Acids and Inflammation}

Inflammation can also be regulated by mechanisms other than altering eicosanoids. Nuclear Factor Kappa B (NFKB) is a key transcription factor that can mediate activation of inflammation. Inhibitor Kappa B Alpha (IKB $\alpha)$ regulates cytoplasmic retention of NFKB by inhibiting DNA binding by NFKB, recruitment and inhibition of protein kinase A (PKA) in the IKB/NFKB complex, and removal of NFKB from the nucleus (45). The human pro-monocytic cell line U937 treated with n-6 PUFA, ARA (45mM) increased NFKB binding/activation. On the other hand, treatment with n-3 PUFA, EPA (45mM) had no significant effect on nuclear translocation (46). Nuclear translocation of the p65 NFKB subunit is key for NFKB activity. Western blots of nuclear proteins from DHA-pretreated human saphenous vein endothelial cells (HSVEC) cells showed significantly less p65 nuclear translocation into nuclei, but not total cellular p65 compared to non-treated HSVEC cells (47).

EPA has been suggested to prevent IKB $\alpha$ degradation and NFKB translocation by preventing the phosphorylation of IKB $\alpha$ (48). NFKB is kept in an inactive form by the inhibitory subunit IKB in most cell types (48). Phosphorylation of IKB by IKKs leads to its ubiquitination and subsequent degradation resulting in the translocation and activation of NFKB (48).

Lipopolysaccharide (LPS) stimulation decreased the levels of IKB $\alpha$ and increased the levels of $\mathrm{p}-\mathrm{IKB} \alpha$ (48). EPA pre-treatment significantly suppressed the levels of LPS-induced p$\mathrm{IKB} \alpha$ by $40 \%$ at $15 \mathrm{~min}$ and by $50 \%$ at $30 \mathrm{~min}$ (48). Measurement of band densities from a Western Blot indicated that EPA pre-treatment of THP-1 cells inhibited LPS-induced decrease in $\mathrm{IKB} \alpha$ by $18 \%$ at $30 \mathrm{~min}$ (48). However, the IKB $\alpha$ levels represented the total amount of preexisted and newly synthesized IKB $\alpha$ since IKB $\alpha$ gene expression is up-regulated by the 
activation of NFKB. A decrease in NFKB activation by EPA may result in a slow regeneration of IKB $\alpha$ that reduced the difference in IKB $\alpha$ levels between EPA treated and non-treated cells (48). Proximal tubular epithelial cells treated with EPA prevented LPS-induced NFKB activation and pre-treatment with IKB $\alpha$ siRNA abolished the effect of EPA. The results indicated that EPA inhibited NFKB activation by regulating IKB $\alpha$ (49). The n-3 LC-PUFAs, EPA and DHA, decreased inflammation; however, specific fatty acid and doses may affect this alteration. Our study examined the effect of feeding healthy animals different n-3 LC-PUFA sources on IKB $\alpha$ gene expression.

\subsection{Summary}

Changing dietary n-3 PUFA intake may be a preventive strategy for reducing risk of CVD as well as other diseases. The effects of n-3 PUFAs on lipogenesis and lipolysis can affect tissue fatty acid composition and circulating lipids and subsequently, health status and disease risk. Studies examining the effects of n-3 LC-PUFA intake on serum lipids and lipoproteins have produced inconsistent results $(2,11,37)$. Instead, n-3 LC-PUFAs may decrease CVD risk by influencing inflammation such as: reducing synthesis of 2-series eicosanoids involved in the regulation of inflammation, platelet aggregation, and vasoconstriction. Studies have reported that gene regulation of lipolysis, lipogenesis, serum lipids and lipoproteins, and inflammation depended on the type of n-3 LC-PUFAs supplemented. Therefore, our study investigated the effects of feeding popular and novel sources of n-3 PUFAs. 


\subsection{Materials and Methods}

\subsection{Diets}

Experimental diets fed to animals were formulated to match the standard purified American Institute of Nutrition-93G (AIN-93 G) diet (Appendix 1). The AIN-93G meets the nutritional requirements for growing rats as defined by the National Research Council (1996). Modifications of the AIN-93G diet consisted of replacing 7\% lipids with $12 \%$ lipid by weight. The high fat diet ( 27\% kcals) was used to reflect the high fat intake typical of the Western diet ( $\sim 33 \%$ kcals). The dietary oils consisted of either: 1) corn oil (CO), 2) flaxseed oil (FO), 3) krill oil (KO), 4) menhaden oil (MO), 5) salmon oil (SO) or 6) tuna oil (TO). All diets were adjusted to be isocaloric.

Table 1 summarizes the characteristics of the dietary oils. The lipid sources were selected on the basis that $\mathrm{CO}$ has a high n-6:n-3 PUFA ratio which is prevalent in the Western diet. KO had the highest total n-3 PUFA content followed by FO. Of the oil sources, FO had the highest ALA content. Of the fish oils, SO had the highest EPA content and in turn, the highest EPA:DHA ratio. Of the fish oils, TO had the highest DHA content and in turn, the lowest EPA:DHA ratio. Dietary n-3 PUFAs were in TG form in FO and fish oil sources. In KO, n-3 PUFAs were equally distributed in TG and PL (25). To meet the National Research Council (1995) nutrient requirements for the essential n-6 PUFA, LA, it was necessary to add CO (2\% lipids by wt) to the KO and MO (10\% lipids by wt) diets (Appendix 1). The CO, FO, MO, SO, and TO were provided by J. Edwards International Inc (Quincy, MA). KO was obtained from Enzymotec Ltd. (Morristown, NJ). 


\subsection{Animal Feeding Study}

All animal procedures were approved by the Animal Care and Use Committee at West Virginia University and were conducted in accordance with the guidelines set forth by the National Research Council Guide for the Care and Use of Laboratory Animals (1996). Growing (28 d) female Sprague-Dawley rats $(n=60)$ were purchased from Taconic Farms (Rockville, MD). Upon arrival at the West Virginia University animal care facility, rats were individually caged in metabolic cages to determine food intake. Rats were kept housed in rooms maintained at $21^{\circ} \mathrm{C}$ with a $12 \mathrm{~h}$ light/dark cycle throughout the 8 week feeding study. Following $7 \mathrm{~d}$ acclimation, rats ( $\mathrm{n}=10$ /group) were randomly assigned to experimental diets consisting of $\mathrm{CO}$, FO, KO, MO, SO or TO. Diets were stored at $-20^{\circ} \mathrm{C}$ until fed.

All rats were provided $15 \pm 0.75 \mathrm{~g}$ diet/d of their assigned diet to prevent variability in food intake. This amount was based on the average amount of food consumed daily by growing female Sprague-Dawley rats (50). Food intake was measured and replaced with fresh diet daily. Water consumption and body weights were measured weekly throughout the 8 week feeding study. At the end of the 8 week feeding study, rats were fasted overnight, and then euthanized by $\mathrm{CO}_{2}$ inhalation.

\subsection{Determination of Gene Expression}

Shown in Table 2 is a list of lipogenesis and lipolysis genes measured in the present study and their functions.

\section{Gene Expression}

Liver and gonadal adipose tissues were dissected then weighed. Retroperitoneal adipose tissue was not analyzed because there was not enough mRNA to properly amplify on qPCR. Tissues were immediately frozen in liquid nitrogen and stored at $-80^{\circ} \mathrm{C}$ until analyzed. Total 
RNA in the liver was isolated using the mirVana ${ }^{\mathrm{TM}}$ Isolation Kit (Ambion Inc, Foster City, CA) according to the manufacturer's instructions for total RNA isolation. To isolate RNA in the adipose tissue, the RNeasy Lipid Tissue Mini Kit (Qiagen) was used. TURBO DNase kit (Ambion/Life Technologies) was then used on the RNA samples. First strand complementary DNA (cDNA) was synthesized using the SuperScript III First-Strand Synthesis System (Invitrogen, Carlsbad, CA). Gene expression of transcription factors and enzymes was determined by qPCR. The housekeeping gene GAPDH was used as a reference. The primer sequences for GAPDH are (forward) 5' - TCA AGA AGG TGG TGA AGC AG - 3' and (reverse) 5' - CCT CAG TGT AGC CCA GGA TG - 3'. Primer efficiencies were determined using LinRegPCR software. Gene expression results were analyzed using Relative Expression Software Tool (REST) 2009 (51).

\section{Lipogenic Gene Expression}

SREBP-1c is a key transcription factor in fatty acid and cholesterol synthesis. The primer sequences for SREBP-1c are (forward) 5' GCC TGC TTG GCT CTT CTC T 3' and (reverse) 5' GCT TGT TTG CGA TGT CTC C 3'. FAS is the enzyme that regulates synthesis of palmitic acid. The primer sequences for FAS are (forward) 5'- GCT GCT ACA AAC AGG ACC ATC-3' and (reverse) 5'- TCC ACT GAC TCT TCA CAG ACC A-3'. SCD-1 is the key enzyme in the synthesis of MUFAs. The primer sequences for SCD-1 are (forward) 5'-TTC GCC ACT GAC TTG CTA TG-3' and (reverse) 5'- CAG GAG GTT CTT GGG ATG ATT -3'.

\section{Lipolysis Gene Expression}

HSL is a key enzyme in the mobilization of fatty acids from adipose tissue. The primer sequences for HSL are (forward) 5'- TCT TCT TTG AGG GCG ATG AG -3'and (reverse) 5'- 
GCA GCC TTT ATG TAG CGT GA -3'. PPAR $\alpha$ is a transcription factor regulating genes involved in lipolysis. The primer sequences for PPAR $\alpha$ are (forward) 5'- ATG AAC AAA GAC GGG ATG CT -3' and (reverse) 5'- AGG AAC TCT CGG GTG ATG AA -3'. The transcription factor PPAR $\gamma$ plays a variety of roles in the adipose, including regulation of genes involved in the release and uptake of fatty acids from adipose tissue. The primer sequences for PPAR $\gamma$ are (forward) 5'- GGA AAG ACA ACA GAC AAA TCA CC-3'and (reverse) 5'- CGA AAC TGG CAC CCT TGA -3'.

Inflammation Gene Expression

The n-3 PUFAs have been suggested to reduce inflammation in the body (4). Therefore, our study analyzed IKB $\alpha$ and $\operatorname{COX} 2$. IKB $\alpha$ alters inflammation through the NFKB pathway and COX 2 affects inflammation through the eicosanoid synthesis pathway. The primer sequences for COX 2 are (forward) 5' TCA ATG CAA AAG GTA TCA GTG G 3' and (reverse) 5' ACC GTG AGC TGG AAG ACA TT -3'. The primer sequences for IKB $\alpha$ are (forward) 5'- CTG GTC TCG CTC CTG TTG A -3' and (reverse) 5'- GCC CTG GTA GGT TAC TCT GTT G -3'.

\subsection{Determination of Fatty Acid Composition}

\section{Lipid Extraction}

At the end of the 8 week feeding study, rats were euthanized by $\mathrm{CO}_{2}$ inhalation. Liver and gonadal adipose tissues were dissected and then weighed. Tissues were immediately frozen in liquid nitrogen and stored at $-80^{\circ} \mathrm{C}$ until analyzed. Lipids were extracted according to Bligh and Dyer (52). Briefly, aliquots of liver $(0.5 \mathrm{~g})$ or adipose tissue $(0.025 \mathrm{~g})$ samples were added to Tris/EDTA buffer ( $\mathrm{pH} 7.4)$ and $48 \mu \mathrm{l}$ nonadecenoic (19:1) added as an internal standard. Chloroform:methanol:acetic acid (2:1:0.15 v/v/v) solution was added and samples were 
centrifuged at $900 \mathrm{~g}$ for $10 \mathrm{~min}$ at $10^{\circ} \mathrm{C}$. The collected chloroform layer was filtered through 1phase separation filters. The centrifugation and filtration steps were repeated and the extracted lipid was dried under nitrogen gas.

\section{Fatty Acid Methylation}

The extracted lipid samples were transmethylated according to Fritsche and Johnston (53). Briefly, fatty acids were methylated by adding $4 \%$ sulfuric acid in anhydrous methanol to the extracted lipid samples followed by incubation in a $90^{\circ} \mathrm{C}$ water bath for $60 \mathrm{~min}$. Samples were cooled to room temperature and $3 \mathrm{~mL}$ of deionized distilled water was added. Chloroform was added to the methylated samples and centrifuged at $900 \mathrm{~g}$ for $10 \mathrm{~min}$ at $10^{\circ} \mathrm{C}$. The collected chloroform layer was filtered through anhydrous sodium sulfate to remove remaining water. Samples were dried under nitrogen gas. Dried samples were diluted in iso-octane to a concentration of $5 \mathrm{mg}$ FAME (fatty acid methyl esters)/mL iso-octane.

FAME samples were analyzed by gas chromatography (CP-3800, Varian, Walnut Creek, CA) using an initial temperature of $140^{\circ} \mathrm{C}$ held for $5 \mathrm{~min}$ and then increased $1^{\circ} \mathrm{C}$ per min to a final temperature of $220^{\circ} \mathrm{C}$. Total separation time was $60 \mathrm{~min}$. A wall-coated open tubular fused silica capillary column (Varian Inc., Walnut Creek, CA) was used to separate FAMEs with CPSil 88 as the stationary phase. Nitrogen was used as the carrier gas. Quantitative 37 Component FAME Sigma Mix (Supelco, Bellefonte, PA) was used as a standard to identify fatty acids. The n-3 PUFAs, ALA, EPA, and DHA, and the n-6 PUFAs, LA and ARA were determined. The FAS end product palmitic acid (16:0) and SCD-1 end products, palmitoleic (16:1n-7) and oleic acid (18:1n-9), and oleic acid precursor stearic acid (18:0) were quantified using peak area counts and retention time.

\subsection{Liver Triglyceride Content}


Total liver triglyceride content was measured using a commercially available triglyceride colorimetric assay kit (Cayman Chemical, Ann Arbor, MI). Briefly, 350-400 mg liver tissue was homogenized in standard diluent. Samples were centrifuged, and the supernatant was collected and diluted 1:5 in standard diluent. Absorbance was determined at $530 \mathrm{~nm}$ using a Spectramax Plus microplate reader (Molecular Devices, Sunnyvale, CA). All samples were determined in duplicate and values were expressed as triglycerides $(\mathrm{mg} / \mathrm{dl})$.

\subsection{Serum Lipid and Lipoprotein Analysis}

Immediately following euthanization, the chest cavity was opened and the aorta was punctured to collect blood. The collected blood was centrifuged at $1,500 \mathrm{~g}$ for $10 \mathrm{~min}$ at $4^{\circ} \mathrm{C}$ and the serum was collected and kept frozen at $-80^{\circ} \mathrm{C}$ until analyzed. Fasting serum cholesterol, TG, VLDL, LDL-C, and HDL-C were determined by lipid test rotor enzymatic colorimetric assays and measured using a Hemagen Analyst automated spectrophotometer (Hemagen Diagnostics Inc., Columbia, MD).

\subsection{Determination of 2-Series Eicosanoids}

$\mathrm{TXB}_{2}$ and $\mathrm{PGE}_{2}$ derived from ARA are short-lived molecules. Therefore, the stable metabolites, 11-dehydro $\mathrm{TXB}_{2}$ and 13, 14-dihydro-15-keto $\mathrm{PGE}_{2}$, were measured. Rats were individually housed in metabolic cages to collect urine. Ascorbic acid $(0.1 \%)$ was added to the urine collection tubes as a preservative and mineral oil ( $1 \mathrm{~mL})$ to prevent evaporation. Pooled 7 d urine samples were collected during the final week of the 8 week feeding study. Collected urine samples were centrifuged at $1,500 \mathrm{~g}$ for $10 \mathrm{~min}$ at $4^{\circ} \mathrm{C}$. Following centrifugation, urine samples were aliquoted into clean tubes. Urinary 11-dehydro $\mathrm{TXB}_{2}$ and 13, 14-dihydro-15-keto $\mathrm{PGE}_{2}$ were determined using a commercially available enzyme immunoassay kits (Cayman 
Chemical, Ann Arbor, MI). Absorbance was determined at wavelength $405 \mathrm{~nm}$ using a Spectramax Plus microplate reader (Molecular Devices, Sunnyvale, CA).

\subsection{Statistical Analysis}

All results are expressed as mean \pm SEM. Data was analyzed by one-way analysis of variance (ANOVA) to determine the differences among the diet groups. Post hoc multiple comparison tests were performed using Tukey’s (parametric) or Kruskal-Wallis (non-parametric) test with results considered significant at $\mathrm{P}<0.05$. All statistical analyses were performed using Sigma Stat 3.1 (Abacus Concepts, Berkeley, CA). Statistically significant differences in gene expression were analyzed by pairwise fixed reallocation randomization test as a statistical model in the relative expression software tool (REST) program developed for group-wise comparison and statistical analysis of relative expression results (51). 


\subsection{Results}

\subsection{Dietary Fatty Acid Content}

Shown in Table 3, of the $\mathrm{n}-6$ PUFAs, $\mathrm{CO}$ and FO diets had increased $(\mathrm{P}<0.001)$ dietary LA content compared to KO, MO, SO, and TO diets. Of the n-3 PUFAs, the FO diet had the highest $(\mathrm{P}<0.001)$ dietary ALA content. The KO diet had the highest $(\mathrm{P}<0.05)$ dietary EPA content compared to all diets, except SO. SO diet had increased $(\mathrm{P}<0.05)$ dietary EPA compared to the TO, FO, and CO diets. DHA content in marine oils was higher than FO and $\mathrm{CO}$ diets.

Of the MUFAs, the fish oil diets $(\mathrm{MO}, \mathrm{SO}, \mathrm{TO})$ had higher $(\mathrm{P}<0.001)$ dietary palmitoleic acid (16:1n-7) content compared to the KO, FO, and CO diets. The FO diet had higher dietary oleic acid (18:1n-9) content than the fish oil groups, $\mathrm{MO}(\mathrm{P}=0.007)$, $\mathrm{SO}(\mathrm{P}=0.036)$, and TO $(\mathrm{P}=0.034)$ diets. Of the SFAs, there were no significant differences for palmitic acid (16:0) content in diets. The FO diet had the highest $(\mathrm{P}<0.001)$ amount of stearic acid $(18: 0)$.

\subsection{Body and Organ Weights}

No significant differences were found in food intake, body weight gain or final body weight among the diet groups. Rats fed SO, TO, or KO had heavier $(\mathrm{P}<0.001)$ liver weights compared to FO or CO-fed rats. There were no significant differences in gonadal adipose tissue weights among the diet groups (Appendix 2). 


\subsection{Liver and Gonadal Adipose Tissue Polyunsaturated Fatty Acids}

Liver Tissue

Previously, Tou et al.(25) reported rats fed SO and TO diets had higher $(\mathrm{P}<0.001)$ total n3 PUFA deposition in the liver compared to the other diet groups. Liver ALA content was highest $(\mathrm{P}<0.001)$ in rats fed the FO diet. EPA liver content was highest $(\mathrm{P}<0.001)$ in rats fed the SO diet. Liver DHA was highest $(\mathrm{P}<0.001)$ in rats fed SO and TO diets. TO had the lowest $(\mathrm{P}<0.05)$ EPA:DHA ratio (Appendix 3). Rats fed n-3 PUFAs had lower $(P<0.001)$ liver LA deposition than CO-fed rats. Rats fed marine oils had lower $(P=0.01)$ liver LA deposition than FO-fed rats. Liver ARA deposition was highest $(P<0.01)$ in TO-fed rats. Rats fed FO, KO, and MO had lower $(P<0.001)$ liver ARA than SO, TO, or CO-fed rats (Appendix 3).

\section{Gonadal Adipose Tissue}

Previously, Tou et al. (25) reported that rats fed FO diet had the highest $(\mathrm{P}<0.001)$ gonadal adipose tissue ALA deposition. Rats fed KO diet had the highest $(\mathrm{P}<0.05)$ gonadal adipose tissue EPA content. Rats fed MO had higher $(\mathrm{P}=0.007)$ gonadal adipose tissue EPA content compared to the FO and CO-fed rats. Gonadal adipose tissue DHA was higher $(\mathrm{P}<0.05)$ in rats fed $\mathrm{MO}$ and $\mathrm{TO}$ compared to rats fed the $\mathrm{SO}, \mathrm{FO}$, and $\mathrm{CO}$ diets. Gonadal adipose tissue DHA was higher $(\mathrm{P}<0.001)$ in the KO compared to the FO and $\mathrm{CO}$ diet groups. Rats fed all n-3 PUFA sources had lower $(\mathrm{P}<0.001)$ gonadal adipose LA content compared to the CO diet group. Rats fed TO had the highest $(\mathrm{P}<0.05)$ gonadal adipose ARA content (Appendix 4). 


\subsection{Liver and Gonadal Adipose Tissue Lipogenic Gene Expression}

Liver Tissue

Hepatic SREBP-1c gene expression was down-regulated in the MO $(\mathrm{P}=0.007)$ compared to the $\mathrm{CO}$ diet group (Figure 4a). FAS gene expression was down-regulated in the FO $(\mathrm{P}=0.010), \mathrm{MO}(\mathrm{P}=0.001), \mathrm{SO}(\mathrm{P}=0.001)$, and $\mathrm{TO}(\mathrm{P}=0.006)$ diet groups compared to the $\mathrm{CO}$ group (Figure 4b). In the liver, $\mathrm{SCD}-1$ expression was down-regulated in the $\mathrm{MO}(\mathrm{P}=0.008)$ and the TO $(\mathrm{P}=0.04)$ diet groups compared to the $\mathrm{CO}$ diet group (Figure 4c).

Gonadal Adipose Tissue

In the gonadal adipose tissue, there were no significant differences in gene expression for SREBP-1c, FAS, or SCD-1 for the n-3 PUFA diet groups compared to the CO diet group (Figures 5a-c).

\subsection{Liver and Gonadal Adipose Tissue Saturated and Monounsaturated Fatty Acids}

Liver Tissue

Hepatic palmitic acid content was significantly higher in rats fed SO and TO diets compared to rats fed MO, FO, and CO diets (Figure 6a). Hepatic stearic acid (18:0) content was increased $(\mathrm{P}<0.005)$ in rats fed $\mathrm{TO}$ diet compared to $\mathrm{KO}, \mathrm{MO}$, and FO-fed rats. Rats fed SO had higher $(\mathrm{P}<0.005)$ hepatic stearic acid $(18: 0)$ content compared to the KO and MO-fed rats (Figure 6b). There was no significant difference in liver palmitoleic acid (C16:1n-7) content among the diet groups (Figure 6c). Liver oleic acid $(\mathrm{C} 18: 1 \mathrm{n}-9)$ content was higher $(\mathrm{P}<0.05)$ in the rats fed KO compared to FO diet (Figure 6d). 


\section{Gonadal Adipose Tissue}

Gonadal adipose palmitic acid $(16: 0)$ content was higher $(\mathrm{P}<0.005)$ in the MO compared to the $\mathrm{SO}$ and $\mathrm{CO}$ diet groups. Gonadal adipose tissue palmitic acid was also higher $(\mathrm{P}=0.013)$ in rats fed the $\mathrm{KO}$ diet compared to rats fed the SO diet (Figure 7a). There were no significant differences in adipose stearic acid (18:0) content among the diet groups (Figure 7b). There were no significant differences in gonadal adipose palmitoleic acid (16:1n-7) and oleic acid (18:1n-9) among the diet groups (Figures 7c-d).

\subsection{Liver and Gonadal Adipose Tissue Lipolytic Gene Expression}

Liver Tissue

PPAR $\alpha$ gene expression was not significantly different in the n-3 PUFA diet groups compared to the $\mathrm{CO}$ diet group (Figure 8).

Gonadal Adipose Tissue

PPAR $\gamma$ gene expression was up-regulated in the FO diet group $(\mathrm{P}=0.039)$ compared to the $\mathrm{CO}$ diet group (Figure 9a). There were no significant differences in HSL gene expression for the n-3 PUFA diet groups compared to the CO diet group (Figure 9b).

\subsection{Total Liver Triglyceride Content}

There were no significant differences in total liver TG content among the different diet groups (Figure 10). 


\subsection{Serum Lipids and Lipoproteins}

Serum total cholesterol concentration was lowest $(\mathrm{P}<0.001)$ in rats fed $\mathrm{SO}$ and $\mathrm{TO}$ diets. Rats fed $\mathrm{KO}$ and $\mathrm{MO}$ diets had significantly lower serum total cholesterol concentration compared to the rats fed FO and $\mathrm{CO}$ diets. There were no significant differences in serum TG, VLDL, and LDL-C among the diet groups. There was a significant decrease in HDL-C in rats fed FO and marine oils compared to rats fed the CO diet (Table 3).

\subsection{Liver and Gonadal Adipose Tissue Inflammation}

Liver Tissue

In liver, there were no significant differences in COX 2 gene expression among the $\mathrm{n}-3$ PUFA diet groups compared to the CO diet group (Figure 11). Hepatic IKB $\alpha$ gene expression was down-regulated in the $\mathrm{FO}(\mathrm{P}=0.003), \mathrm{KO}(\mathrm{P}=0.04), \mathrm{SO}(\mathrm{P}=0.007)$, and $\mathrm{TO}(\mathrm{P}=0.008)$ diet groups compared to the $\mathrm{CO}$ diet group (Figure 12).

Gonadal Adipose Tissue

COX 2 gene expression was not consistently detected in gonadal adipose tissue, therefore, gene expression was not measured. In the gonadal adipose tissue, there were no significant differences in IKB $\alpha$ gene expression among rats fed the n-3 PUFA diets compared to the $\mathrm{CO}$ diet (Figure 13).

\subsection{Eicosanoids}

ARA-derived pro-inflammatory metabolites of $\mathrm{PGE}_{2}$ and $\mathrm{TXB}_{2}$ were measured in the urine. There were no significant differences in urinary $\mathrm{PGE}_{2}$ metabolites (Figure 14a) and urinary $\mathrm{TXB}_{2}$ metabolites (Figure 14b) among the diet groups. 


\subsection{Discussion}

\section{Serum Lipids and Lipoproteins}

Based on our results, rats fed marine sources of n-3 PUFAs (12\% wt diet) significantly reduced serum total CHL compared to CO-fed rats. Of the marine sources, rats fed $\mathrm{SO}$ and $\mathrm{TO}$ showed the greatest $(\mathrm{P}<0.05)$ reduction in serum total CHL. Rats fed the n-3 PUFA sources also reduced $(\mathrm{P}<0.05)$ serum HDL-C compared to CO-fed rats. Similarly, male spontaneously hypertensive rats fed fish oil (14\% wt diet) lowered HDL-C concentrations compared to rats fed corn oil (12). Healthy male Wistar rats fed fish oil (10\% total calories) had significantly lower HDL-C compared to rats fed sunflower oil rich in omega- 6 fatty acids, olive oil rich in omega-9 fatty acids, and coconut oil rich in saturated fatty acids (54) (55) (56) (11). Rodents, unlike humans, mainly transport cholesterol in the HDL fraction (36). Therefore, reduced HDL-C indicates reduced circulating cholesterol in rats. Since SCD-1 plays a role in synthesis of MUFAs (16:1 and 18:1) which regulates TG and CHL biosynthesis, the effects of different n-3 PUFA sources on lipogenic gene expression were analyzed (57).

\section{Lipogenesis}

Although, liver total TG content was not significantly different among the n-3 PUFA diet groups, different sources of n-3 PUFAs had different effects on lipogenic gene expression. TO and SO-fed rats had the lowest $(\mathrm{P}<0.05)$ serum total CHL. Rats fed TO had no significant effect on lipogenic transcription factor SREBP1c, but down-regulated FAS $(\mathrm{P}=0.006)$ gene expression compared to CO-fed rats. FAS end product, SFA 16:0 was significantly increased rather than decreased in rats fed TO compared to $\mathrm{CO}$ and FO diet. SFA, 18:0 was also significantly increased in TO compared to FO and KO-fed rats. Accumulation of SFAs may be due to decreased desaturation to MUFAs due to down-regulated ( $\mathrm{P}=0.04)$ SCD-1 in TO compared to 
CO-fed rats. However, SCD-1 end products MUFAs, 16:1 and 18:1were not significantly reduced. There were no significant differences in dietary SFA content among the diets, but tissue MUFA content may have been confounded due to differences in dietary MUFA content among the diets. TO had higher $(\mathrm{P}<0.001)$ hepatic DHA deposition compared to the $\mathrm{MO}, \mathrm{KO}$, FO, and $\mathrm{CO}$ diet groups and the lowest $(\mathrm{P}<0.05)$ hepatic EPA:DHA ratio. Increased hepatic DHA may have directly influenced FAS and SCD-1 rather than through the lipogenic transcription factor, SREBP-1c.

Similar to rats fed TO, the SO-fed rats had the lowest total serum CHL and decreased FAS $(\mathrm{P}=0.001)$ gene expression. However, the SO diet group had no significant effect on SCD1 or SREBP-1c gene expression. Rats fed SO had the highest $(\mathrm{P}<0.001)$ EPA hepatic deposition among the diet groups. Male Wistar rats fed a high (62\% energy, dry weight) fat diet supplemented with EPA had no significant effect on hepatic SREBP-1c expression (9). Both EPA and DHA, had no effect on lipogenic transcription factor SREBP-1c gene expression, but may have acted directly on lipogenic enzymes. Despite decreased FAS gene expression and no effect on SCD-1, hepatic 16:0 was significantly increased in rats fed SO compared to MO, FO, and $\mathrm{CO}$ diet. Also, 18:0 was increased in $\mathrm{SO}$ compared to $\mathrm{MO}, \mathrm{KO}$, and $\mathrm{FO}-$ fed rats. This may be because when dietary n-3 LC-PUFAs are provided, less SFAs may be desaturated by the body. Both SO and TO-fed rats decreased FAS gene expression, but only TO-fed rats decreased SCD-1 gene expression. TO and SO-fed rats had similar hepatic DHA content, but hepatic EPA content was highest $(\mathrm{P}<0.001)$ in the SO diet group. This resulted in TO-fed rats having the lowest $(\mathrm{P}<0.05)$ hepatic tissue EPA:DHA ratio. Based on the results, EPA had no effect on SCD-1 gene expression, but decreased tissue EPA:DHA ratio decreased SCD-1 gene expression. 
Of the n-3 PUFA sources, only the MO diet caused a down-regulation in SREBP-1c, FAS, and SCD-1 $(\mathrm{P}<0.05)$ gene expression compared to the CO diet. Reduced hepatic SFAs, 16:0 and 18:0 content in MO compared to SO and TO-fed rats suggested reduced lipogenesis due to down-regulated FAS gene expression. Similarly, FAS gene expression was down-regulated in male rats fed $10 \% \mathrm{MO}(6)$. In our study, rats fed MO down-regulated hepatic SCD-1 gene expression, but had no significant effect on end products MUFAs, 16:1 and 18:1 possibly due to higher $(\mathrm{P}<0.05)$ dietary 16:1 content in $\mathrm{MO}$ compared to $\mathrm{CO}, \mathrm{FO}$, and $\mathrm{KO}$ diets. Lu et al. (2) reported hepatic SREBP-1 gene expression and SREBP-1 and FAS protein expression were down-regulated in male obese rats fed high cholesterol diets supplemented with 5\% n-3 PUFA mixture of fish oil derived EPA and DHA. In our study, rats fed MO had lower $(\mathrm{P}<0.001)$ hepatic EPA deposition compared to SO-fed rats and lower $(\mathrm{P}<0.001)$ hepatic DHA deposition compared TO and SO-fed rats. However, hepatic ARA deposition was lower $(\mathrm{P}<0.001)$ in the MO compared to TO and SO-fed rats. The results suggested that ARA affected lipogenesis through transcription factor SREBP-1c whereas, EPA and DHA regulated lipogenic gene expression independent of SREBP-1c. Therefore, SO and TO, and not MO, had the lowest serum total CHL.

KO diet had the highest EPA and DHA, yet rats fed KO had no significant effects on SREBP-1c, FAS, or SCD-1 gene expression. Despite higher dietary n-3 LC-PUFA content, hepatic EPA deposition in rats fed KO was significantly lower than SO-fed rats and hepatic DHA content was significantly lower than SO and TO-fed rats. Fatty acids in KO are in both PL and TG form; whereas, fish oil (SO, TO, and MO) fatty acids are mainly in TG form (24). The results indicated lower liver deposition when n-3 LC-PUFAs are fed in PL form and in turn, this resulted in no significant effects on hepatic tissue lipogenic gene expression in rats fed KO. 
Rats fed FO down-regulated FAS gene expression, but had no effect on SCD-1 or SREBP-1c gene expression. The FO group diet contains high amounts of ALA and subsequently, had the highest $(\mathrm{P}<0.001)$ hepatic ALA content. Despite higher dietary 18:0 content, FO-fed rats down-regulated FAS and decreased hepatic 16:0 content compared to SO and TO-fed rats and decreased hepatic 18:0 content compared to TO-fed rats. Dietary 18:1 content was higher $(\mathrm{P}<0.05)$ in $\mathrm{FO}$ compared to MO, TO, and SO diets, yet hepatic 18:1 deposition was not significantly different compared to the other n-3 PUFA groups, except KO. Higher dietary 18:1 content in FO may be transported to extrahepatic tissues as indicated by the increased $(\mathrm{P}<0.05)$ serum total $\mathrm{CHL}$ compared to marine oils.

In gonadal adipose tissue, there were no differences in gene expression of SREBP-1c, FAS, or SCD-1 among rats fed the different n-3 PUFA sources. In contrast, male mice fed a high (20\% wt) fat diet consisting of an n-3 PUFA concentrate (6\% EPA and 51\% DHA as 44\% total lipid; 56\% flaxseed oil as total lipid) significantly down-regulated SCD-1 gene expression in epididymal fat compared to male mice fed a high fat diet supplemented with $100 \%$ flaxseed oil (15). This study differed from our study because n-3 PUFA concentrate instead of pure oils was used. Also, male rather than female rats were studied (15). Gender differences may exist in n-3 PUFA metabolism with females having more efficient conversion of ALA to EPA and DHA due to lower partitioning of ALA towards beta-oxidation and higher activity of the desaturationelongation pathway (13). Mulhausler et al. (18) fed female rats differing amounts of ALA $(0.095 \%, 0.19 \%, 0.38 \%, 0.76 \%, 1.00 \%, 2.05 \%, 4.1 \%$, and $6.3 \%$ total energy). Gene expressions of SREBP-1c, FAS, and SCD-1 increased until a level of $0.38 \%$ to $0.76 \%$ ALA in the diet. Further increases in ALA dose decreased or had no significant effect on gene expression (18). Although lipid metabolism occurs in the adipose tissue, it does not contribute to a significant 
portion of lipogenesis (29). Instead, adipose tissue consists mainly of lipids both dietary and de novo synthesized in the liver and transported to the adipose tissue where they are stored until required for lipolysis (58).

Lipolysis

HSL releases fatty acids stored in the adipose tissue. In our study, HSL expression was not significantly different in the n-3 PUFA diet groups compared to the CO diet group. PPAR $\gamma$ is a transcription factor that regulates lipid storage in adipose tissue (29). In our study, gonadal adipose PPAR $\gamma$ gene expression was up-regulated $(\mathrm{P}=0.039)$ in $\mathrm{FO}$ compared to $\mathrm{CO}$-fed rats. In contrast, PPAR $\gamma$ was unchanged in omental adipose tissue of female Agouti rats fed differing doses of flaxseed oil ( $0.095 \%$ to $6.3 \%$ of total energy) (18). Our study provided a higher dose ALA of $27 \%$ of kcal compared to $6.3 \%$ of kcal. In our study, rats fed ALA-rich FO resulted in EPA and DHA deposition in the adipose tissue. Therefore, up-regulated PPAR $\gamma$ gene expression may be due to the increased EPA:DHA ratio in gonadal adipose tissue.

Fatty acids released by the adipose tissue can be taken up by tissue for oxidation. PPAR $\alpha$ is a transcription factor that regulates the expression of a number of genes involved in hepatic mitochondrial and peroxisome fatty acid oxidation. Our study found no differences in hepatic PPAR $\alpha$ gene expression among the diet groups. Similarly, male Hooded-Wistar rats (age 3 weeks) fed differing doses $(0.2,0.5,1.0,1.9,2.9 \%)$ of ALA from flaxseed oil had no significant effect on hepatic PPAR $\alpha$ gene expression (30). However, male Wistar rats provided EPA ethyl ester supplements resulted in a significant down-regulation of hepatic PPAR $\alpha$ gene expression (9). Purified EPA ethyl ester supplementation provides a higher dose of EPA than when provided as an oil source. 
In our study, the MO diet lowered hepatic ARA content and down-regulated transcription factor SREBP-1c gene expression, which subsequently down-regulated FAS and SCD-1 gene expression, suggesting decreased lipogenesis. All n-3 PUFA sources (except KO) reduced lipogenic enzyme FAS, but only the rats fed $\mathrm{MO}$ and TO diets decreased EPA:DHA ratio which down-regulated the desaturase enzyme SCD-1. In adipose tissue, the FO diet increased EPA:DHA ratio and up-regulated PPAR $\gamma$ expression suggesting increased lipolysis. Since the anti-inflammatory effects of n-3 PUFAs, specifically EPA and DHA, are partly mediated through PPAR $\gamma(59)$; our study evaluated the effects of tissue fatty acid changes on inflammation.

\section{Inflammation}

Of the n-3 PUFA sources, only rats fed FO up-regulated ( $\mathrm{P}=0.039)$ PPAR $\gamma$ gene expression compared to CO. FO-fed rats had the highest $(\mathrm{P}<0.05)$ gonadal adipose tissue EPA:DHA ratio. Another key transcription factor regulating inflammation is NFKB. IKB $\alpha$ is the inhibitory subunit of NFKB. Phosphorylation degrades IKB $\alpha$ and activates NFKB (48). Therefore, IKB $\alpha$ is up-regulated when NFKB is activated (60). In our study, hepatic IKB $\alpha$ gene expression was significantly down-regulated in rats fed $\mathrm{FO}, \mathrm{KO}, \mathrm{SO}$, and $\mathrm{TO}$ compared to rats fed CO. THP-1 cell line stimulated by LPS and treated with EPA resulted in suppressed phosphorylated IKB $\alpha$ levels, indicating that EPA prevents IKB $\alpha$ degradation and subsequent NFKB translocation/activation by preventing phosphorylation of IKB $\alpha$ (48). The KO group had the highest $(\mathrm{P}<0.05)$ gonadal adipose EPA content, and the MO group had higher $(\mathrm{P}=0.007)$ gonadal adipose EPA content than the FO group. However, MO was the only diet that did not significantly down-regulate IKB $\alpha$, yet down-regulated lipogenic transcription factor SREBP-1c. Anti-inflammatory effects can also be exerted through other pathways; therefore, our study also determined de novo synthesis of the eicosanoids by the COX 2 pathway. ARA, an n-6 PUFA, 
synthesizes "pro-inflammatory" $\mathrm{PGE}_{2}$ or $\mathrm{TXB}_{2}$ through the $\mathrm{COX} 2$ pathway. In our study, rats fed MO had the lowest hepatic ARA content. However there were no significant differences in hepatic COX 2 gene expression or urinary $\mathrm{PGE}_{2}$ or $\mathrm{TXB}_{2}$ metabolite concentrations in the $\mathrm{n}-3$ PUFA diet groups compared to CO diet group. Gene expression of the COX 2 enzyme is typically up-regulated in disease and inflammatory conditions (44). Our study used non-diseased animals. Sankaran et al. (44) reported that n-3 LC-PUFAs attenuate the increase in COX 2 expression in diseased animal models. In contrast, normal Han:SPRD-cy rats fed a high fat (20g fat/100g diet) diet consisting of cottonseed oil rich in n-6 PUFA or MO + soybean oil rich in ALA, EPA and DHA resulted in no statistical differences in renal COX 2 mRNA and protein levels (44). Therefore, attenuation of COX 2 expression by n-3 PUFAs may be specific to diseased models.

\subsection{Conclusion}

In conclusion, different type and structural forms of n-3 LC-PUFAs exerted different effects on lipogenic gene expression and lipid metabolism. Feeding rats MO resulted in lower $(\mathrm{P}<0.001)$ hepatic ARA content than SO and TO and down-regulated gene expression of the transcription factor SREBP-1c, which subsequently down regulated FAS and SCD-1. All n-3 PUFAs sources in TG form down-regulated FAS gene expression. Only MO and TO-fed rats down-regulated SCD-1 gene expression. None of the n-3 PUFAs sources altered lipogenic gene expression in the adipose tissue. On the other hand, FO had the highest gonadal adipose tissue $(\mathrm{P}<0.05)$ EPA:DHA ratio and was the only n-3 PUFA source that up-regulated adipose tissue $\operatorname{PPAR} \gamma$, lipolytic gene expression. 
All n-3 PUFA sources reduced serum HDL-C levels. Additionally, marine sources of n-3 PUFAs reduced serum total cholesterol, particularly SO and TO, due to the high dietary EPA and DHA content. Rats fed n-3 LC-PUFA sources, with the exception of the MO diet, decreased inflammation indicated by down-regulated hepatic IKB $\alpha$ gene expression. Despite resulting in the lower hepatic ARA content, in rats fed MO there was no effect on COX 2 gene expression or 2-series eicosanoids. The study results showed that different n-3 LC-PUFA sources had various effects on risk factors for CVD such as changing the balance of lipogenesis and lipolysis gene expression, altering circulating lipids, and inflammation. Therefore, different n-3 PUFA sources have altered certain, but not all CVD risk factors.

\subsection{Future Research}

Studies of the beneficial effects of n-3 PUFA consumption are constantly emerging, resulting in the food industry fortifying various food products with n-3 PUFAs. This study showed that n-3 PUFAs affected gene transcription. Further research needs to determine whether the n-3 PUFAs also affected translation, since some end products did not match changes in gene expression. This can be achieved by measuring subsequent changes in protein expression and enzyme activity. Additionally, further research needs to determine whether tissue deposition of fatty acids was from a dietary source or de novo synthesis, which can be investigated utilizing a tracer, such as radiolabeling carbons. In our study, results also showed n3 PUFAs had different effects on serum lipids, serum lipoproteins, and inflammation. Oxidized LDL-C and cellular oxidative stress induced by modification of lipids by reactive oxygen species can induce NFKB mediated transcription of inflammation-related genes such as interleukin-8 (61). Therefore, future studies should investigate whether the reported inconsistent serum lipid 
and lipoprotein results may be exerted through the inflammation cascade in order to determine the anti-atherosclerotic effects of n-3 PUFA consumption. 
Table 1. Diet Characteristics

\begin{tabular}{|l|l|l|l|}
\hline \multirow{3}{*}{ Plant Sources } & Oil Source & Acronym & Characteristic \\
\hline \multirow{3}{*}{ Marine Sources } & Corn & CO & Control (Western diet) \\
\cline { 2 - 4 } & Flaxseed & FO & Highest ALA \\
\cline { 2 - 4 } & Salmon & KO & Highest n-3 PUFA \\
\cline { 2 - 4 } & Tuna & TO & Highest EPA of fish oil sources, highest EPA:DHA ratio \\
\cline { 2 - 4 } & Menhaden & MO & Contains n-3 PUFAs in lesser amounts than other groups \\
\hline
\end{tabular}


Table 2. Genes Analyzed

\begin{tabular}{|c|c|c|c|c|}
\hline Gene & Gene ID & Tissue & Function & Metabolism \\
\hline GAPDH & 24383 & Liver, Adipose & Housekeeping gene & \\
\hline SREBP-1c & 78968 & Liver, Adipose & Transcription Factor & Lipogenesis \\
\hline FAS & 50671 & Liver, Adipose & Enzyme & Lipogenesis \\
\hline SCD-1 & 246074 & Liver, Adipose & Enzyme & Lipogenesis \\
\hline PPAR $\alpha$ & 25747 & Liver & Transcription Factor & Lipolysis \\
\hline PPAR $\gamma$ & 25664 & Adipose & Transcription Factor & Lipolysis/Inflammation \\
\hline HSL & 25330 & Adipose & Enzyme & Lipolysis \\
\hline $\mathrm{IKB} \alpha$ & 25493 & Liver, Adipose & $\begin{array}{l}\text { Regulatory protein that } \\
\text { inhibits NFKB }\end{array}$ & Inflammation \\
\hline COX 2 & 29527 & Liver & Rate limiting enzyme & $\begin{array}{l}\text { Eicosanoid } \\
\text { synthesis/Inflammation }\end{array}$ \\
\hline
\end{tabular}


Table 3. Dietary fatty acids and lipid classes.

\begin{tabular}{|c|c|c|c|c|c|c|}
\hline \multirow[b]{2}{*}{ Fatty Acids (mg FA/g Diet) } & \multicolumn{6}{|c|}{ Treatments } \\
\hline & $\mathrm{CO}$ & FO & KO & MO & SO & TO \\
\hline \multicolumn{7}{|l|}{ SFA } \\
\hline Palmitic Acid $(\mathrm{C} 16: 0)^{1}$ & $1.0 \pm 0.2$ & $1.4 \pm 0.2$ & $2.0 \pm 0.5$ & $2.0 \pm 0.2$ & $2.0 \pm 0.2$ & $1.7 \pm 0.2$ \\
\hline Stearic Acid $(\mathrm{C} 18: 0)^{1}$ & $0.2 \pm 0.02^{b}$ & $1.2 \pm 0.2^{\mathrm{a}}$ & $0.3 \pm 0.1^{b}$ & $0.4 \pm 0.03^{b}$ & $0.4 \pm 0.03^{b}$ & $0.5 \pm 0.04^{b}$ \\
\hline \multicolumn{7}{|l|}{ MUFA } \\
\hline Palmitoleic $(16: 1 \mathrm{n}-7)^{1}$ & $0.02 \pm 0.005^{\mathrm{b}}$ & $0.03 \pm 0.002^{\mathrm{b}}$ & $0.8 \pm 0.4^{\mathrm{b}}$ & $2.5 \pm 0.2^{\mathrm{a}}$ & $3.09 \pm 0.4^{\mathrm{a}}$ & $2.5 \pm 0.2^{\mathrm{a}}$ \\
\hline Oleic $(18: 1 n-9)^{1}$ & $1.6 \pm 0.4^{\mathrm{ab}}$ & $3.08 \pm 0.2^{\mathrm{a}}$ & $1.6 \pm 0.7^{\mathrm{ab}}$ & $0.9 \pm 0.07^{b}$ & $1.3 \pm 0.2^{b}$ & $1.3 \pm 0.1^{\mathrm{b}}$ \\
\hline \multicolumn{7}{|l|}{ n-3 PUFA } \\
\hline $\operatorname{ALA}(18: 3 n-3)^{1}$ & $0.1 \pm 0.01^{\mathrm{b}}$ & $14.6 \pm 2.1^{\mathrm{a}}$ & $0.2 \pm 0.04^{\mathrm{b}}$ & $0.2 \pm 0.01^{b}$ & $0.1 \pm 0.01^{\mathrm{b}}$ & $0.1 \pm 0.01^{b}$ \\
\hline $\operatorname{EPA}(20: 5 n-3)^{1}$ & ND & ND & $13.2 \pm 2.8^{\mathrm{a}}$ & $5.5 \pm 0.4^{\mathrm{bc}}$ & $10.0 \pm 0.7^{\mathrm{ab}}$ & $2.6 \pm 0.3^{c}$ \\
\hline DHA $(22: 6 n-3)^{1}$ & ND & ND & $4.6 \pm 1.9$ & $2.0 \pm 0.2$ & $1.9 \pm 0.1$ & $2.9 \pm 0.2$ \\
\hline EPA/DHA & ND & ND & $3: 1$ & $3: 1$ & $5: 1$ & $1: 2$ \\
\hline \multicolumn{7}{|l|}{ n-6 PUFA } \\
\hline LA $(18: 2 n-6)^{1}$ & $6.4 \pm 0.9^{\mathrm{a}}$ & $5.4 \pm 0.8^{\mathrm{a}}$ & $0.5 \pm 0.1^{b}$ & $0.2 \pm 0.1^{\mathrm{b}}$ & $0.5 \pm 0.1^{\mathrm{b}}$ & $0.2 \pm 0.03^{b}$ \\
\hline $\operatorname{ARA}(20: 4 n-6)^{1}$ & ND & ND & $0.23 \pm 0.04$ & $0.16 \pm 0.01$ & $0.22 \pm 0.01$ & $0.30 \pm 0.1$ \\
\hline$n-6 / n-3^{2}$ & $73: 1$ & $1: 3$ & $1: 33$ & $1: 48$ & $1: 23$ & $1: 12$ \\
\hline
\end{tabular}

${ }^{\mathrm{T}}$ Values are expressed as mean \pm SEM, $\mathrm{n}=3-4$ replicates/diet.

${ }^{2}$ Values are expressed as mean $(\%) \pm$ SEM

Abbreviations are: CO, corn oil; FO, flaxseed oil; KO, krill oil; MO, menhaden oil; SO, salmon oil; TO, tuna oil.; SFA, saturated fatty acids; PUFA, polyunsaturated fatty acids; LA, linolenic acid; ARA, arachidonic acid; ALA, $\alpha$-linolenic acid; EPA, eicosapentaenoic acid; DHA, docosahexaenoic acid; ND, not detectable. 
Figure 4a: The Effect of Feeding Growing Female Rats Different Sources of Omega-3 Polyunsaturated Fatty Acids on the mRNA Expression of SREBP-1c in Hepatic Tissue.

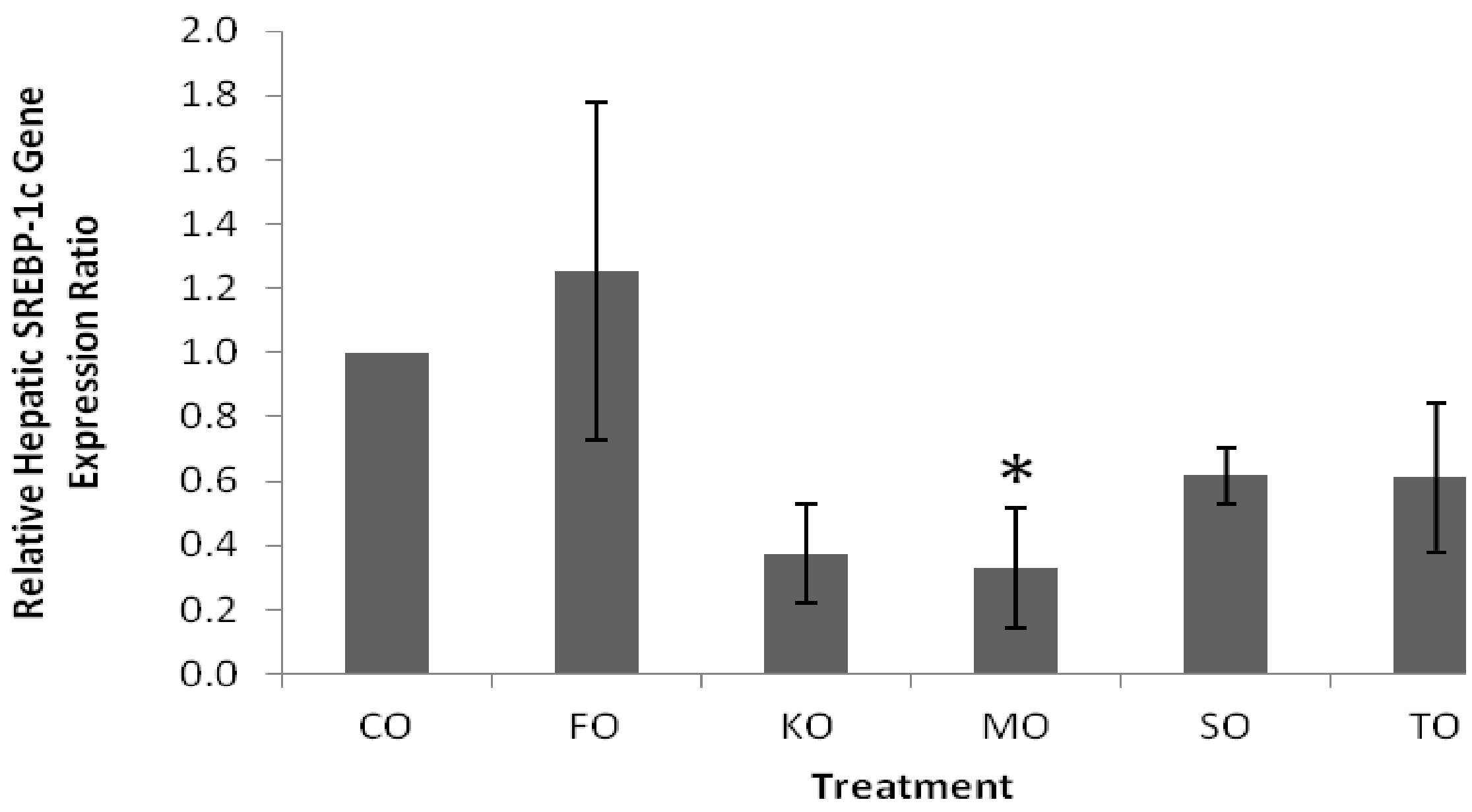

Expression compared to $\mathrm{CO}$ group and normalized to GAPDH. ( $* \mathrm{P}<0.05$ indicates down regulation, $\mathrm{n}=5$ rats/group). Gene expression was analyzed by pairwise fixed reallocation randomization test. Abbreviations are CO, corn oil; FO, flaxseed oil; KO, krill oil; MO, menhaden oil; SO, salmon oil; TO, tuna oil. 
Figure 4b: The Effect of Feeding Growing Female Rats Different Sources of Omega-3 Polyunsaturated Fatty Acids on the mRNA Expression of FAS in Hepatic Tissue.

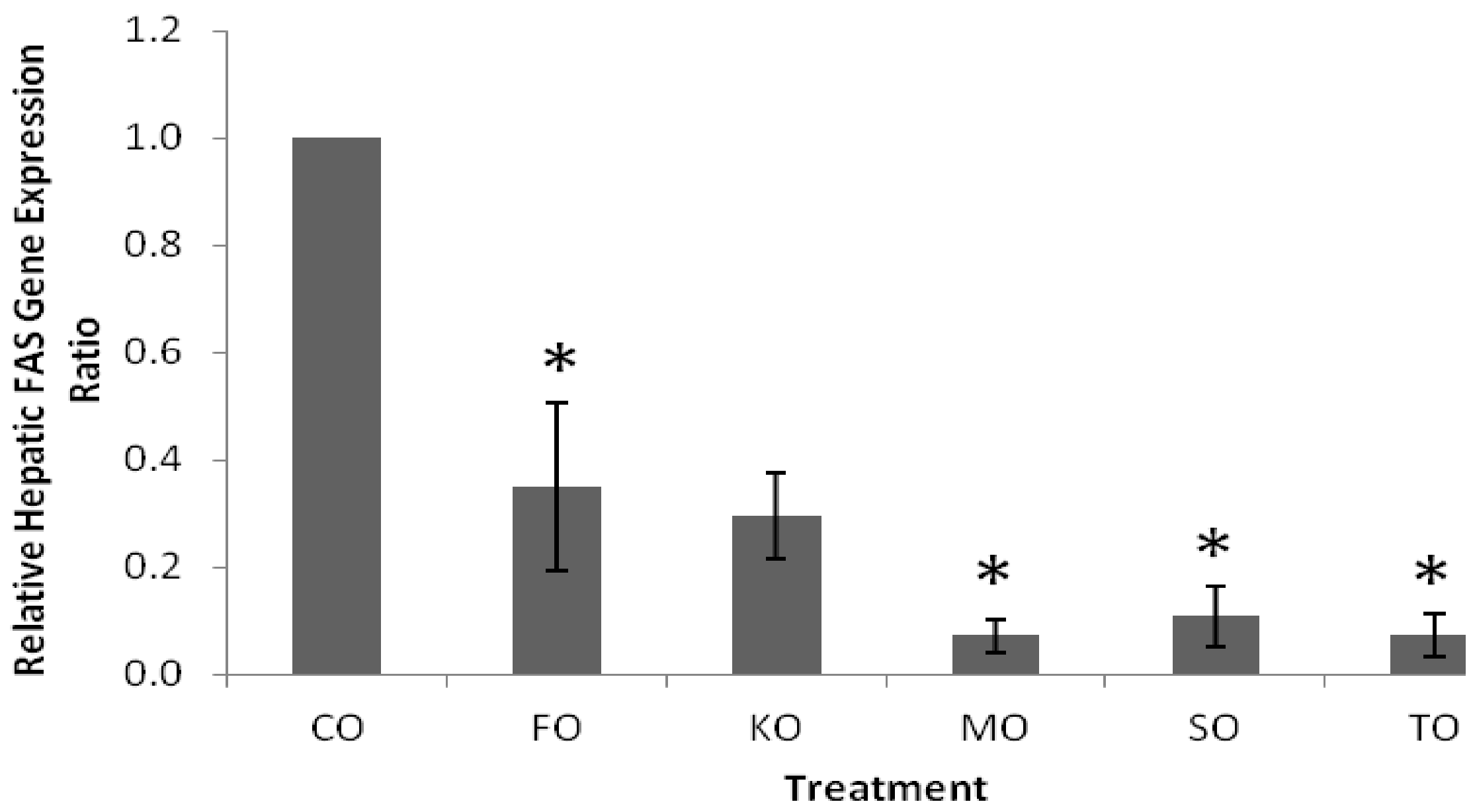

Expression compared to $\mathrm{CO}$ group and normalized to GAPDH. (* $\mathrm{P}<0.05$ indicates down regulation, $\mathrm{n}=5$ rats/group). Gene expression was analyzed by pairwise fixed reallocation randomization test. Abbreviations are CO, corn oil; FO, flaxseed oil; KO, krill oil; MO, menhaden oil; SO, salmon oil; TO, tuna oil. 
Figure 4c: The Effect of Feeding Growing Female Rats Different Sources of Omega-3 Polyunsaturated Fatty Acids on the mRNA Expression of SCD-1 in Hepatic Tissue.

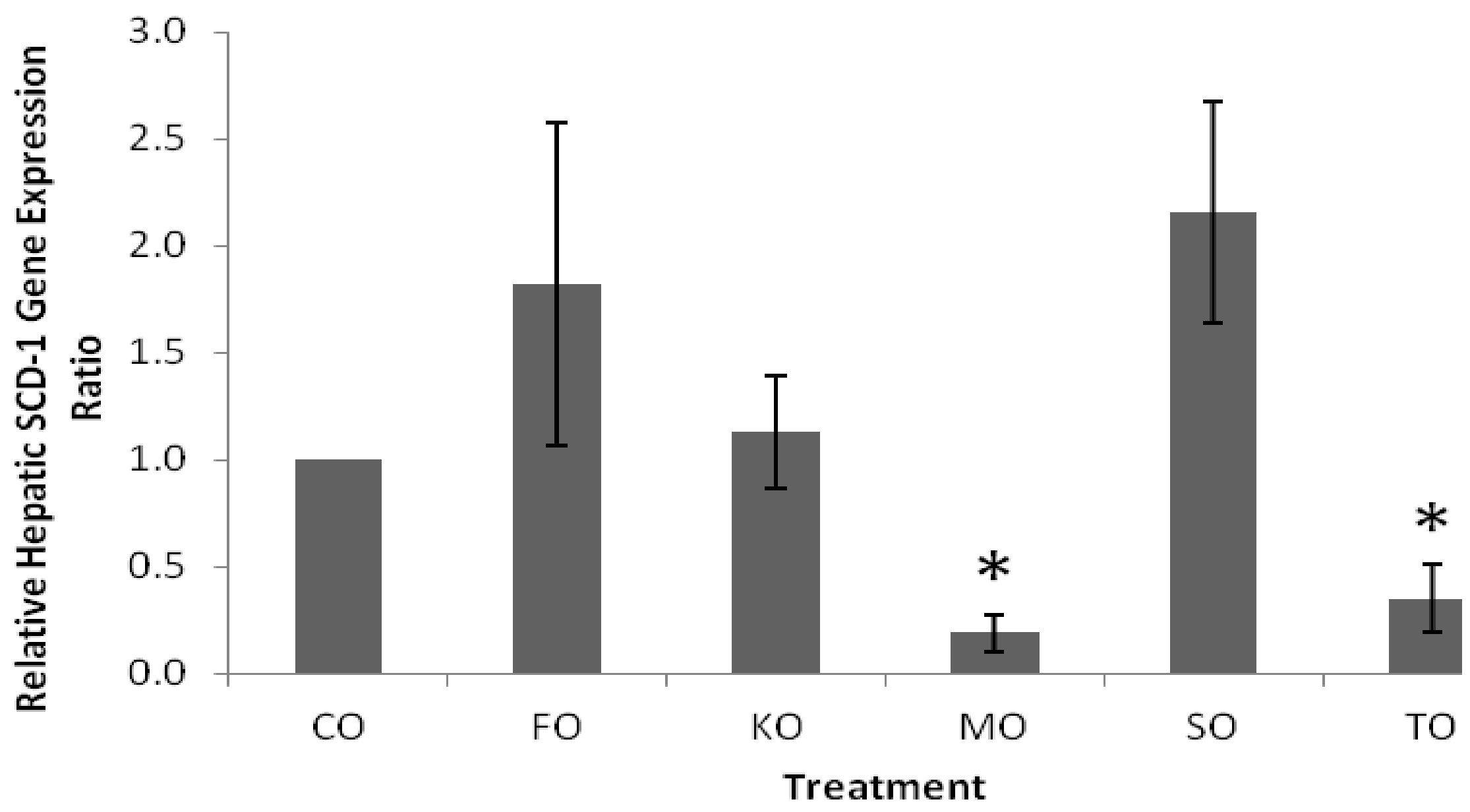

Expression compared to $\mathrm{CO}$ group and normalized to GAPDH. (* $\mathrm{P}<0.05$ indicates down regulation, $\mathrm{n}=5$ rats/group). Gene expression was analyzed by pairwise fixed reallocation randomization test. Abbreviations are CO, corn oil; FO, flaxseed oil; KO, krill oil; MO, menhaden oil; SO, salmon oil; TO, tuna oil. 
Figure 5a: The Effect of Feeding Growing Female Rats Different Sources of Omega-3 Polyunsaturated Fatty Acids on the mRNA Expression of SREBP-1c in Gonadal Adipose Tissue.

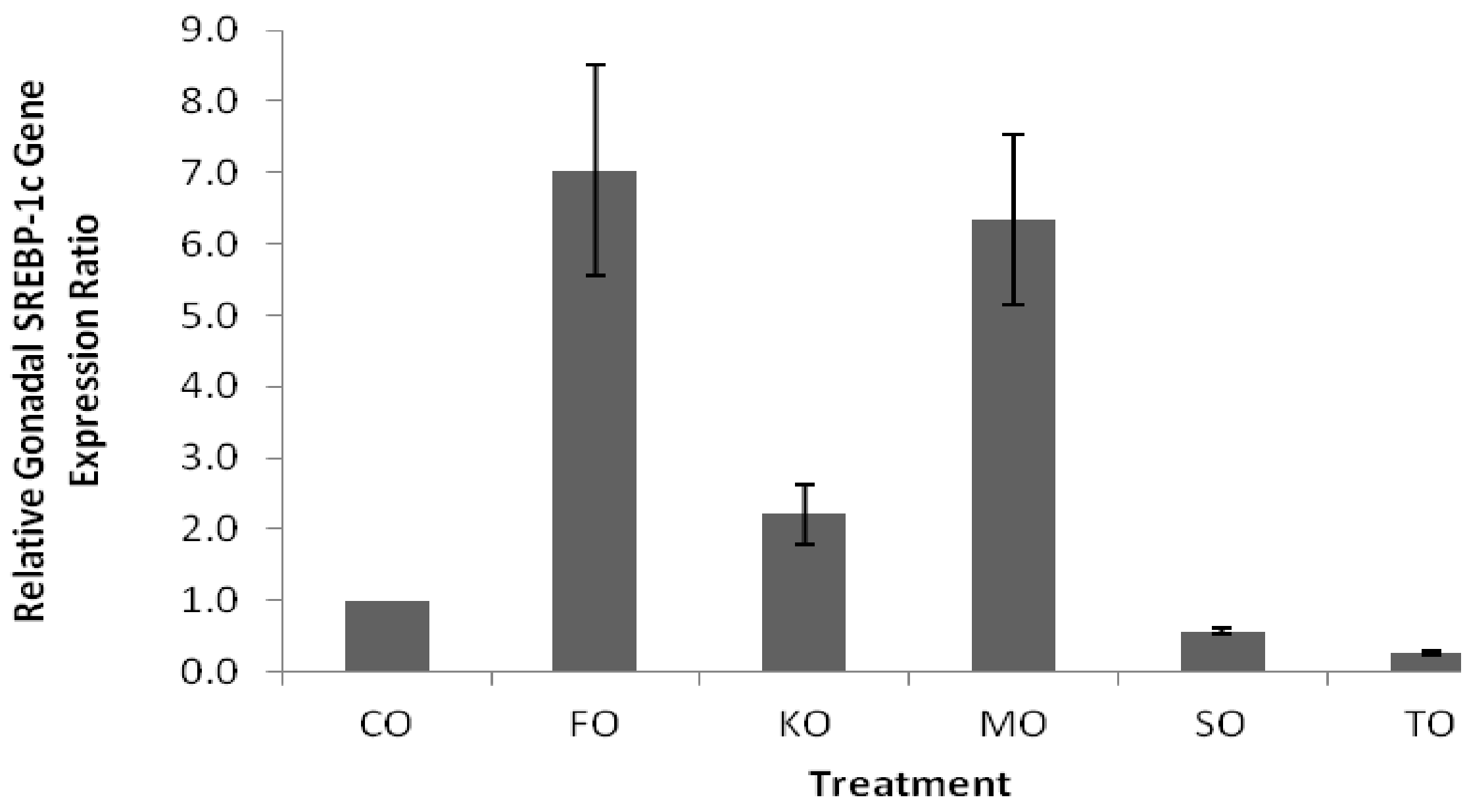

Expression compared to $\mathrm{CO}$ group and normalized to GAPDH. ( $* \mathrm{P}<0.05$ indicates down regulation, $\mathrm{n}=5$ rats/group). Gene expression was analyzed by pairwise fixed reallocation randomization test. Abbreviations are CO, corn oil; FO, flaxseed oil; KO, krill oil; MO, menhaden oil; SO, salmon oil; TO, tuna oil. 
Figure 5b: The Effect of Feeding Growing Female Rats Different Sources of Omega-3 Polyunsaturated Fatty Acids on the mRNA Expression of FAS in Gonadal Adipose Tissue.

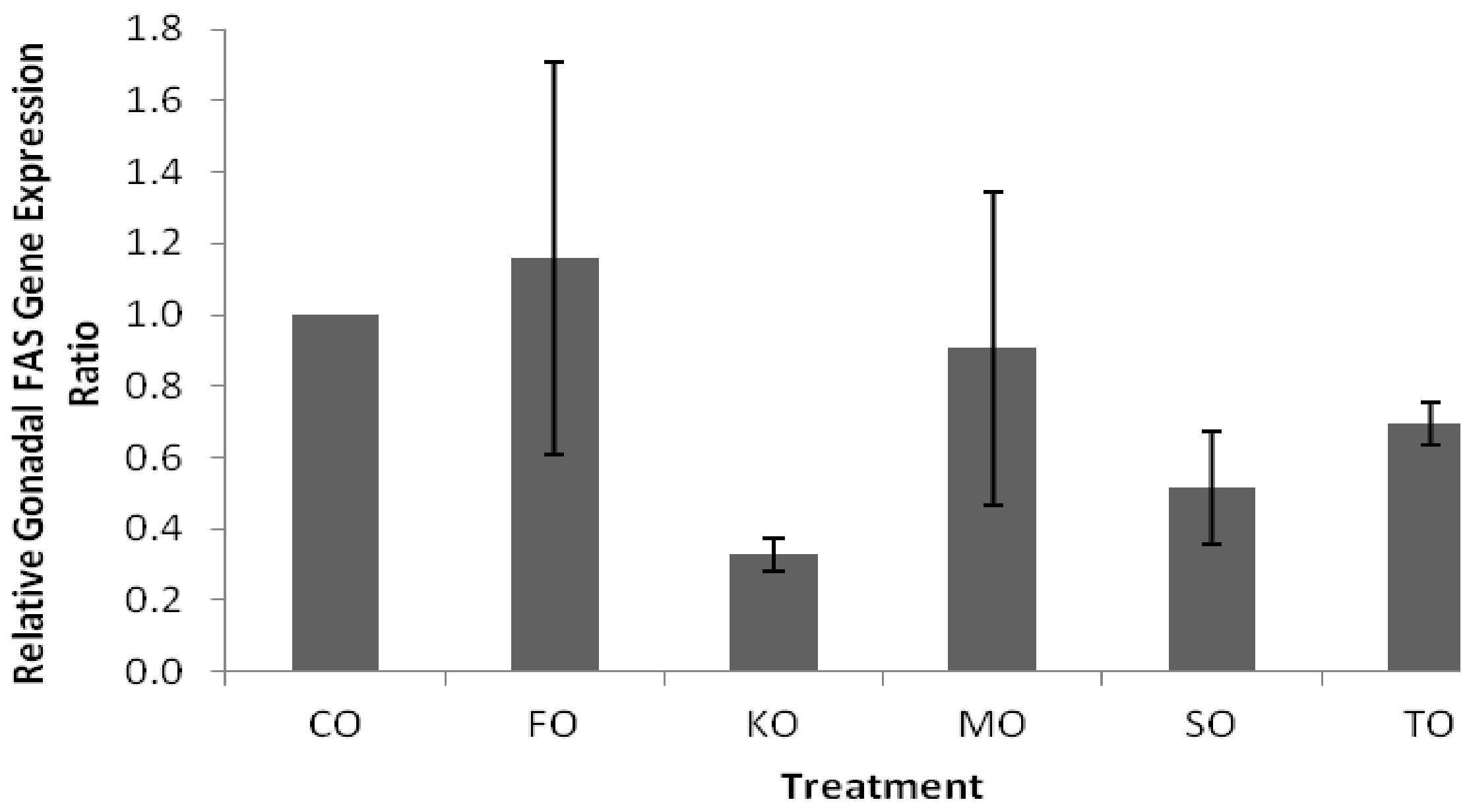

Expression compared to $\mathrm{CO}$ group and normalized to GAPDH. ( $* \mathrm{P}<0.05$ indicates down regulation, $\mathrm{n}=5$ rats/group). Gene expression was analyzed by pairwise fixed reallocation randomization test. Abbreviations are CO, corn oil; FO, flaxseed oil; KO, krill oil; MO, menhaden oil; SO, salmon oil; TO, tuna oil. 
Figure 5c: The Effect of Feeding Growing Female Rats Different Sources of Omega-3 Polyunsaturated Fatty Acids on the mRNA levels of SCD-1 in Gonadal Adipose Tissue.

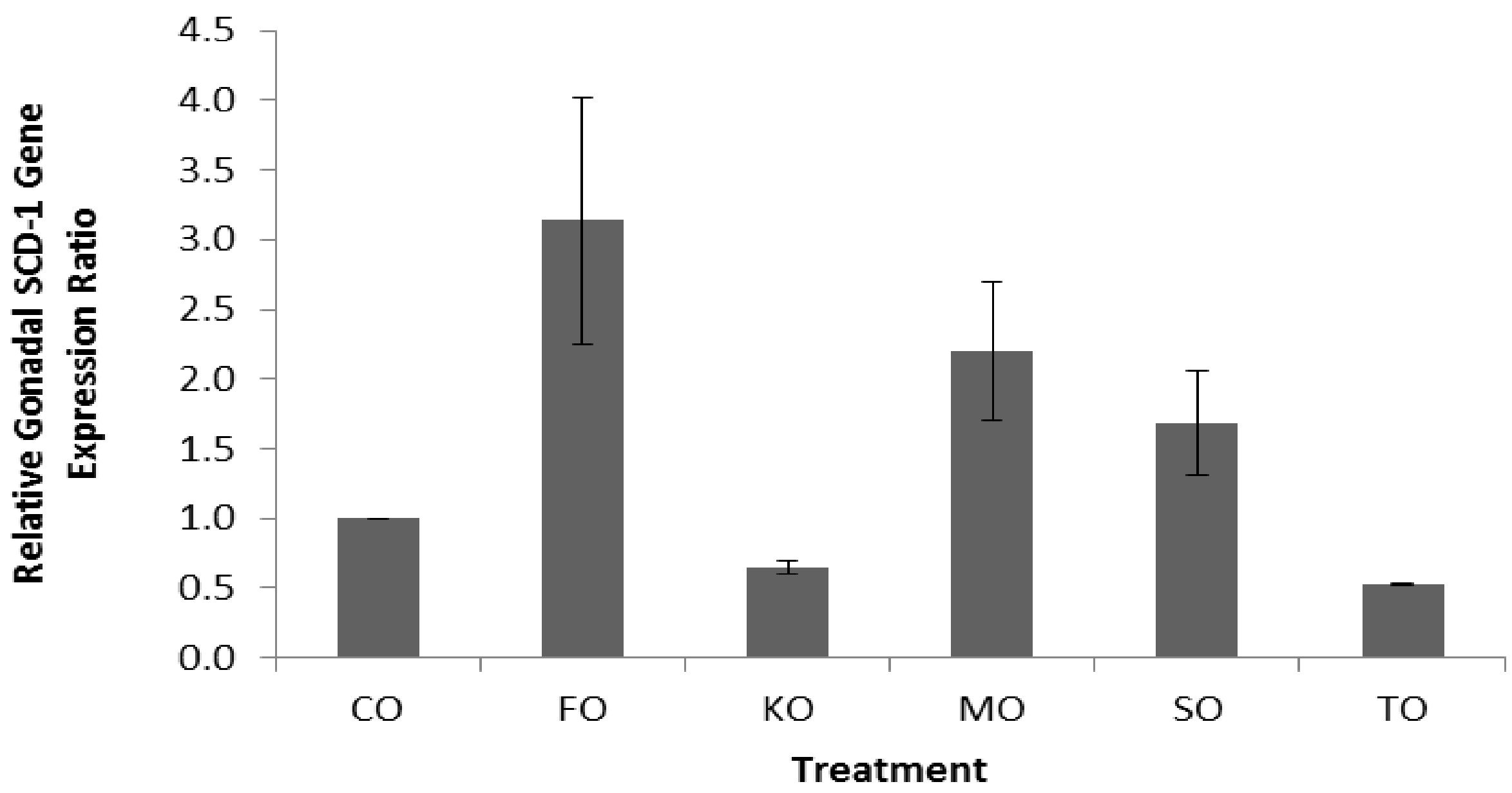

Expression compared to $\mathrm{CO}$ group and normalized to GAPDH. ( $* \mathrm{P}<0.05$ indicates down regulation, $\mathrm{n}=5$ rats/group. Gene expression was analyzed by pairwise fixed reallocation randomization test. Abbreviations are CO, corn oil; FO, flaxseed oil; KO, krill oil; MO, menhaden oil; SO, salmon oil; TO, tuna oil. 
Figure 6a: The Effect of Feeding Growing Female Rats Different Sources of Omega-3 Polyunsaturated Fatty Acids on Liver Palmitic Acid (16:0) Content.

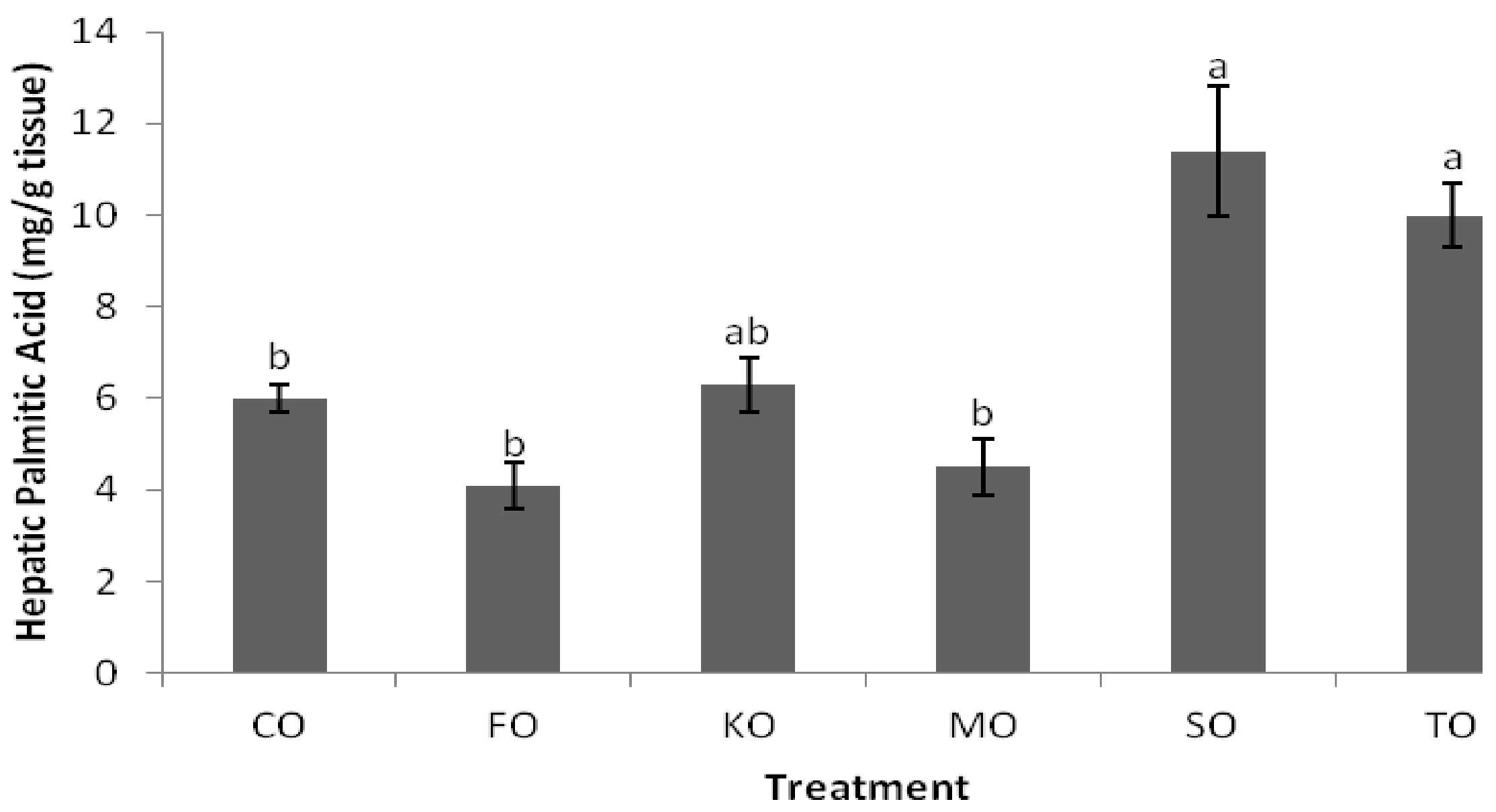

Values are expressed as the mean (mg FA/g tissue) \pm SEM of $n=10$ rats/group. Different superscript letters a, b, c indicate significant differences at $P<0.05$ by one-way ANOVA followed by Tukey's test. Abbreviations are CO, corn oil; FO, flaxseed oil; KO, krill oil; MO, menhaden oil; SO, salmon oil; TO, tuna oil. 
Figure 6b: The Effect of Feeding Growing Female Rats Different Sources of Omega-3 Polyunsaturated Fatty Acids on Liver Stearic Acid (18:0) Content.

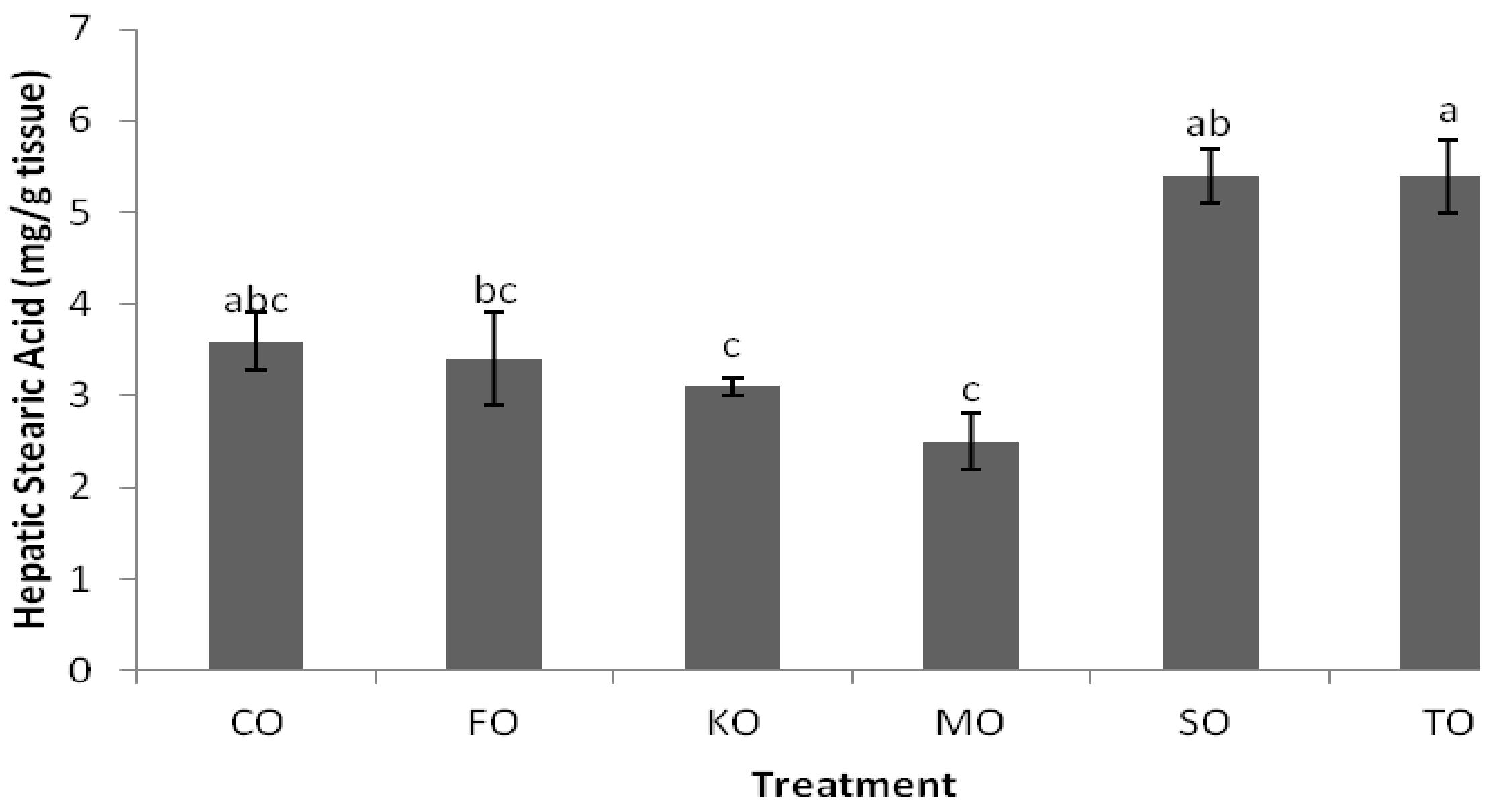

Values are expressed as the mean (mg FA/g tissue) \pm SEM of $n=10$ rats/group. Different superscript letters a, b, c indicate significant differences at $P<0.05$ by one-way ANOVA followed by Tukey's test. Abbreviations are CO, corn oil; FO, flaxseed oil; KO, krill oil; MO, menhaden oil; SO, salmon oil; TO, tuna oil. 
Figure 6c: The Effect of Feeding Growing Female Rats Different Sources of Omega-3 Polyunsaturated Fatty Acids on Liver Palmitoleic Acid (16:1n-7) Content.

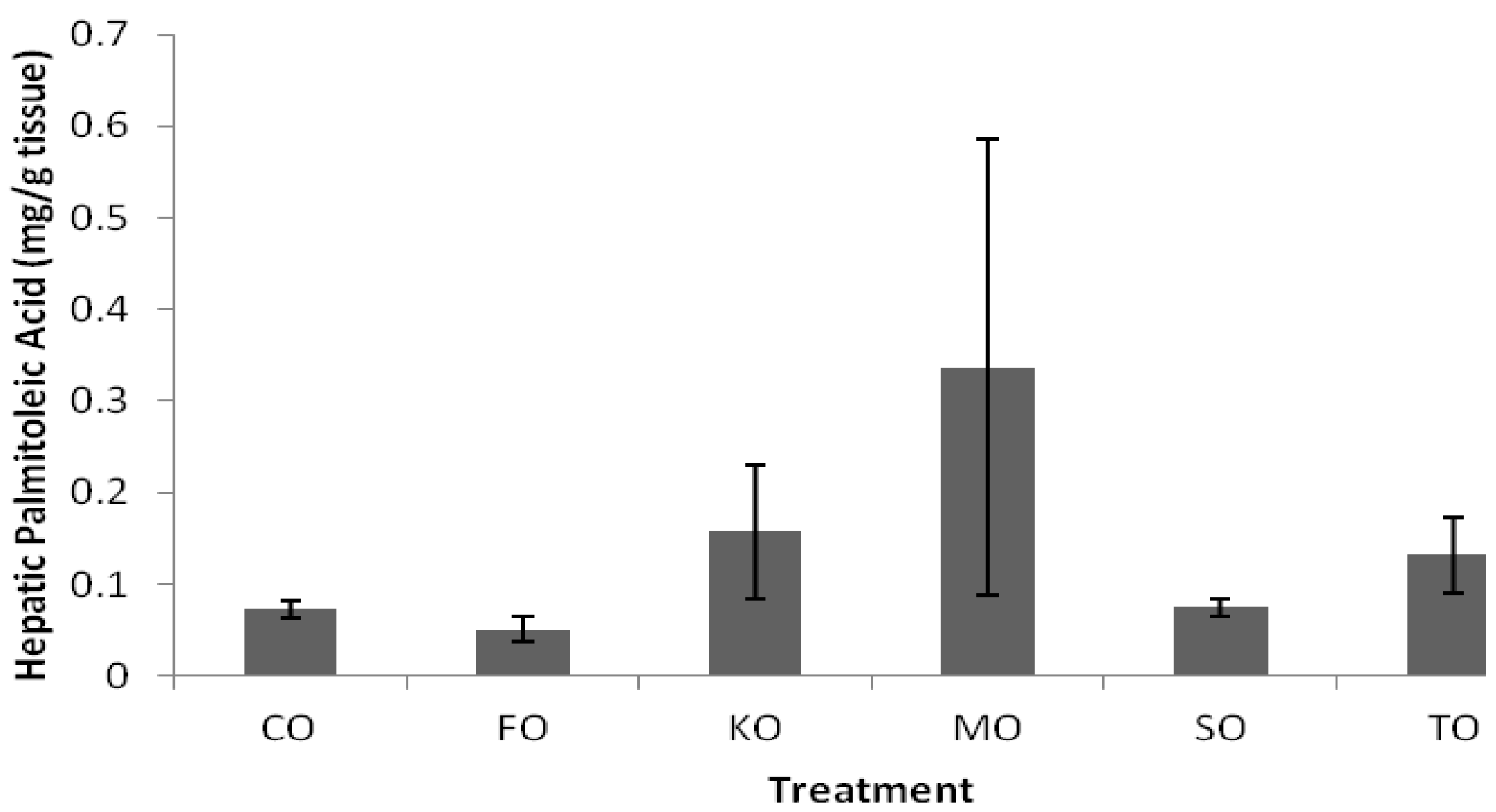

Values are expressed as the mean (mg FA/g tissue) \pm SEM of $n=5$ rats/group. Different superscript letters a, b, c indicate significant differences at $P<0.05$ by one-way ANOVA followed by Tukey's test. Abbreviations are CO, corn oil; FO, flaxseed oil; KO, krill oil; MO, menhaden oil; SO, salmon oil; TO, tuna oil. 
Figure 6d: The Effect of Feeding Growing Female Rats Different Sources of Omega-3 Polyunsaturated Fatty Acids on Liver Oleic Acid (18:1n-9) Content.

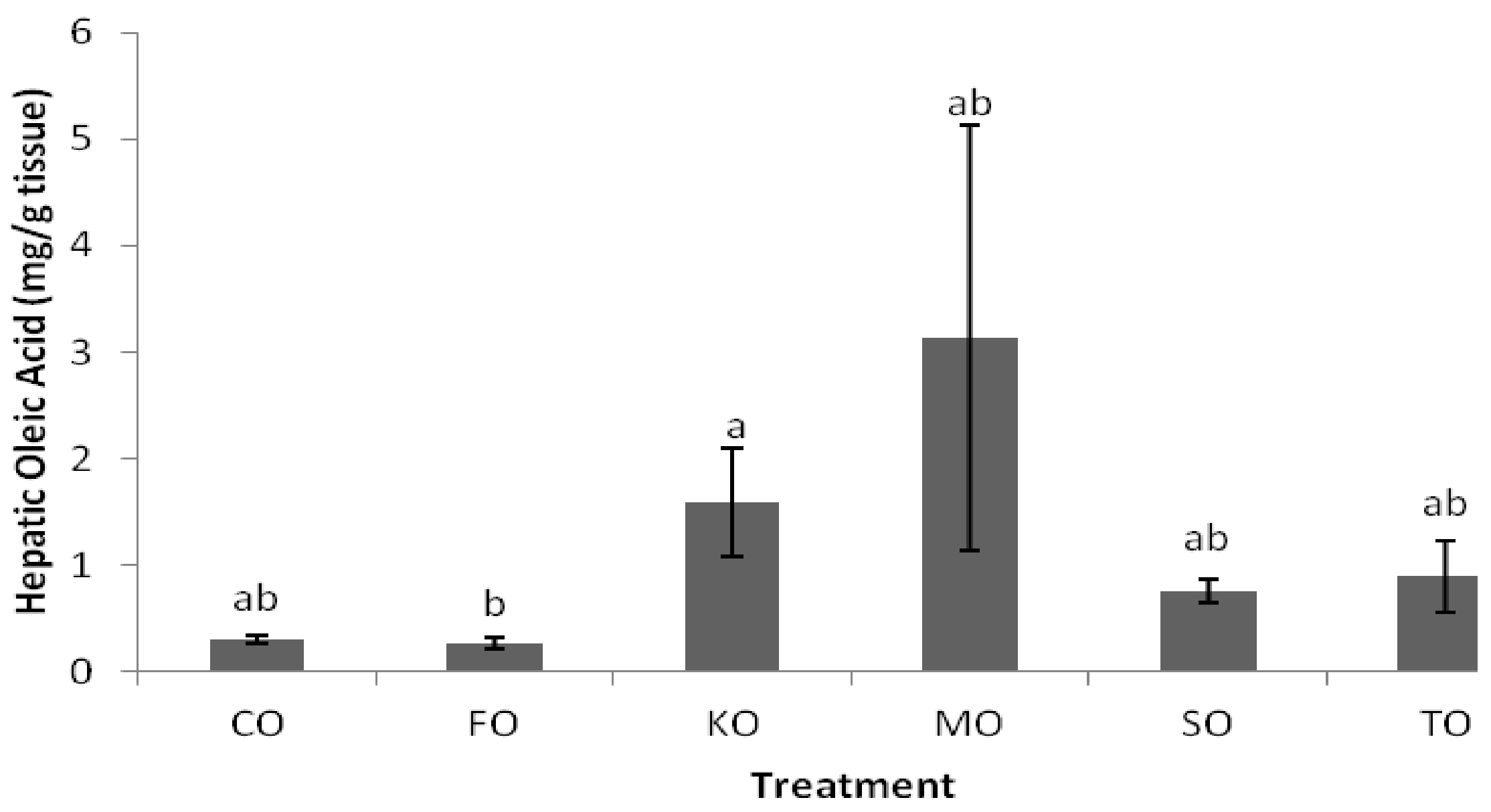

Values are expressed as the mean (mg FA/g tissue) \pm SEM of $n=5$ rats/group. Different superscript letters a, b, c indicate significant differences at $P<0.05$ by one-way ANOVA followed by Tukey's test. Abbreviations are CO, corn oil; FO, flaxseed oil; KO, krill oil; MO, menhaden oil; SO, salmon oil; TO, tuna oil. 
Figure 7a: The Effects of Feeding Growing Female Rats Different Sources of Omega-3 Polyunsaturated Fatty Acids on Gonadal Adipose Tissue Palmitic Acid (16:0) Content.

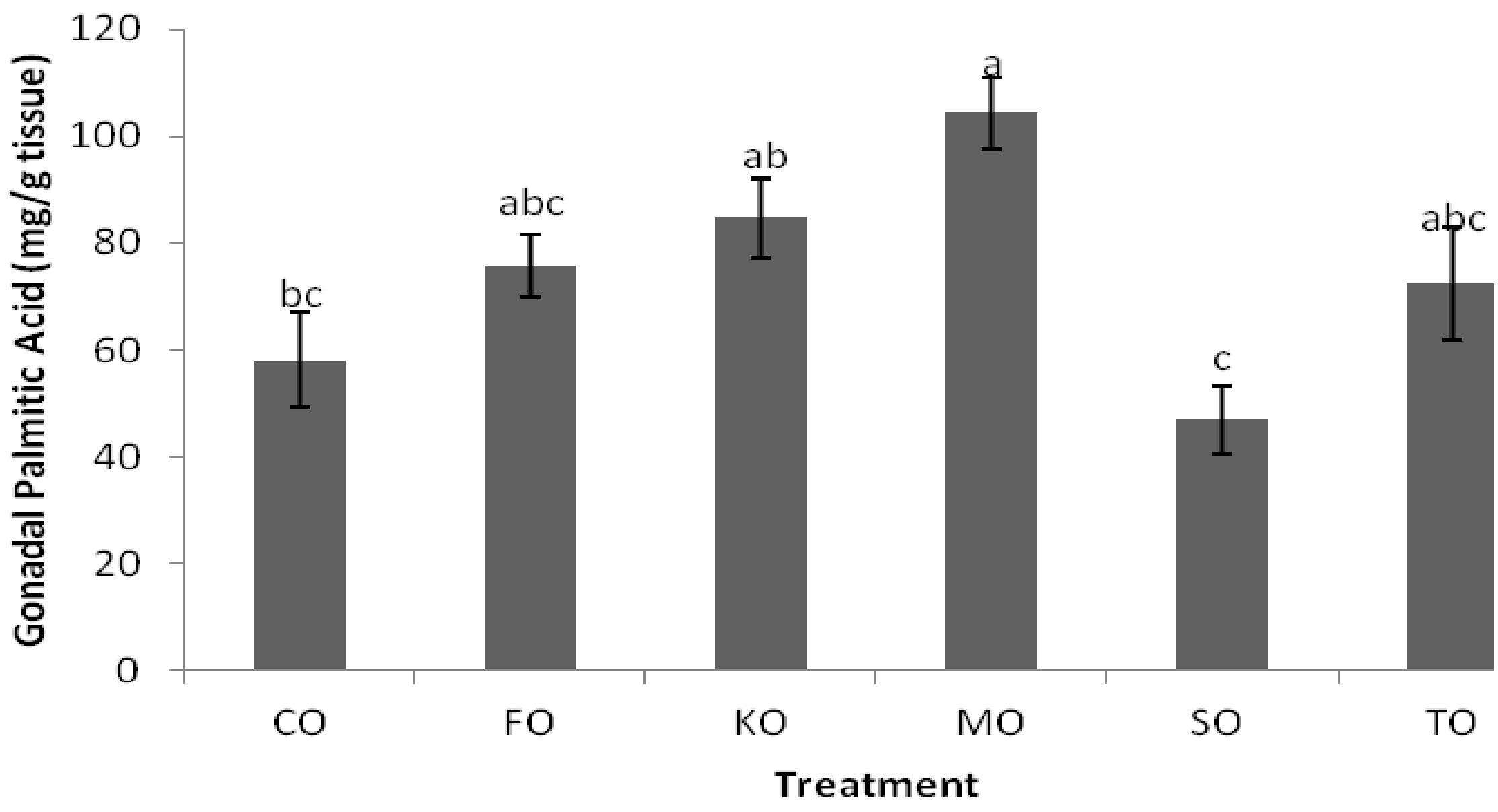

Values are expressed as the mean \pm SEM of $n=10$ rats/group. Different superscript letters $a, b, c$ indicate significant differences at $P<0.05$ by one-way ANOVA followed by Tukey's test. Abbreviations are CO, corn oil; FO, flaxseed oil; KO, krill oil; MO, menhaden oil; SO, salmon oil; TO, tuna oil. 
Figure 7b: The Effects of Feeding Growing Female Rats Different Sources of Omega-3 Polyunsaturated Fatty Acids on Gonadal Adipose Tissue Stearic Acid (18:0) Content.

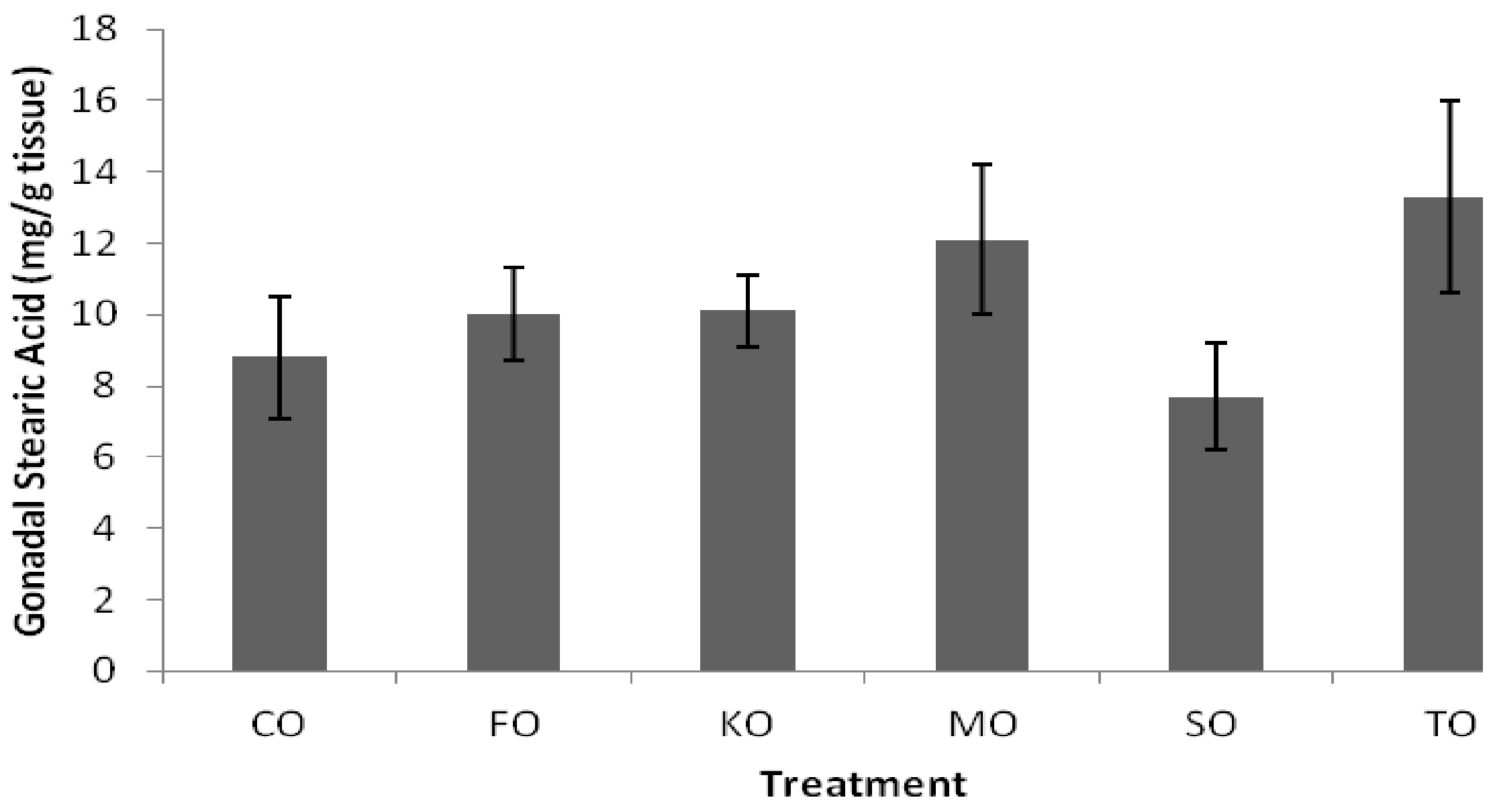

Values are expressed as the mean \pm SEM of $n=10$ rats/group. Different superscript letters $a, b, c$ indicate significant differences at $P<0.05$ by one-way ANOVA followed by Tukey's test. Abbreviations are CO, corn oil; FO, flaxseed oil; KO, krill oil; MO, menhaden oil; SO, salmon oil; TO, tuna oil. 
Figure 7c: The Effects of Feeding Growing Female Rats Different Sources of Omega-3 Polyunsaturated Fatty Acids on Gonadal Adipose Tissue Palmitoleic Acid (16:1n-7) Content.

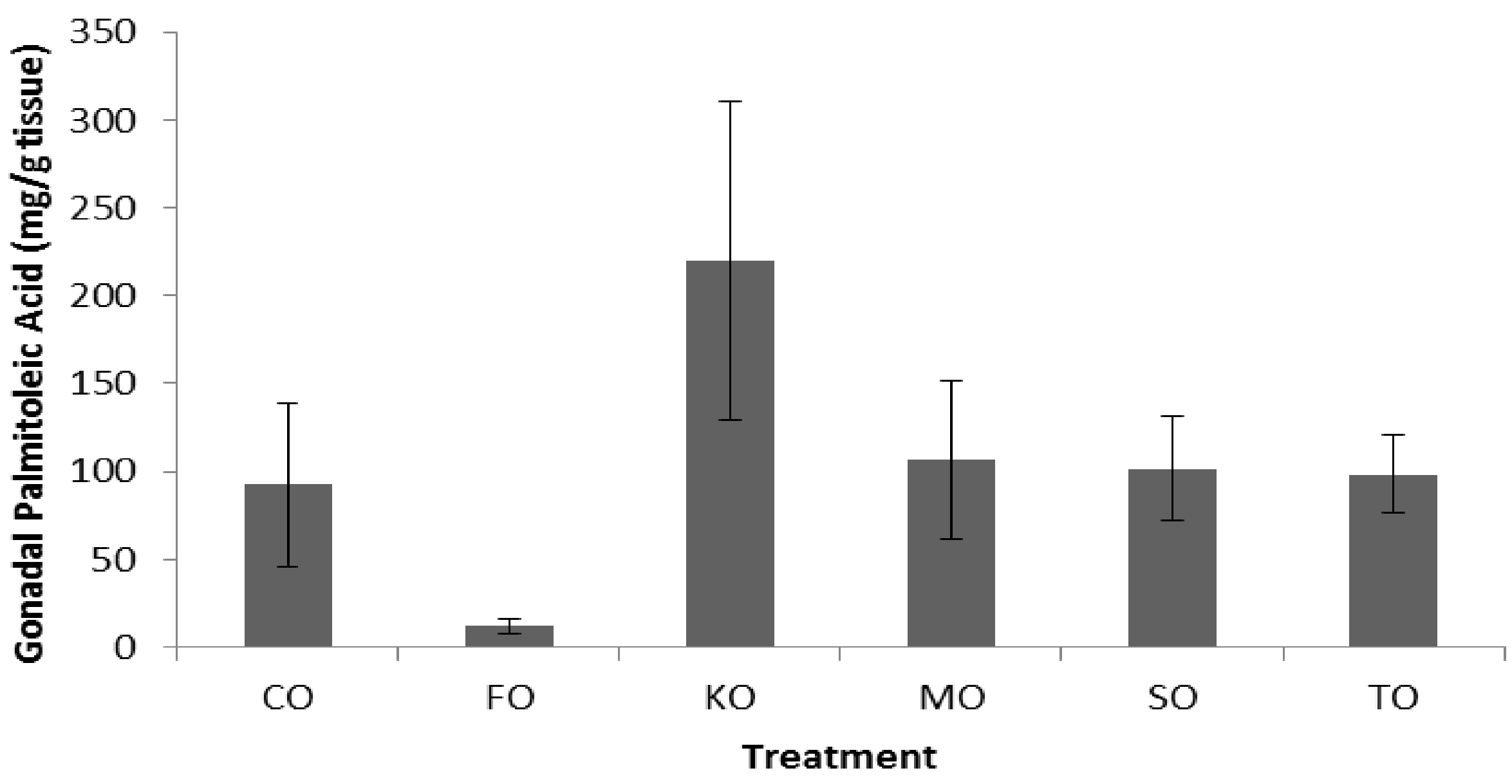

Values are expressed as the mean \pm SEM of $n=4-5$ rats/group. Different superscript letters a, $b, c$ indicate significant differences at $P<0.05$ by one-way ANOVA followed by Tukey's test. Abbreviations are CO, corn oil; FO, flaxseed oil; KO, krill oil; MO, menhaden oil; SO, salmon oil; TO, tuna oil. 
Figure 7d: The Effects of Feeding Growing Female Rats Different Sources of Omega-3 Polyunsaturated Fatty Acids on Gonadal Adipose Tissue Oleic Acid (18:1n-9) Content.

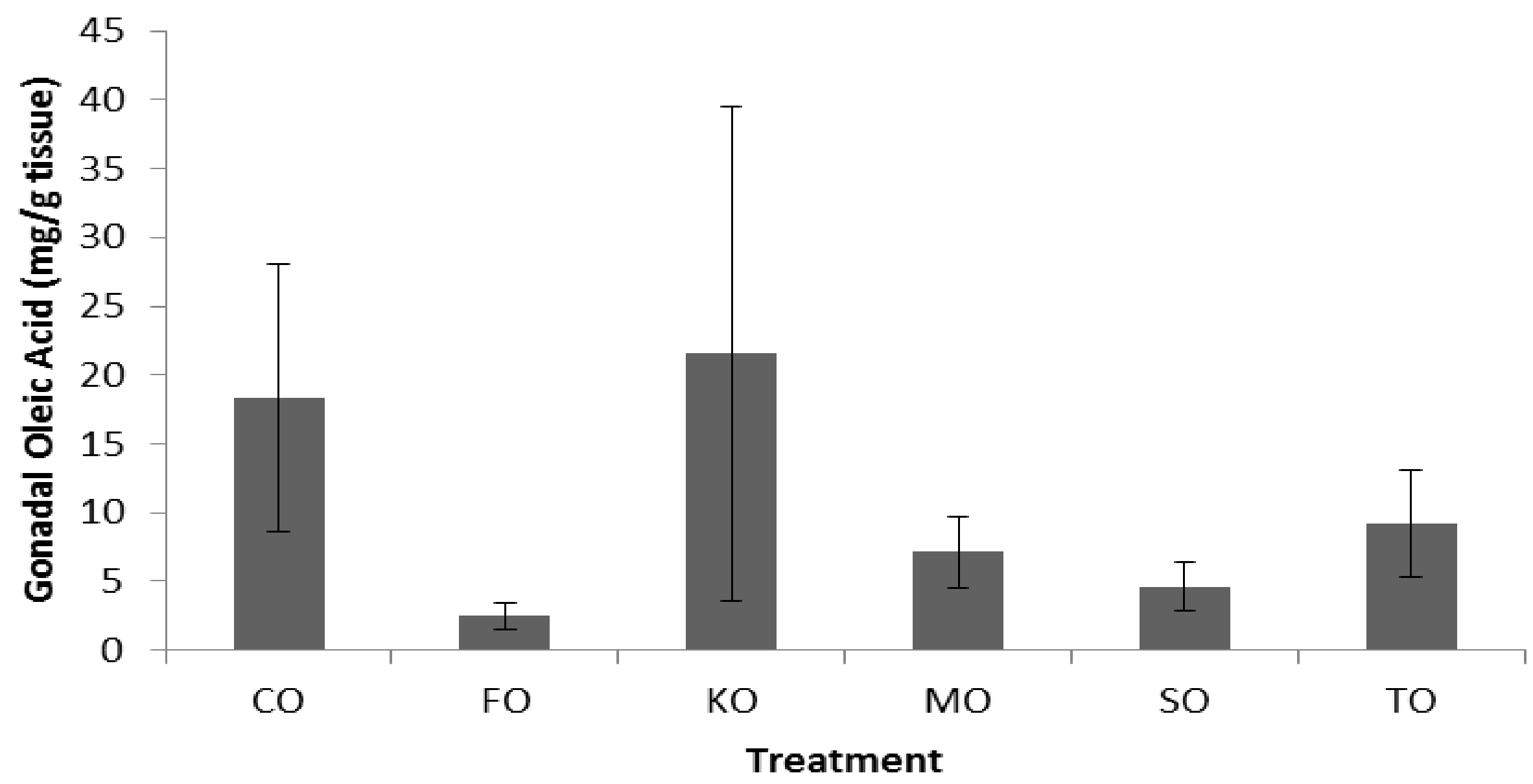

Values are expressed as the mean \pm SEM of $n=4-5$ rats/group. Different superscript letters $a, b, c$ indicate significant differences at $P<0.05$ by one-way ANOVA followed by Tukey's test. Abbreviations are CO, corn oil; FO, flaxseed oil; KO, krill oil; MO, menhaden oil; SO, salmon oil; TO, tuna oil. 
Figure 8: The Effect of Feeding Growing Female Rats Different Sources of Omega-3 Polyunsaturated Fatty Acids on the mRNA Expression of PPAR $\alpha$ in Hepatic Tissue.

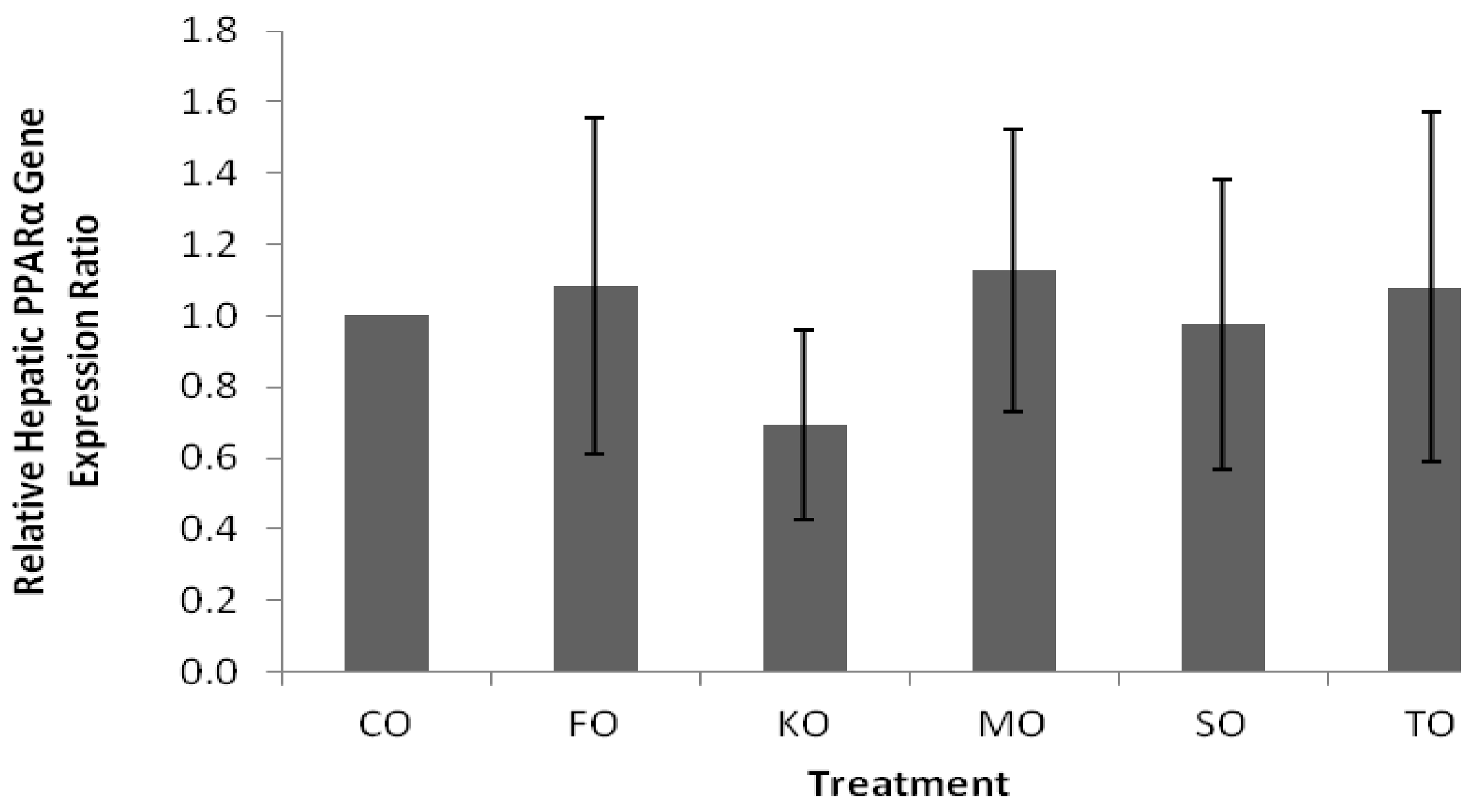

Expression compared to $\mathrm{CO}$ group and normalized to GAPDH. (* $\mathrm{P}<0.05$ indicates up- regulation, $\mathrm{n}=5$ rats/group). Gene expression was analyzed by pairwise fixed reallocation randomization test. Abbreviations are CO, corn oil; FO, flaxseed oil; KO, krill oil; MO, menhaden oil; SO, salmon oil; TO, tuna oil. 
Figure 9a: The Effect of Feeding Growing Female Rats Different Sources of Omega-3 Polyunsaturated Fatty Acids on the mRNA Expression of PPAR $\gamma$ in Gonadal Adipose Tissue.

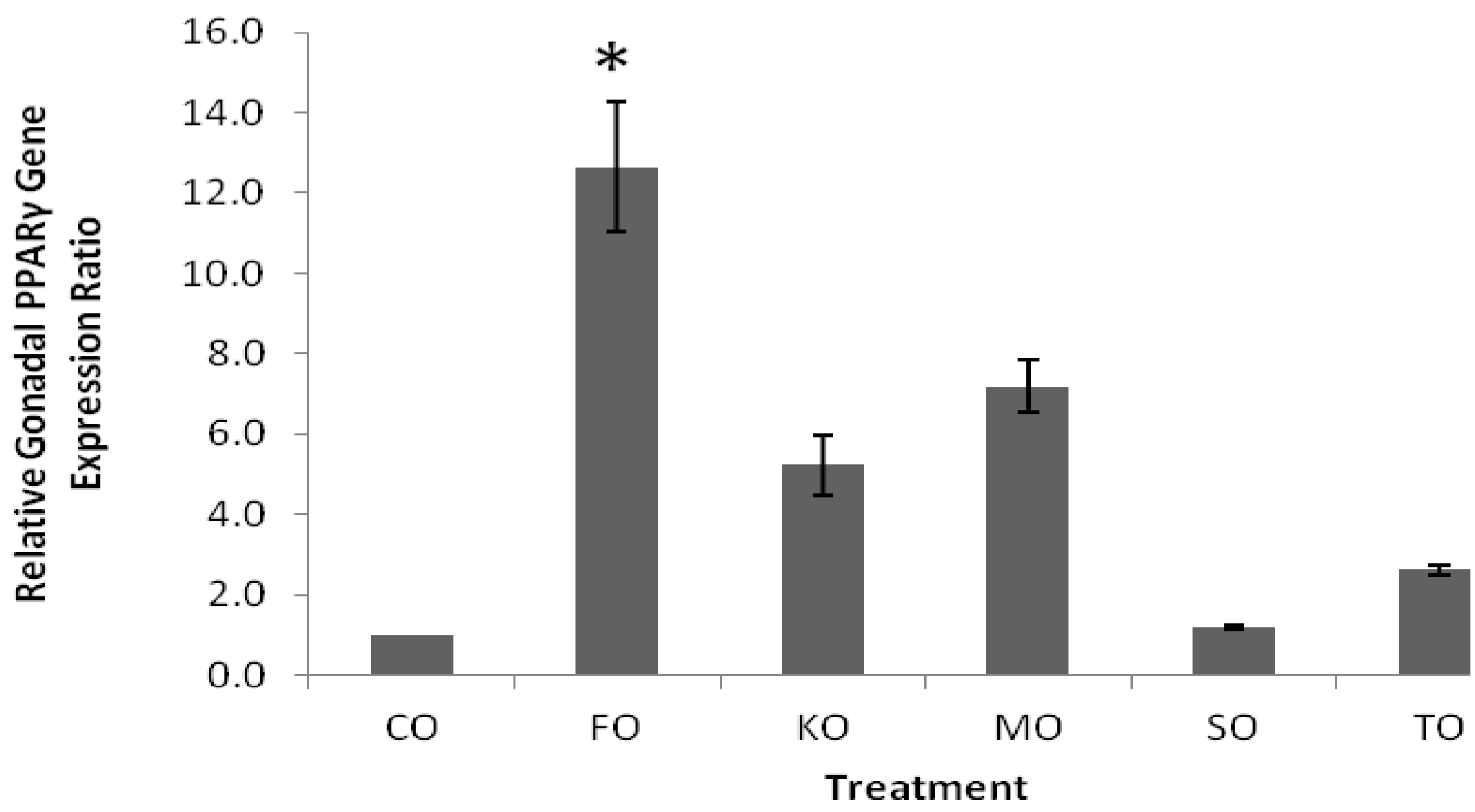

Expression compared to $\mathrm{CO}$ group and normalized to GAPDH. ( $* \mathrm{P}<0.05$ indicates up-regulation, $\mathrm{n}=4-5$ rats/group). Gene expression was analyzed by pairwise fixed reallocation randomization test. Abbreviations are CO, corn oil; FO, flaxseed oil; KO, krill oil; MO, menhaden oil; SO, salmon oil; TO, tuna oil. 
Figure 9b: The Effect of Feeding Growing Female Rats Different Sources of Omega-3 Polyunsaturated Fatty Acids on the mRNA Expression of HSL in Gonadal Adipose Tissue.

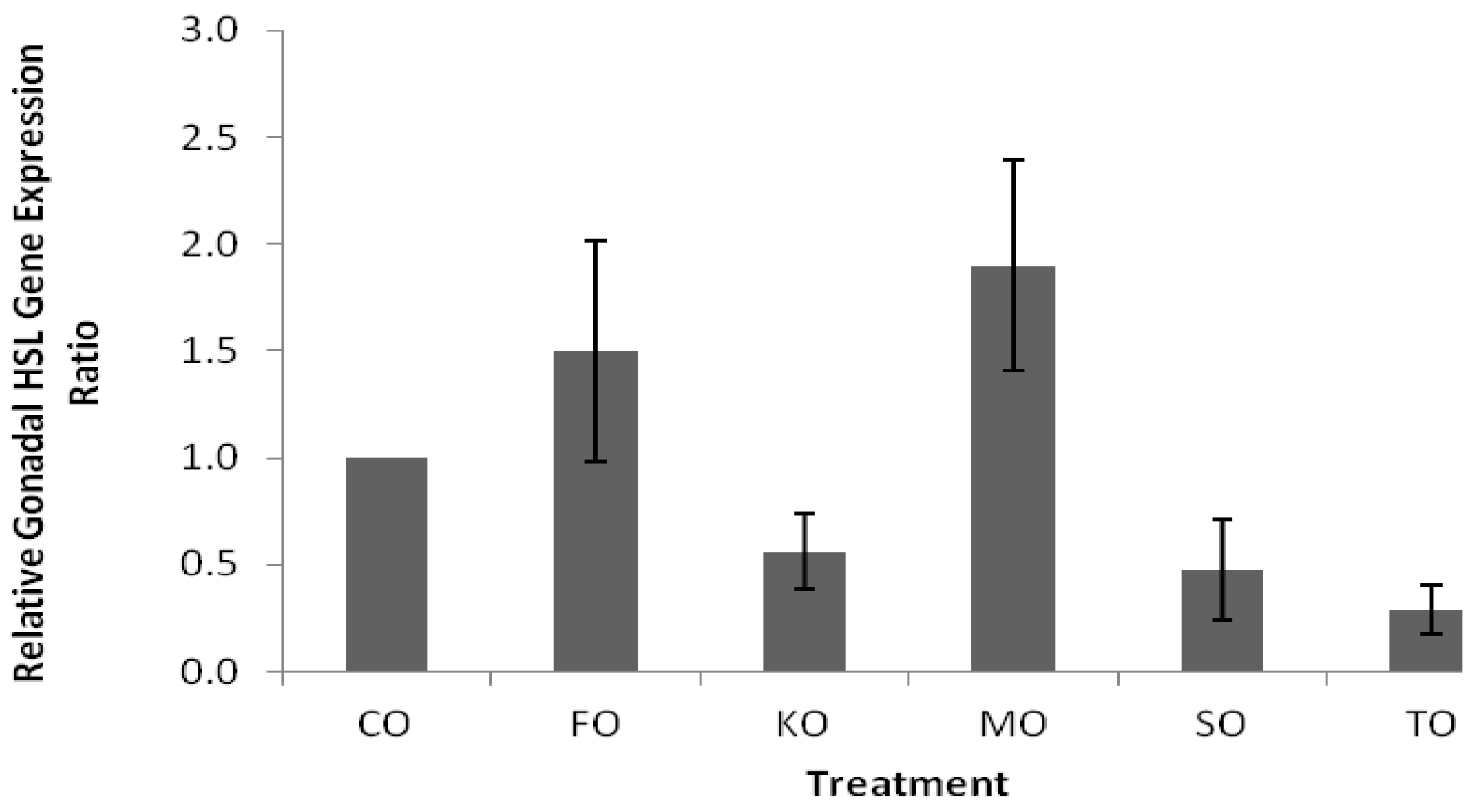

Expression compared to $\mathrm{CO}$ group and normalized to GAPDH. ( ${ }^{*} \mathrm{P}<0.05$ indicates up-regulation, $\mathrm{n}=5$ rats/group). Gene expression was analyzed by pairwise fixed reallocation randomization test. Abbreviations are CO, corn oil; FO, flaxseed oil; KO, krill oil; MO, menhaden oil; SO, salmon oil; TO, tuna oil. 
Figure 10: The Effect of Feeding Growing Female Rats Different Sources of Omega-3 Polyunsaturated Fatty Acids on Liver Total Triglyceride Content.

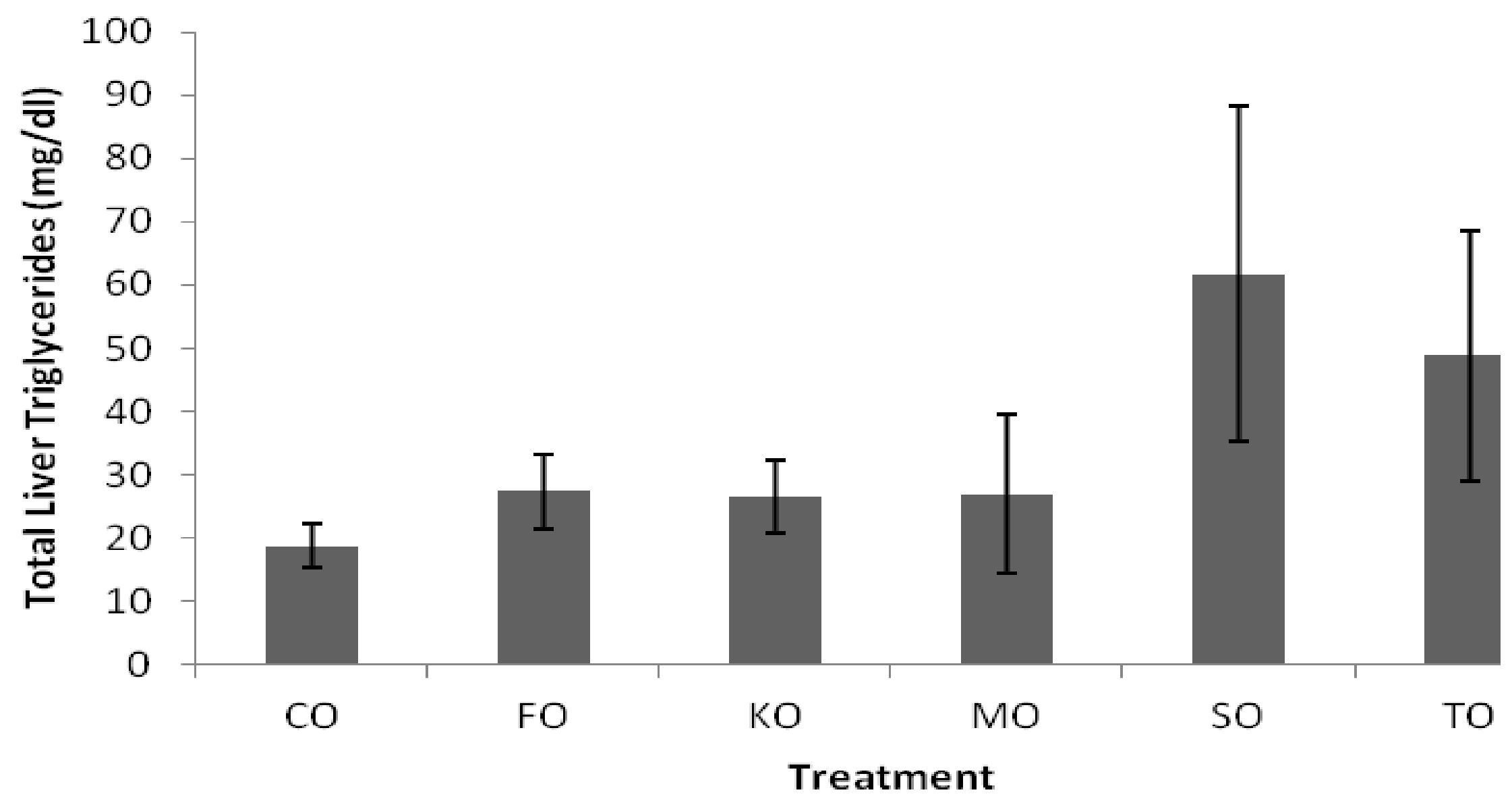

Values are expressed as mean $(\mathrm{mg} / \mathrm{dl}) \pm \mathrm{SEM}, \mathrm{n}=5$ rats/group. Different superscript letters a, b, $\mathrm{c}$ indicate significant differences at $P<0.05$ by one-way ANOVA followed by Tukey’s test. Abbreviations are CO, corn oil; FO, flaxseed oil; KO, krill oil; MO, menhaden oil; SO, salmon oil; TO, tuna oil; TG, triglyceride. 
Table 4: The Effect of Feeding Growing FemaleRats Different Sources of Omega-3 Polyunsaturated Fatty Acids on Serum Lipids and Lipoproteins.

\begin{tabular}{lcccccc}
\hline Measurement & CO & FO & KO & MO & SO & TO \\
\hline $\begin{array}{l}\text { Total CHL } \\
\text { (mg/dl) }\end{array}$ & $144.9 \pm 8.4^{\mathrm{a}}$ & $117.5 \pm 3.6^{\mathrm{a}}$ & $104.3 \pm 5.4^{\mathrm{b}}$ & $101.8 \pm 3.7^{\mathrm{b}}$ & $61.7 \pm 5.2^{\mathrm{c}}$ & $58.4 \pm 1.6^{\mathrm{c}}$ \\
$\begin{array}{l}\text { Total TG } \\
\text { (mg/dl) }\end{array}$ & $89.9 \pm 6.4$ & $88.6 \pm 6.7$ & $97.7 \pm 12.1$ & $80.4 \pm 5.1$ & $82.9 \pm 7.3$ & $76.4 \pm 6.1$ \\
$\begin{array}{l}\text { VLDL } \\
\text { (mg/dl) }\end{array}$ & $18.0 \pm 1.3$ & $17.7 \pm 1.3$ & $19.6 \pm 2.4$ & $16.2 \pm 1.0$ & $16.8 \pm 1.5$ & $15.2 \pm 1.2$ \\
$\begin{array}{l}\text { LDL-C } \\
(\mathbf{m g} / \mathbf{d l})\end{array}$ & $6.4 \pm 3.2$ & $17.9 \pm 4.2$ & $10.6 \pm 4.4$ & $9.2 \pm 2.3$ & $13.1 \pm 5.2$ & $4.2 \pm 2.2$ \\
$\begin{array}{l}\text { HDL-C } \\
\text { (mg/dl) }\end{array}$ & $56.8 \pm 4.81^{\mathrm{a}}$ & $34.99 \pm 2.98^{\mathrm{b}}$ & $31.49 \pm 3.84^{\mathrm{b}}$ & $26.35 \pm 2.48^{\mathrm{b}}$ & $24.68 \pm 1.74^{\mathrm{b}}$ & $29.27 \pm 1.46^{\mathrm{b}}$ \\
\hline
\end{tabular}

Values are expressed as mean \pm SEM, $n=5-10$ rats/group. Different superscript letters a, $b$, c within the same rows indicate significant differences at $P<0.05$ by one-way ANOVA followed by Tukey's test. Abbreviations are cholesterol (CHL), triglyceride (TG), very low density lipoprotein (VLDL), low density lipoprotein (LDL-C), high density lipoprotein (HDL-C), corn oil (CO), flaxseed oil (FO), krill oil (KO), menhaden oil (MO), salmon oil (SO), tuna oil (TO). 
Figure 11: The Effect of Feeding Growing Female Rats Different Sources of Omega-3 Polyunsaturated Fatty Acids on the mRNA Expression of COX 2 in Hepatic Tissue.

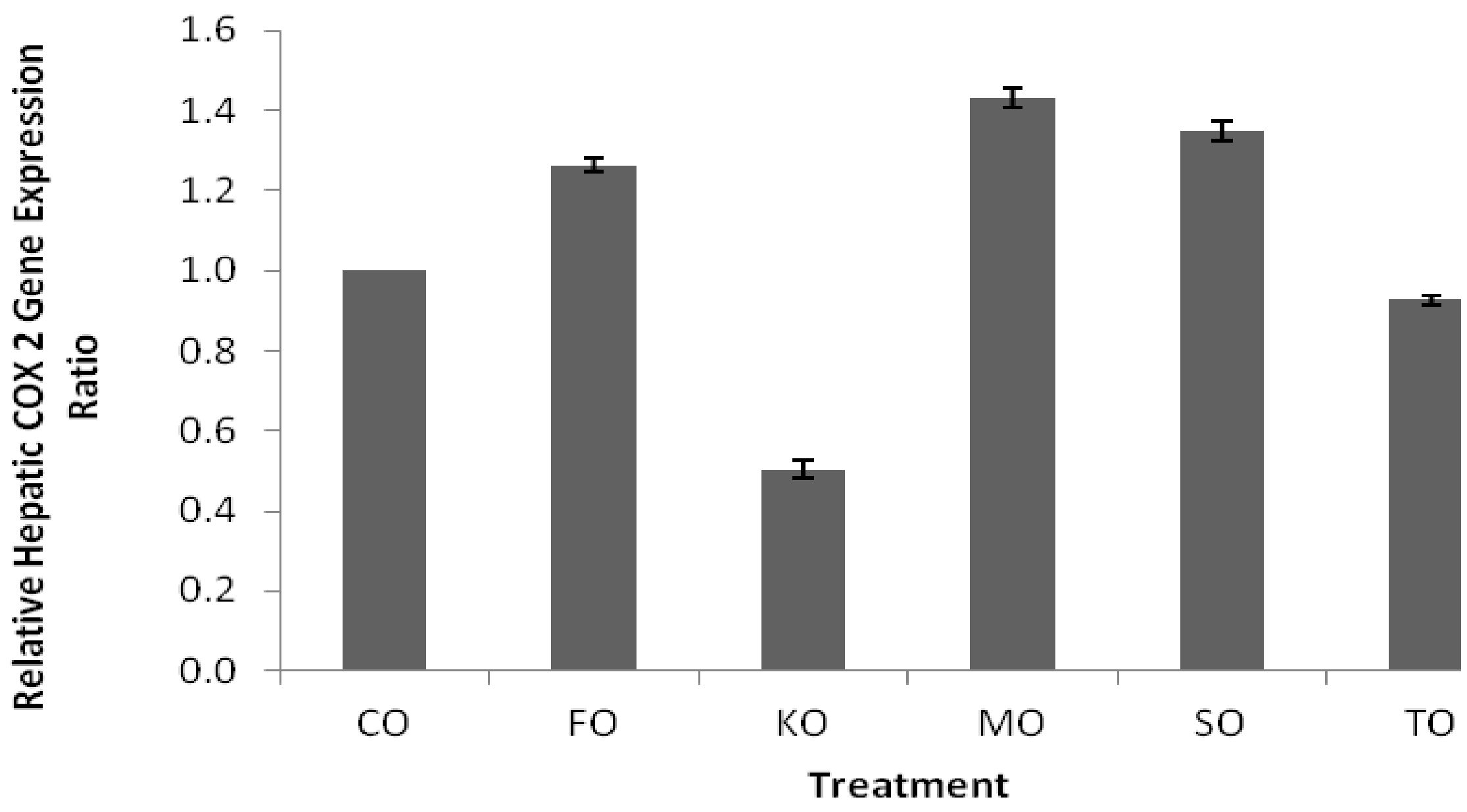

Expression compared to $\mathrm{CO}$ group and normalized to GAPDH. ( $* \mathrm{P}<0.05$ indicates down regulation, $\mathrm{n}=5$ rats/group). Gene expression was analyzed by pairwise fixed reallocation randomization test. Abbreviations are CO, corn oil; FO, flaxseed oil; KO, krill oil; MO, menhaden oil; SO, salmon oil; TO, tuna oil. 
Figure 12: The Effect of Feeding Growing Female Rats Different Sources of Omega-3 Polyunsaturated Fatty Acids on the mRNA Expression of IKBa in Hepatic Tissue.

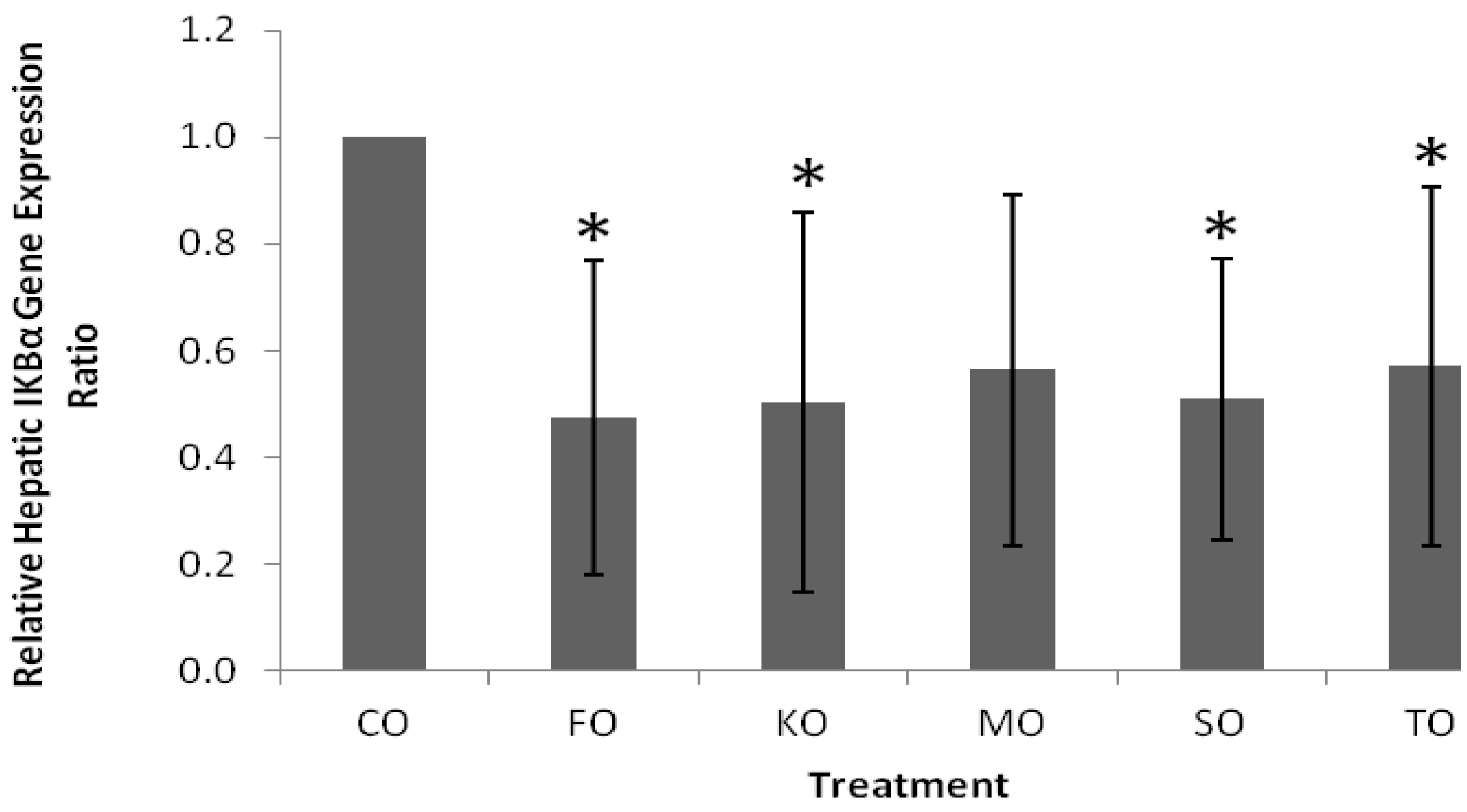

Expression compared to $\mathrm{CO}$ group and normalized to GAPDH. ( $* \mathrm{P}<0.05$ indicates down regulation, $\mathrm{n}=5$ rats/group). Gene expression was analyzed by pairwise fixed reallocation randomization test. Abbreviations are CO, corn oil; FO, flaxseed oil; KO, krill oil; MO, menhaden oil; SO, salmon oil; TO, tuna oil. 
Figure 13: The Effect of Feeding Growing Female Rats Different Sources of Omega-3 Polyunsaturated Fatty Acids on the mRNA Expression of IKB $\alpha$ in Gonadal Adipose Tissue.

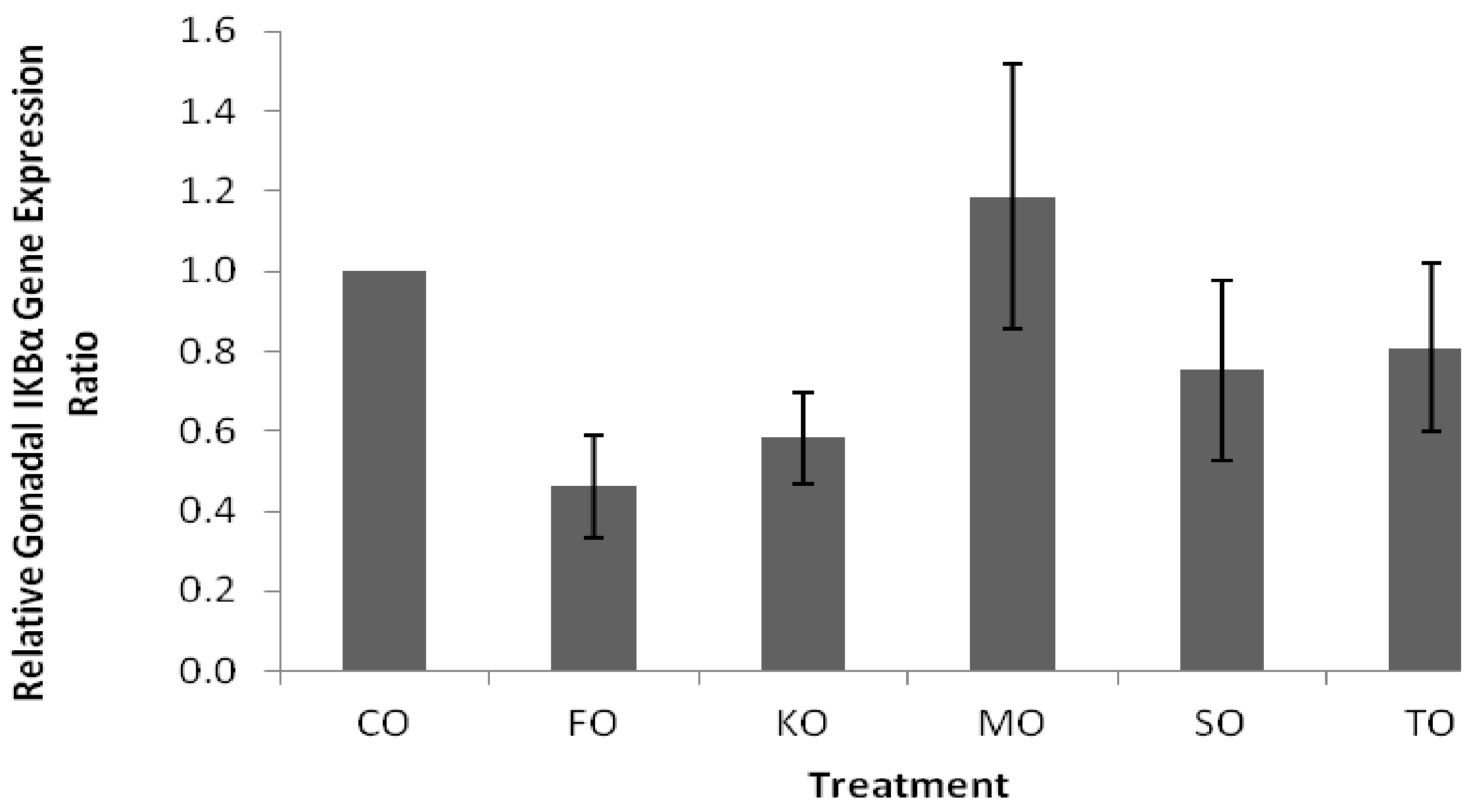

Expression compared to $\mathrm{CO}$ group and normalized to GAPDH. ( $* \mathrm{P}<0.05$ indicates down regulation, $\mathrm{n}=5$ rats/group). Gene expression was analyzed by pairwise fixed reallocation randomization test. Abbreviations are CO, corn oil; FO, flaxseed oil; KO, krill oil; MO, menhaden oil; SO, salmon oil; TO, tuna oil. 
Figure 14a: The Effect of Feeding Growing Female Rats Different Sources of Omega-3 Fatty Acids on Urinary Levels of PGE 2 Metabolite.

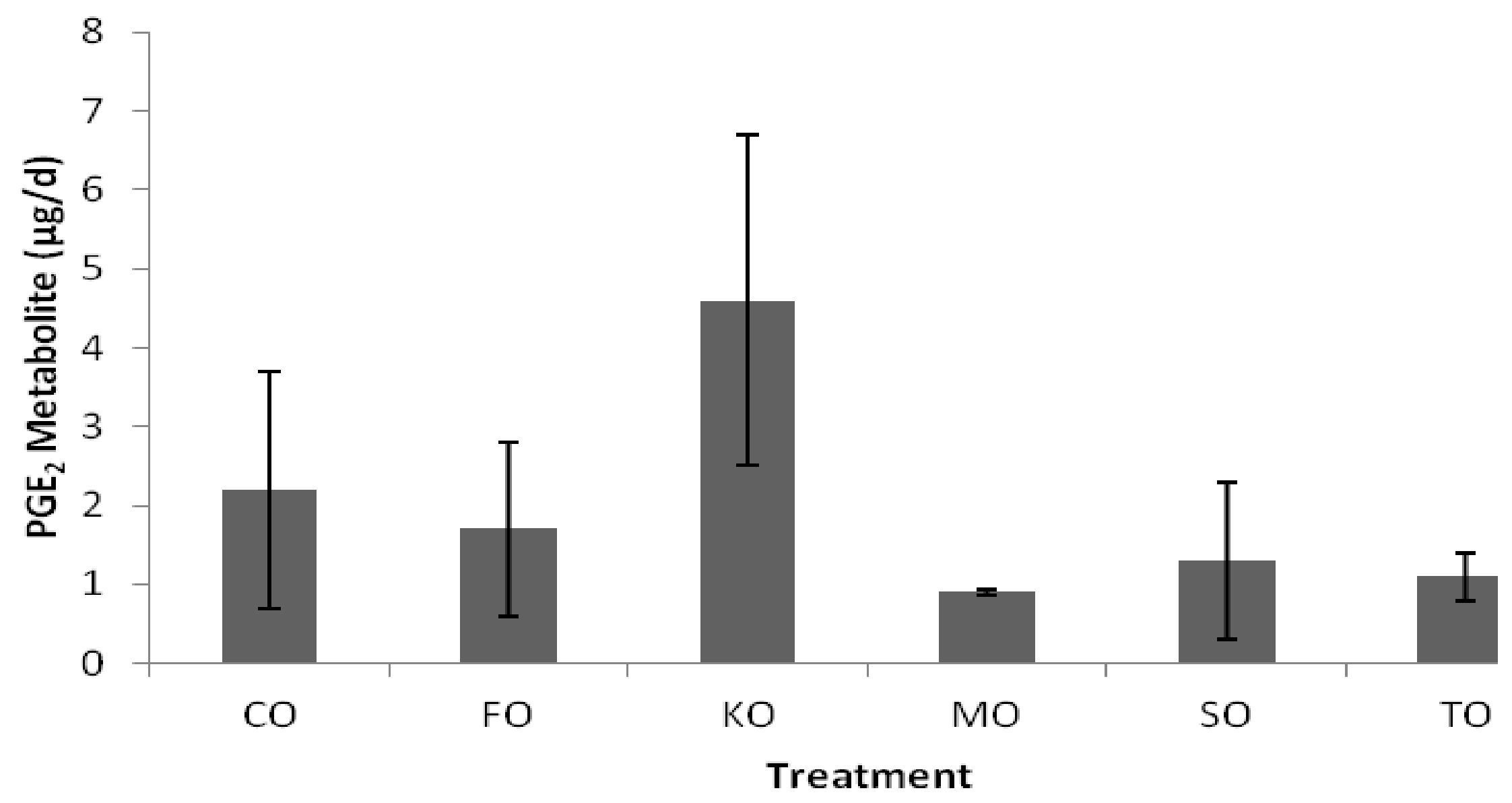

Values are expressed as the mean \pm SEM of $n=7$ rats/group. Different superscript letters $a, b, c$ indicate significant differences at $P<0.05$ by one-way ANOVA followed by Tukey's test. Abbreviations are CO, corn oil; FO, flaxseed oil; KO, krill oil; MO, menhaden oil; SO, salmon oil; TO, tuna oil; $\mathrm{PGE}_{2}$, prostaglandin $\mathrm{E}_{2}$. 
Figure 14b: The Effect of Feeding Growing Female Rats Different Sources of Omega-3 Fatty Acids on Urinary TXB Metabolite.

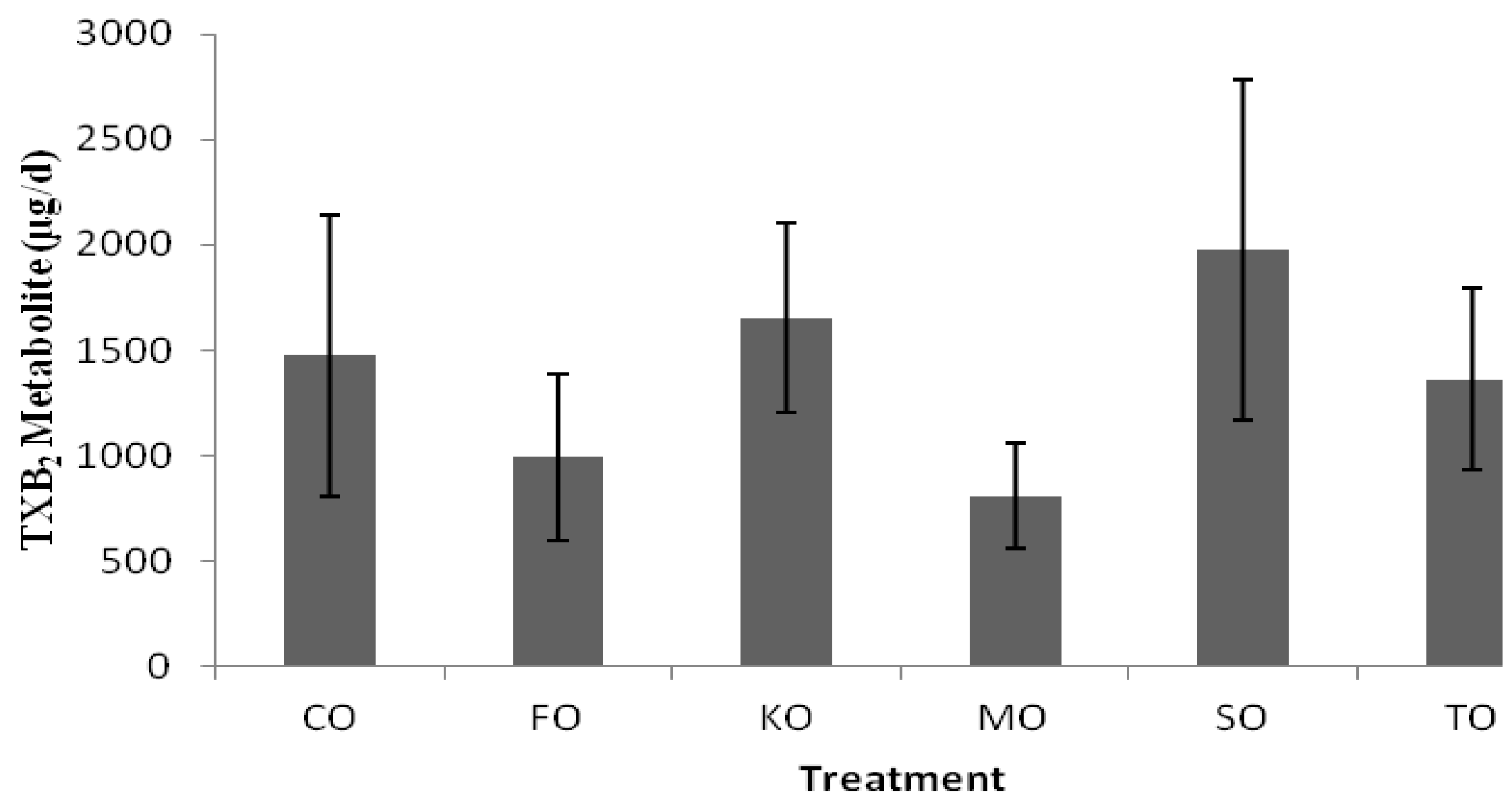

Values are expressed as the mean \pm SEM of $n=7$ rats/group. Different superscript letters $a, b, c$ indicate significant differences at $P<0.05$ by one-way ANOVA followed by Tukey's test. Abbreviations are CO, corn oil; FO, flaxseed oil; KO, krill oil; MO, menhaden oil; SO, salmon oil; TO, tuna oil; $\mathrm{TXB}_{2}$, thromboxane $\mathrm{B}_{2}$. 


\section{Appendices}

Appendix 1. Whole Diet Composition.

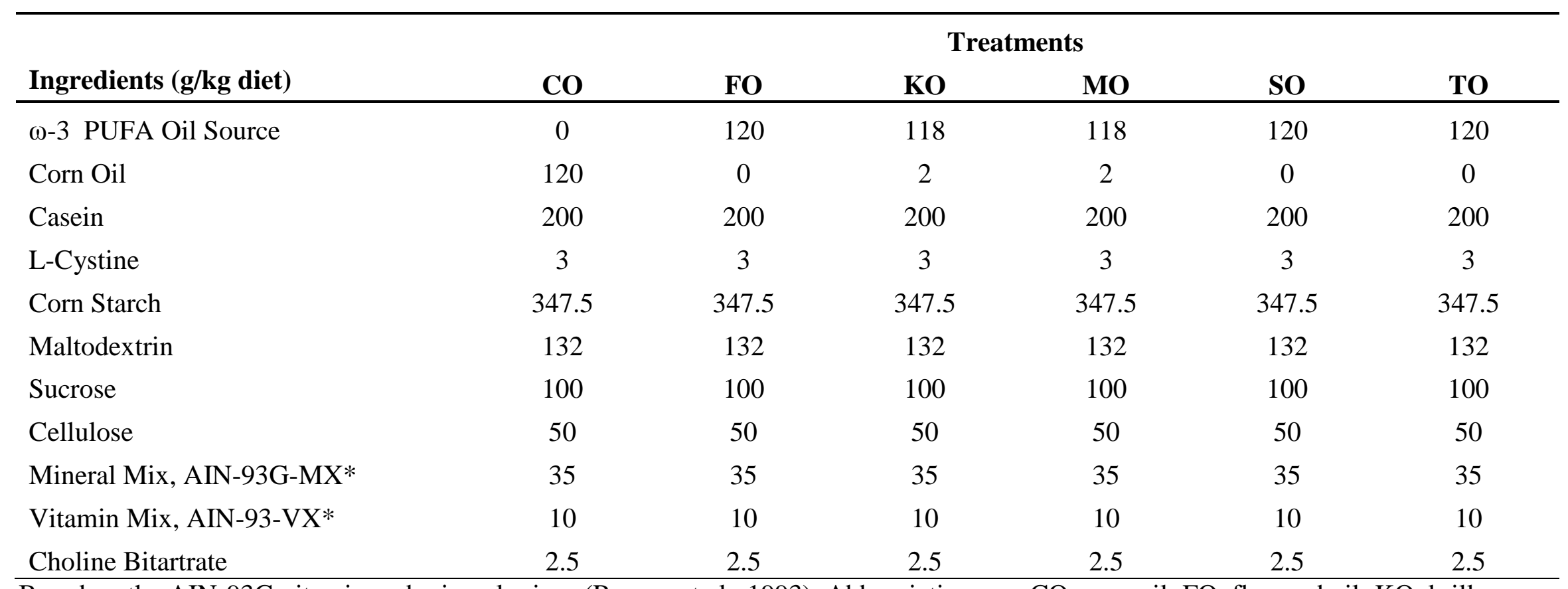

Based on the AIN-93G vitamin and mineral mixes (Reeves et al., 1993). Abbreviations are CO, corn oil; FO, flaxseed oil; KO, krill oil; MO, menhaden oil; SO, salmon oil; TO, tuna oil. 
Appendix 2. The Effect of Feeding Growing Female Rats Different Sources of Omega-3 Polyunsaturated Fatty Acids on Food Intake, Body Weight, and Tissue Weights.

\begin{tabular}{|c|c|c|c|c|c|c|}
\hline \multirow[b]{2}{*}{ Measurement } & \multicolumn{6}{|c|}{ Treatments } \\
\hline & $\mathrm{CO}$ & FO & KO & MO & SO & TO \\
\hline Food intake $(\mathrm{g})$ & $750.1 \pm 12.5$ & $762.9 \pm 14.3$ & $767.4 \pm 10.9$ & $761.2 \pm 17.6$ & $706.8 \pm 17.4$ & $738.3 \pm 16.4$ \\
\hline Body weight gain (g) & $76.0 \pm 7.4$ & $103.8 \pm 8.1$ & $98.4 \pm 6.1$ & $107.6 \pm 12.5$ & $86.0 \pm 8.4$ & $106.0 \pm 6.7$ \\
\hline Final body weight (g) & $214.9 \pm 6.4$ & $239.6 \pm 8.2$ & $231.7 \pm 6.6$ & $241.5 \pm 14.4$ & $215.5 \pm 10.3$ & $235.0 \pm 8.2$ \\
\hline Liver weight ( $g / 100 g$ bwt) & $2.9 \pm 0.1^{\mathrm{c}}$ & $2.8 \pm 0.1^{\mathrm{c}}$ & $3.6 \pm 0.1^{\mathrm{ab}}$ & $3.2 \pm 0.2^{\mathrm{bc}}$ & $3.7 \pm 0.1^{\mathrm{a}}$ & $3.8 \pm 0.1^{\mathrm{a}}$ \\
\hline Gonadal adipose weight ( $\mathrm{g} / 100 \mathrm{~g}$ bwt) & $1.1 \pm 0.2$ & $1.7 \pm 0.2$ & $1.6 \pm 0.1$ & $1.8 \pm 0.4$ & $1.3 \pm 0.2$ & $1.3 \pm 0.2$ \\
\hline
\end{tabular}

Values are expressed as the mean \pm SEM of $n=10$ rats/group. Different superscript letters $a, b, c$ within the same rows indicate significant differences at $P<0.05$ by one-way ANOVA followed by Tukey's test. Abbreviations are CO, corn oil; FO, flaxseed oil; $\mathrm{KO}$, krill oil; MO, menhaden oil; SO, salmon oil; TO, tuna oil; bwt, body weight. 
Appendix 3. The Effect of Feeding Growing Female Rats Different Sources of Omega-3 Polyunsaturated Fatty Acids on Liver Fatty Acid Profile.

\begin{tabular}{|c|c|c|c|c|c|c|}
\hline \multirow[b]{2}{*}{ Fatty Acid Measurement } & \multicolumn{6}{|c|}{ Treatments } \\
\hline & $\mathrm{CO}$ & FO & KO & MO & SO & TO \\
\hline n-3 PUFA & $0.9 \pm 0.1^{\mathrm{b}}$ & $7.8 \pm 1.0^{\mathrm{b}}$ & $9.6 \pm 1.3^{b}$ & $9.5 \pm 1.1^{b}$ & $43.6 \pm 5.8^{\mathrm{a}}$ & $35.9 \pm 2.5^{\mathrm{a}}$ \\
\hline EPA $(20: 5 n-3)$ & ND & $1.7 \pm 0.2^{b}$ & $3.7 \pm 0.5^{b}$ & $3.0 \pm 0.6^{\mathrm{b}}$ & $19.4 \pm 3.1^{\mathrm{a}}$ & $6.3 \pm 0.6^{\mathrm{b}}$ \\
\hline DHA (22:6n-3) & $0.9 \pm 0.1^{\mathrm{b}}$ & $1.7 \pm 0.2^{b}$ & $5.7 \pm 0.8^{b}$ & $6.2 \pm 0.7^{b}$ & $23.8 \pm 2.9^{\mathrm{a}}$ & $29.4 \pm 2.0^{\mathrm{a}}$ \\
\hline n-6 PUFA & $11.9 \pm 0.9^{\mathrm{a}}$ & $5.9 \pm 0.9^{b}$ & $3.0 \pm 0.1^{\mathrm{c}}$ & $2.7 \pm 0.3^{\mathrm{c}}$ & $6.7 \pm 0.6^{\mathrm{b}}$ & $7.6 \pm 0.5^{\mathrm{b}}$ \\
\hline LA (18:2n-6) & $7.1 \pm 0.7^{\mathrm{a}}$ & $4.1 \pm 0.7^{b}$ & $1.4 \pm 0.1^{\mathrm{c}}$ & $1.3 \pm 0.2^{\mathrm{c}}$ & $2.0 \pm 0.4^{\mathrm{c}}$ & $1.6 \pm 0.2^{\mathrm{c}}$ \\
\hline ARA $(20: 4 n-6)$ & $4.8 \pm 0.3^{\mathrm{b}}$ & $1.9 \pm 0.3^{\mathrm{c}}$ & $1.6 \pm 0.1^{\mathrm{c}}$ & $1.4 \pm 0.1^{\mathrm{c}}$ & $4.7 \pm 0.3^{\mathrm{b}}$ & $6.0 \pm 0.4^{\mathrm{a}}$ \\
\hline$n-6 / n-3$ & $14.6 \pm 1.6^{\mathrm{a}}$ & $0.8 \pm 0.1^{\mathrm{b}}$ & $0.4 \pm 0.04^{\mathrm{b}}$ & $0.3 \pm 0.02^{\mathrm{b}}$ & $0.2 \pm 0.02^{\mathrm{b}}$ & $0.2 \pm 0.01^{\mathrm{b}}$ \\
\hline
\end{tabular}

Values are expressed as mean (mg FA/g tissue) \pm SEM of $n=10$ rats/group. Different superscript letters a, b, c, $d$ within the same rows indicate significant differences at $\mathrm{P}<0.05$ by one-way ANOVA followed by Tukey's test (parametric). Abbreviations are: $\mathrm{CO}$, corn oil; FO, flaxseed oil; KO, krill oil; MO, menhaden oil; SO, salmon oil; TO, tuna oil.; SFA, saturated fatty acids; PUFA,

polyunsaturated fatty acids; LA, linoleic acid; ARA, arachidonic acid; ALA, $\alpha$-linolenic acid; EPA, eicosapentaenoic acid; DHA, docosahexaenoic acid; ND, not detectable. 
Appendix 4. The Effect of Feeding Growing Female Rats Different Sources of Omega-3 Polyunsaturated Fatty Acids on the Gonadal Adipose Tissue Fatty Acid Profile.

\begin{tabular}{|c|c|c|c|c|c|c|}
\hline \multirow[b]{2}{*}{ Fatty Acid Measurement } & \multicolumn{6}{|c|}{ Treatments } \\
\hline & $\mathrm{CO}$ & FO & KO & MO & SO & TO \\
\hline n-3 PUFA & $1.3 \pm 0.2^{c}$ & $81.7 \pm 6.8^{\mathrm{a}}$ & $21.5 \pm 2.6^{\mathrm{b}}$ & $21.6 \pm 2.0^{b}$ & $9.5 \pm 2.8^{b c}$ & $13.5 \pm 2.4^{\mathrm{bc}}$ \\
\hline EPA $(20: 5 n-3)$ & ND & $0.7 \pm 0.2^{c}$ & $9.7 \pm 1.3^{\mathrm{a}}$ & $5.6 \pm 0.9^{b}$ & $4.2 \pm 1.4^{\mathrm{bc}}$ & $1.9 \pm 0.4^{b c}$ \\
\hline DHA $(22: 6 n-3)$ & ND & $0.07 \pm 0.02^{\mathrm{c}}$ & $8.7 \pm 1.2^{\mathrm{ab}}$ & $10.9 \pm 1.0^{\mathrm{a}}$ & $4.2 \pm 1.2^{\mathrm{bc}}$ & $9.7 \pm 2.0^{\mathrm{a}}$ \\
\hline n-6 PUFA & $107.9 \pm 14.1^{\mathrm{a}}$ & $59.8 \pm 5.8^{\mathrm{b}}$ & $17.0 \pm 2.0^{\mathrm{c}}$ & $21.0 \pm 1.8^{\mathrm{c}}$ & $8.0 \pm 1.4^{\mathrm{c}}$ & $11.6 \pm 2.2^{\mathrm{c}}$ \\
\hline LA $(18: 2 n-6)$ & $106.5 \pm 13.9^{\mathrm{a}}$ & $59.4 \pm 5.6^{\mathrm{b}}$ & $15.5 \pm 1.9^{\mathrm{c}}$ & $19.5 \pm 1.7^{\mathrm{c}}$ & $6.5 \pm 1.3^{c}$ & $8.5 \pm 1.6^{c}$ \\
\hline $\operatorname{ARA}(20: 4 n-6)$ & $1.4 \pm 0.2^{b}$ & $0.5 \pm 0.1^{b}$ & $1.6 \pm 0.2^{\mathrm{b}}$ & $1.5 \pm 0.1^{b}$ & $1.4 \pm 0.3^{\mathrm{b}}$ & $3.1 \pm 0.7^{\mathrm{a}}$ \\
\hline$n-6 / n-3$ & $93.6 \pm 11.1^{\mathrm{a}}$ & $0.7 \pm 0.02^{b}$ & $0.8 \pm 0.1^{\mathrm{b}}$ & $1.0 \pm 0.1^{b}$ & $1.1 \pm 0.2^{\mathrm{b}}$ & $1.0 \pm 0.2^{\mathrm{b}}$ \\
\hline
\end{tabular}

Values are expressed as mean (mg FA/g tissue) \pm SEM of $n=10$ rats/group. Different superscript letters a, b, $c$ within the same rows indicate significant differences at $\mathrm{P}<0.05$ by one-way ANOVA followed by Tukey's test. Abbreviations are: $\mathrm{CO}$, corn oil; FO,

flaxseed oil; KO, krill oil; MO, menhaden oil; SO, salmon oil; TO, tuna oil; PUFA, polyunsaturated fatty acids; LA, linoleic acid; AA, arachidonic acid; ALA, $\alpha$-linolenic acid; EPA, eicosapentaenoic acid; DHA, docosahexaenoic acid; ND, not detectable. 


\subsection{References}

(1) Skulas-Ray, A., P. Kris-Etherton, W. Harris S., P., P. Wagner R., and S. West G. 2011. Dose-response effects of omega-3 fatty acids on triglycerides, inflammation, and endothelial function in healthy persons with moderate hypertriglyceridemia. Am. J. Clin. Nutr. 93: $243-252$.

(2) Lu, J., F. Borthwick, Z. Hassanali, Y. Wang, R. Mangat, M. Ruth, D. Shi, A. Jaeschke, J. C. Russell, C. J. Field, S. D. Proctor, and D. F. Vine. 2011. Chronic dietary n-3 PUFA intervention improves dyslipidaemia and subsequent cardiovascular complications in the JCR:LA- cp rat model of the metabolic syndrome. Br. J. Nutr. 105: 1572-1582.

(3) Dimitrow, P. P., M. Jawien. 2009. Pleiotropic, cardioprotective effects of omega-3 polyunsaturated fatty acids. Mini Reviews in Medicinal Chemistry 9: 1030-1039.

(4) Wall, R., R. P. Ross, G. F. Fitzgerald, and C. Stanton. 2010. Fatty acids from fish: the anti-inflammatory potential of long-chain omega-3 fatty acids. Nutr. Rev. 68: 280-289.

(5) Yeh, S. L., K. Y. Chang, P. C. Huang, and W. J. Chen. 1997. Effects of n-3 and n-6 fatty acids on plasma eicosanoids and liver antioxidant enzymes in rats receiving total parenteral nutrition. Nutrition 13: 32-36.

(6) Jump, D. B., S. D. Clarke, A. Thelen, and M. Liimatta. 1994. Coordinate regulation of glycolytic and lipogenic gene expression by polyunsaturated fatty acids. J. Lipid Res. 35: 10761084. 
(7) Gaíva, M.H., R. C. Couto, L. M. Oyama, G. E. Couto, V. L. Silveira, E. B. Riberio, and C. M. Nascimento. 2001. Polyunsaturated fatty acid-rich diets: effect on adipose tissue metabolism in rats. Br. J. Nutr. 86: 371-377.

(8) Raclot, T., R. Groscolas, D. Langin, and P. Ferré. 1997. Site-specific regulation of gene expression by n-3 polyunsaturated fatty acids in rat white adipose tissues. J. Lipid Res. 38: 1963-1972.

(9) Pérez-Echarri, N., P. Pérez-Matute, B. Marcos-Gómez, A. Marti, J. A. Martínez, and M. Moreno-Aliaga. 2009. Down-regulation in muscle and liver lipogenic genes: EPA ethyl ester treatment in lean and overweight (high-fat-fed) rats. J. Nutr. Biochem. 20: 705-714.

(10) Ramaprasad, T. R., K. Srinivasan, V. Baskaran, K. Sambaiah, and B. R. Lokesh. 2006. Spray-dried milk supplemented with alpha-linolenic acid or eicosapentaenoic acid and docosahexaenoic acid decreases HMG Co A reductase activity and increases biliary secretion of lipids in rats. Steroids 71: 409-415.

(11) Morgado, N., A. Rigotti, and A. Valenzuela. 2005. Comparative effect of fish oil feeding and other dietary fatty acids on plasma lipoproteins, biliary lipids, and hepatic expression of proteins involved in reverse cholesterol transport in the rat. Ann. Nutr. Metab. 49: 397-406.

(12) Chen, H. W., C. K. Lii, J. J. Ko, S. T. Wang, and J. D. Hsu. 1996. Regulatory effects of dietary n-3 and n-6 lipids on plasma and hepatic lipid levels, liver cell number and microsomal protein content in spontaneously hypertensive rats. Prostaglandins Leukot. Essent. Fatty Acids 55: 329-335. 
(13) Williams, C. M., G. Burdge. 2006. Long-chain n-3 PUFA: plant v. marine sources. Proc. Nutr. Soc. 65: 42-50.

(14) Ferramosca, A., A. Conte, L. Burri, K. Berge, F. De Nuccio, A. M. Giudetti, and V. Zara. 2012. A krill oil supplemented diet suppresses hepatic steatosis in high-fat fed rats. PLoS ONE 7: 1-14.

(15) Flachs, P., O. Horakova, P. Brauner, M. Rossmeisl, P. Pecina, N. Franssen-van Hal, J. Ruzickova, J. Sponarova, Z. Drahota, C. Vlcek, J. Keijer, J. Houstek, and J. Kopecky. 2005. Polyunsaturated fatty acids of marine origin upregulate mitochondrial biogenesis and induce beta-oxidation in white fat. Diabetologia 48: 2365-2375.

(16) Lorente-Cebrián, S., M. Bustos, A. Marti, M. Fernández-Galilea, J. A. Martinez, and M. J. Moreno-Aliaga. 2012. Eicosapentaenoic acid inhibits tumour necrosis factor- $\alpha$-induced lipolysis in murine cultured adipocytes. J. Nutr. Biochem. 23: 218-227.

(17) Luo, J., S. W. Rizkalla, H. Vidal, J. M. Oppert, C. Colas, A. Boussairi, M. GuerreMillo, A. S. Chapuis, A. Chevalier, G. Durand, and G. Slama. 1998. Moderate intake of n-3 fatty acids for 2 months has no detrimental effect on glucose metabolism and could ameliorate the lipid profile in type 2 diabetic men. Results of a controlled study. Diabetes Care 21: 717-724.

(18) Muhlhausler, B. S., R. Cook-Johnson, M. James, D. Miljkovic, E. Duthoit, and R. Gibson. 2010. Opposing effects of omega-3 and omega-6 long chain polyunsaturated fatty acids on the expression of lipogenic genes in omental and retroperitoneal adipose depots in the rat. Journal of Nutrition \& Metabolism 1-9. 
(19) Dobrzyn, A., J. M. Ntambi. 2005. Stearoyl-CoA desaturase as a new drug target for obesity treatment. Obes $\operatorname{Rev}$ 6: 169-174.

(20) Chong, M. F., B. A. Fielding, and K. N. Frayn. 2007. Mechanisms for the acute effect of fructose on postprandial lipemia. The American Journal of Clinical Nutrition 85: 15111520.

(21) Cunnane, S. C., S. Ganguli, C. Menard, A. C. Liede, M. J. Hamadeh, Z. Y. Chen, T. M. Wolever, and D. J. Jenkins. 1993. High alpha-linolenic acid flaxseed (Linum usitatissimum): some nutritional properties in humans. Br. J. Nutr. 69: 443-453.

(22) Plourde, M., S. C. Cunnane. 2007. Extremely limited synthesis of long chain polyunsaturates in adults: implications for their dietary essentiality and use as supplements. Appl Physiol Nutr Metab 32: 619-634.

(23) Tou, J. C. 2011. Different sources of omega-3 polyunsaturated fatty acids affects apparent digestibility, tissue deposition, and tissue oxidative stability in growing female rats. Lipids Health Dis. 10: 179-192.

(24) Gigliotti, J. C., J. C. Tou, J. Jaczynski, M. P. Davenport, and S. K. Beamer. 2011. Extraction and characterisation of lipids from Antarctic krill (Euphausia superba). Food Chem. 125: 1028-1036.

(25) Tou, J. C., S. N. Altman, J. C. Gigliotti, V. A. Benedito, and E. L. Cordonier. 2011. Different sources of omega-3 polyunsaturated fatty acids affects apparent digestibility, tissue deposition, and tissue oxidative stability in growing female rats. Lipids Health Dis 10: 179-192. 
(26) Kopecky, J., M. Rossmeisl, P. Flachs, O. Kuda, P. Brauner, Z. Jilkova, B. Stankova, E. Tvrzicka, and M. Bryhn. 2009. n-3 PUFA: bioavailability and modulation of adipose tissue function. Proc. Nutr. Soc. 68: 361-369.

(27) Kris-Etherton, P., D. S. Taylor, S. Yu-Poth, P. Huth, K. Moriarty, V. Fishell, R. L. Hargrove, G. Zhao, and T. D. Etherton. 2000. Polyunsaturated fatty acids in the food chain in the United States. The American Journal of Clinical Nutrition 71: 179S-188S.

(28) Frémont, L., M. T. Gozzelino, and T. Hojjat. 1995. Effects of moderate fat intake with different n-3 fatty acid sources and n-6/n-3 ratios on serum and structural lipids in rats. Reprod. Nutr. Dev. 35: 503-515.

(29) Lodhi, I. J., X. Wei, and C. F. Semenkovich. 2011. Lipoexpediency: de novo lipogenesis as a metabolic signal transmitter. Trends Endocrinol. Metab. 22: 1-8.

(30) Tu, W. C., R. J. Cook-Johnson, M. J. James, B. S. Mühlhäusler, and R. A. Gibson. 2010. Omega-3 long chain fatty acid synthesis is regulated more by substrate levels than gene expression. Prostaglandins, Leukotrienes and Essential Fatty Acids 83: 61-68.

(31) Kraemer, F. B., W. Shen. 2002. Hormone-sensitive lipase: control of intracellular tri-(di-)acylglycerol and cholesteryl ester hydrolysis. Journal of Lipid Research 43: 1585-1594.

(32) Rakhshandehroo, M., L. M. Sanderson, M. Matilainen, R. Stienstra, C. Carlberg, P. J. De Groot, M. M“uller, and S. Kersten. 2007. Comprehensive analysis of PPAR $\alpha$-dependent regulation of hepatic lipid metabolism by expression profiling. PPAR Research 1-13. 
(33) Deng, T., S. Shan, P. Li, Z. Shen, X. Lu, J. Cheng, and Z. Ning. 2006. Peroxisome proliferator-activated receptor- $\gamma$ transcriptionally up-regulates hormone-sensitive lipase via the involvement of specificity protein-1. Endocrinology 147: 875-884.

(34) Deckelbaum, R. J., T. S. Worgall, and T. Seo. 2006. N-3 fatty acids and gene expression. Am. J. Clin. Nutr. 83: 1520S-1525S.

(35) Magkos, F. 2009. Basal very low-density lipoprotein metabolism in response to exercise: mechanisms of hypotriacylglycerolemia. Prog. Lipid Res. 48: 171-190.

(36) Kozarsky, K. F., M. H. Donahee, A. Rigotti, S. N. Iqbal, E. R. Edelman, and M. Krieger. 1997. Overexpression of the HDL receptor SR-BI alters plasma HDL and bile cholesterol levels. Nature 387: 414-417.

(37) Zhu, J., J. Shi, W. Qian, Z. Cai, and D. Li. 2008. Effects of krill oil on serum lipids of hyperlipidemic rats and human SW480 cells. Lipids in Health and Disease 7: 1-2-6.

(38) Iniguez, M. A., C. Cacheiro-Llaguno, N. Cuesta, M. Diaz-Munoz, and M. Fresno. 2008. Prostanoid function and cardiovascular disease. Archives of Physiology \& Biochemistry 114: 201-209.

(39) Cheuk, B., S. Cheng. 2008. Can local secretion of Prostaglandin $E_{2}$, Thromboxane $\mathrm{B}_{2}$, and interleukin-6 play a Role in ruptured abdominal aortic aneurysm? World Journal of Surgery 32: 55-56-61.

(40) Boudreau, M. D., P. S. Chanmugam, S. B. Hart, S. H. Lee, and D. H. Hwang. 1991. Lack of dose response by dietary n-3 fatty acids at a constant ratio of n-3 to n-6 fatty acids in suppressing eicosanoid biosynthesis from arachidonic acid. Am. J. Clin. Nutr. 54: 111-117. 
(41) Sohal, P. S., V. E. Baracos, and M. T. Clandinin. 1992. Dietary omega 3 fatty acid alters prostaglandin synthesis, glucose transport and protein turnover in skeletal muscle of healthy and diabetic rats. Biochem. J. 286 ( Pt 2): 405-411.

(42) Bommareddy, A., B. L. Arasada, D. P. Mathees, and C. Dwivedi. 2006. Chemopreventive effects of dietary flaxseed on colon tumor development. Nutr. Cancer 54: 216222.

(43) Won, S. A., H. J. Kim, Kyu-Hyang Cho, and N. D. Vaziri. 2009. Omega-3 fatty acid supplementation attenuates oxidative stress, inflammation, and tubulointerstitial fibrosis in the remnant kidney. American Journal of Physiology: Renal Physiology 66: F895-F903.

(44) Sankaran, D., J. Lu, M. R. Ogborn, and H. M. Aukema. 2007. COX-2 expression in cystic kidneys is dependent on dietary n-3 fatty acid composition. J. Nutr. Biochem. 18: 806-812.

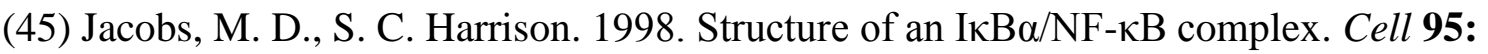
$749-758$.

(46) Camandola, S., G. Leonarduzzi, T. Musso, L. Varesio, R. Carini, A. Scavazza, E. Chiarpotto, P. A. Baeuerle, and G. Poli. 1996. Nuclear factor kB is activated by arachidonic acid but not by eicosapentaenoic acid. Biochem. Biophys. Res. Commun. 229: 643-647.

(47) Massaro, M., A. Habib, L. Lubrano, S. Del Turco, G. Lazzerini, T. Bourcier, B. B. Weksler, and R. De Caterina. 2006. The omega-3 fatty acid docosahexaenoate attenuates endothelial cyclooxygenase-2 induction through both NADP(H) oxidase and PKC $\varepsilon$ inhibition. Proc. Natl. Acad. Sci. U. S. A. 103: 15184-15189. 
(48) Joshi, Z. Y. 2004. Eicosapentaenoic acid prevents LPS-induced TNF-alpha expression by preventing NF-kappaB activation. J. Am. Coll. Nutr. 23: 71-78.

(49) Takase, O., K. Hishikawa, N. Kamiura, M. Nakakuki, H. Kawano, K. Mizuguchi, and T. Fujita. 2011. Eicosapentaenoic acid regulates $\mathrm{I} \kappa \mathrm{B} \alpha$ and prevents tubulointerstitial injury in kidney. Eur. J. Pharmacol. 669: 128-135.

(50) Lukas, R. 2011. Consumption of different sources of omega-3 polyunsaturated fatty acids by growing female rats affects long bone mass and microarchitecture. Bone.

(51) Pfaffl, M. W. 2001. A new mathematical model for relative quantification in realtime RT-PCR. Nucleic Acids Res. 29: e45-e45.

(52) Bligh, E. G., W. J. Dyer. 1959. A rapid method of total lipid extraction and purification. Can. J. Biochem. Physiol. 37: 911-917.

(53) Fritsche, K., P. Johnston. 1990. Effect of dietary alpha-linolenic acid on growth, metastasis, fatty acid profile and prostaglandin production of two murine mammary adenocarcinomas. J. Nutr. 120: 1601-1609.

(54) de Rodriguez, J., editor. 2001. Grain yield and fatty acid composition of sunflower seed for cultivars developed under dry land conditions. Trends in new crops and new uses. Proceedings of the Fifth National Symposium, Atlanta, Georgia, USA, 10-13 November, 2001. 139-42.

(55) Svensson, J., A. Rosenquist, and L. Ohlsson. 2011. Postprandial lipid responses to an alpha-linolenic acid-rich oil, olive oil and butter in women: A randomized crossover trial. Lipids in Health \& Disease 10: 106-115. 
(56) Lau, B. Y., V. A. Fajardo, L. McMeekin, S. M. Sacco, W. E. Ward, B. D. Roy, S. J. Peters, and P. J. LeBlanc. 2010. Influence of high-fat diet from differential dietary sources on bone mineral density, bone strength, and bone fatty acid composition in rats. Applied Physiology, Nutrition \& Metabolism 35: 598-606.

(57) Velliquette, R. A., P. J. Gillies, P. Kris-Etherton, J. W. Green, G. Zhao, and J. Vanden Heuvel P. 2009. Regulation of human stearoyl-CoA desaturase by omega-3 and omega-6 fatty acids: Implications for the dietary management of elevated serum triglycerides. J Clin Lipidol 3: 281-288.

(58) Strable, M. S., J. M. Ntambi. 2010. Genetic control of de novo lipogenesis: role in diet-induced obesity. Crit. Rev. Biochem. Mol. Biol. 45: 199-214.

(59) Li, H., X. Z. Ruan, S. H. Powis, R. Fernando, W. Y. Mon, D. C. Wheeler, J. F. Moorhead, and Z. Varghese. 2005. EPA and DHA reduce LPS-induced inflammation responses in HK-2 cells: Evidence for a PPAR- $\gamma$-dependent mechanism. Kidney Int. 67: 867-874.

(60) Chiao PJ, Miyamoto S, and I. M. Verma. 1994. Autoregulation of I kappa B alpha activity. Proc. Natl. Acad. Sci. U. S. A. 91: 28-32.

(61) Mehra, V. C., V. S. Ramgolam, and J. R. Bender. 2005. Cytokines and cardiovascular disease. Journal of Leukocyte Biology 78: 805-818. 